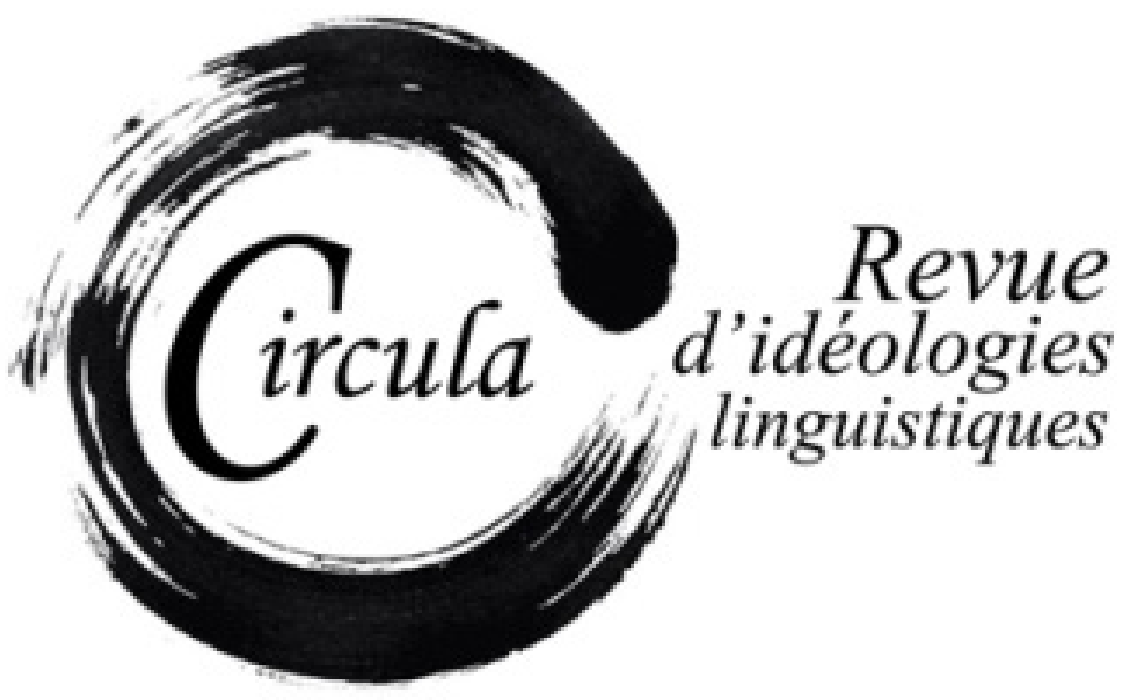

Publication: NUMÉRO 11 (PRINTEMPS 2020)

PAgES: $1-130$

ISSN: 2369-6761

Directeurs: Carmen Marimón Llorca, Wim Remysen et Sabine SchWarze ÉdITEUR: LES ÉdITIONS DE L'UNIVERSITÉ DE SHERBROOKE (ÉDUS)

URI: HTTP://HDL.HANDLE.NET/11143/17837

DOI: HTTPS://DOI.ORG/10.17118/11143/17837 


\section{Table des matières}

Intervenciones sobre la lengua en la Argentina de finales de los 1920:

Babel y el castellano (1928) de Arturo Capdevila, entre la prensa y el libro 2 Juan Antonio Ennis

Actitudes hacia las lenguas indígenas por estudiantes en León, Guanajuato, México

Felipe Canuto Castillo

Il commento linguistico come tradizione discorsiva nella stampa periodica di metà Settecento 47

Raphael Merida

Sur quelques principes d'argumentation néolibérale dans l'enseignement du français en Acadie. 64

Samuel Vernet

La norma linguistica nell'epoca dei social network:

da petaloso a scendi il cane. 86

Gianluca Frenguelli

Qu'est-ce que la lexicographie parasite ? Typologie d'une pratique qui influence la représentation du français québécois 107

Nadine Vincent

Chiss, Jean-Louis (2018), La culture du langage et les idéologies linguistiques, Limoges, Lambert-Lucas, 234 p. [ISBN : 978-2-35935-238-2] 126

Laurence Arrighi 


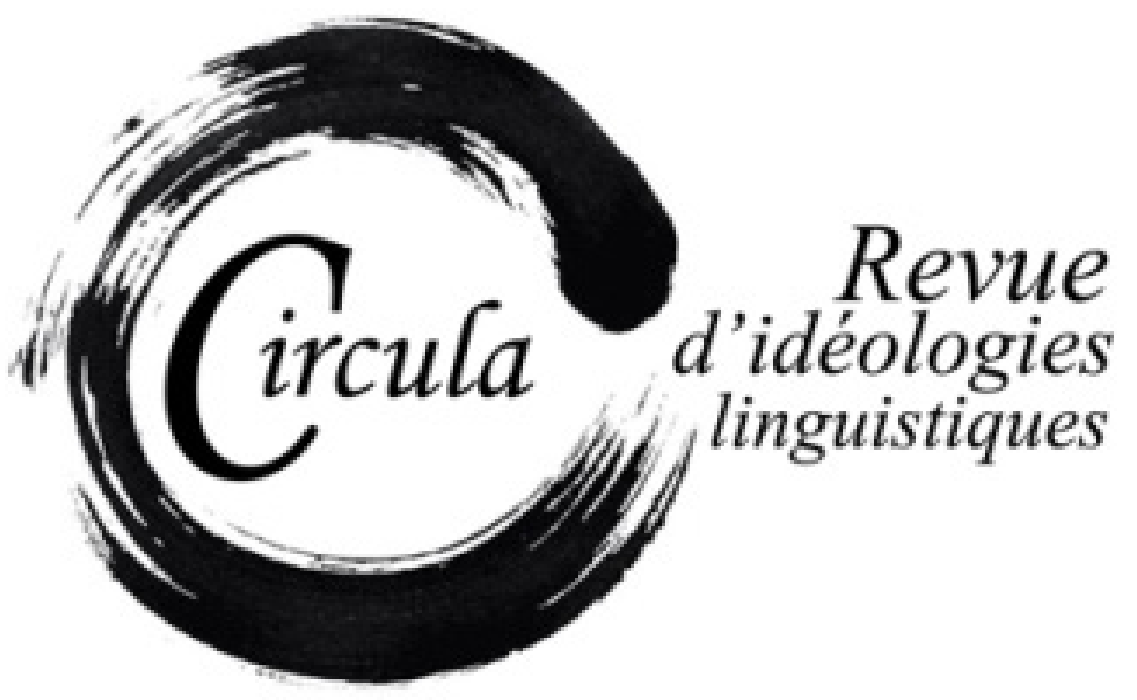

TITRE: INTERVENCIONES SOBRE LA LENGUA EN LA ARGENTINA DE FINALES DE LOS 1920: Babel y EL CASTELLANo (1928) DE ARTURO CAPDEVILA, ENTRE LA PRENSA Y EL LIBRO Auteur: JuAn Antonio EnNis, CONICET-Universidad Nacional de LA PLATA Revue: CIRCULA, NUMÉRO 11

PAgES: $1-23$

ISSN: 2369-6761

URI: HTTP://HDL.HANDLE.NET/11143/17838

DOI: HTTPS://DOI.ORG/10.17118/11143/17838 


\section{Intervenciones sobre la lengua en la Argentina de finales de los 1920: Babel y el castellano (1928) de Arturo Capdevila, entre la prensa y el libro}

Juan Antonio Ennis, CONICET-Universidad Nacional de La Plata juanennis@ conicet.gov.ar

Resumen: El presente trabajo propone un recorrido por una obra particularmente influyente en la historia de los debates so bre la lengua en Argentina: Babel y el castellano (1928), de Arturo Capdevila, considerándola desde su gestación en las columnas publicadas por su autor en el periódico La Prensa de Buenos Aires a partir de 1925. El análisis atiende asimismo a la articulación que estas intervenciones, por parte de un escritor versátil aunque lego en materia de ciencias del lenguaje, encuentran en sus distintas manifestaciones con campos y discursos en proceso de consolidación y diferenciación en la época en el país, como el de la literatura y los estudios lingüísticos, así como a los ecos que estas hallan en desarrollos posteriores, especialmente en el campo de la lingüística profesional.

Palabras clave: debates ideológico-lingüísticos; Argentina; Arturo Capdevila; prensa periódica

Abstract: The following paper attempts to give an insight into a particularly influential work in the history of language-ideological debates in Argentina: Babely el castellano (1928), by Arturo Capdevila, considering it from its very origin in the columns published by its author in the Buenos Aires' newspaper La Prensa from 1925 to 1927. The analysis also points to the way in which these interventions by a versatile writer -although a layman in the field of language sciences- deal with fields and discourses which were going through several processes of consolidation and differentiation in Argentina at the time (such as literature and linguistic studies). It also highlights the echoes that Capdevila's texts find in later developments, especially in the field of professional linguistics.

Keywords: language-ideological debates; Argentina; Arturo Capdevila; periodical press 


\section{Introducción: escenarios compartidos ${ }^{1}$}

En 1962, la Academia Argentina de Letras recibió en su seno a Jorge Luis Borges, por entonces ya un escritor mundialmente reconocido, que entre otras cosas acababa de recibir el premio Formentor, compartido con Samuel Beckett. El testimonio de su recepción, publicado en el tomo XXVII del Boletín de dicha institución, sigue el paso ceremonial de rigor, con un miembro que invita con su discurso la apertura del propio de quien acaba de ser designado. El encargado de esa recepción fue Arturo Capdevila, abogado, poeta y ensayista cordobés de gran reputación en la primera parte del siglo XX y escasa memoria en la historia literaria actual. En su breve presentación, Capdevila llama a Borges "gran señor de las letras, gran señor del idioma" (1962: 297), y sitúa la aparición providencial de su literatura en el contexto de la doble herencia de la que todo escritor local gozaría: por la tradición española acarreada por la sangre, por un lado, y la apropiada en suelo americano, por el otro. Seguidamente, pondera la novedad de la obra de Borges comenzando con la siguiente observación: "Toda nueva generación viene a descubrir el mundo. ¡Mirad el sol! ¡Mirad las estrellas! ¡Contemplad la fiesta de las nubes que pasan!’” (Capdevila 1962: 298). Llama la atención en su discurso la opción por la variante peninsular de la segunda persona del plural, que en ese entonces se restringía probablemente a no mucho más allá de los manuales escolares y los discursos de Capdevila. Borges, por su parte, al comenzar su conferencia, que abundaría sobre la afinidad entre el concepto de la academia y el remoto mundo de los celtas, recordaría que al oír el primer término se tendería a pensar en primer lugar "en la policía del lenguaje, en las autorizaciones o prohibiciones de palabras, todo esto es bastante baladí, ya lo sabemos todos" (Borges, 1962: 303).

No era la primera vez que Borges mostraba su menosprecio por la banalidad del ejercicio de limpieza purista al que se abocaban las Academias, y en especial la española. Tampoco era la primera vez que lo hacía compartiendo escenario con Arturo Capdevila. Treinta y cinco años antes había tenido lugar una de las más célebres intervenciones del enonces joven y promisorio escritor argentino, tal como lo había anunciado entonces el periódico La Prensa, al publicitar la conferencia en su edición del 21 de septiembre de 1927. No es uno de los objetivos de este trabajo analizar el contenido de la conferencia (que ya cuenta con estudios muy completos ${ }^{2}$ ), sino solamente describir el escenario en que tiene lugar, como extensión de un espacio de intervención pública paralelo a los más restringidos círculos literarios y académicos, aunque de gran popularidad y prestigio.

En ese momento, había en Argentina cuatro periódicos que podían considerarse en la categoría moderna de los grandes diarios, por la magnitud de su tirada, la amplitud nacional de su alcance "y un emplazamiento social tan significativo como amplio y complejo": La Prensa, La Nación, La Razón y Crítica (Gómez 2008). Como se ocupa de referir Saítta (2013: 73), el primero de estos periódicos, el

1. Este trabajo guarda una deuda de gratitud con Guillermo Toscano y García, cuyos comentarios y observaciones resultaron sumamente enriquecedores en la redacción final. Las falencias, por supuesto, son responsabilidad del autor.

2. Resulta sobre todo recomendable, para el análisis tanto de la escena como del propio texto y sus implicancias el muy completo trabajo de Fernando Degiovanni y Guillermo Toscano y García (2010a y b). 
más antiguo de ellos (había sido fundado en 1869), tenía mediando los años 1920 una presencia en la vida pública de la capital argentina y más allá de ella que no se limitaba a su notable tirada de 230000 ejemplares diarios, ni a las 36 páginas que alcanzaban los mismos en la semana (64 páginas los domingos), y a lo concurridas que resultaban sus páginas de avisos (Saítta recuerda que el 6 de noviembre de 1924 el periódico bate el récord de 6312 avisos, y dos años después, según nuestra propia constatación, el 7 de noviembre de 1926, se registra la superación de esa marca), sino que además ofrecía a sus lectores una serie de servicios gratuitos, entre los que destacaba -además de servicios sanitarios y legales, biblioteca y otros- el Instituto Popular de Conferencias, fundado el 18 de julio de 1914.

El objetivo del Instituto Popular de Conferencias de La Prensa era el de generar un espacio de difusión de saber especializado de relevancia pública, por fuera de las instituciones académicas oficiales e independiente de adscripciones políticas o religiosas definidas. Afirmado en su rol de orientador de la opinión (Gómez, 2008: 69), el periódico procuraba de este modo ampliar su porción de espacio público, reclamando para sí un lugar, que si bien no venía a competir con el de la universidad, sí decía complementarla. Tal como consta en el acta fundacional del Instituto, el director de La Prensa, Ezequiel P. Paz, habría manifestado lo siguiente a su primera Comisión:

Es mi propósito, y para eso os he llamado y solicitado concurso, fundar un centro de difusión y cultura, que, al par que atestigüe la potencia intelectual de nuestra raza, contribuya a fomentar la educación espiritual del pueblo en forma amena y sintética de conferencias selectas, dando de este modo a los espíritus ávidos de emociones desinteresadas, tras los desasosiegos de la lucha diaria, solaz y esparcimiento en lo más noble y puro, las ciencias y las artes: y sin tolerar límites al anhelo, aspirar en los grandes momentos, y aún durante el curso tranquilo de los acontecimientos, a propiciar orientaciones sobre los grandes problemas nacionales y humanos, sean circunstanciales o permanentes. (Zeballos, 1915: 4)

Las conferencias tenían lugar en el fastuoso salón de actos del segundo piso del edificio -réplica de uno de los salones del Palacio de Versalles (Gómez, 2008: 265) - y eran publicadas en lugares centrales y visibles del periódico (primera plana o páginas centrales) al día siguiente. La de Borges del 23 de septiembre de 1927 no sería la excepción, apareciendo a doble página el 24, con una descripción detenida de la concurrencia y las circunstancias, así como del aval prestado por distintas personalidades de la filología institucionalizada y publicística a través de su presencia en el escenario. Borges no asistiría personalmente, sino que Manuel Rojas Silveyra hará lectura de su discurso, en presencia de un nutrido público y personalidades relevantes de la cultura (v. Degiovanni y Toscano y García 2010), el mismo que al año siguiente coronaría el volumen que llevaba igual título: El idioma de los argentinos (1928). El presentador, también entonces, era Capdevila, vocal de la institución. 
En las páginas del mismo periódico, Borges y Capdevila compartían en la misma época asimismo un espacio de especial visibilidad. La segunda sección dominical de La Prensa albergaba columnas de materia literaria, artística, científica y cultural de reconocidas firmas del campo intelectual local y europeo. De presencia constante eran los nombres de los españoles Azorín, Manuel de Montoliu, Ramón Pérez de Ayala, Ramiro de Maeztu, el argentino Sáenz Hayes, entre otros; de regular aparición (al menos entre 1925 y 1928, período relevado en el presente trabajo) los de Borges, Capdevila, Rafael Alberto Arrieta, José Imbelloni, Juan B. Terán, Víctor Mercante, Robert Lehmann-Nitsche, Luis Franco, Máximo Soto Hall, Ricardo Sáenz Hayes, o intelectuales de fama internacional como Benedetto Croce o Marcel Prevost, entre otros. La controversia glotopolítica soterrada que se insinúa en la presentación académica -entre la notoria persistencia en el uso del "vosotros" y el carácter baladí de la policía lingüística académica- podría recuperarse sin más en las páginas de La Prensa, probablemente no como enfrentamiento abierto, sino como sencilla copresencia. Entre sus intervenciones sobre temas de estética e historia literaria, Borges había publicado en esta segunda sección de este periódico algunas de sus intervenciones previas a la conferencia en torno a la discusión por el idioma, trabajos que aparecerían sobre todo en sus volúmenes de ensayos El tamaño de mi esperanza (1926) y El idioma de los argentinos (1928). Se trata, por ejemplo de "Carriego y el sentido del arrabal" (4 de abril de 1926), "Acerca del vocabulario" (2 de mayo de 1926) o "Invectiva contra el arrabalero" (6 de junio de 1926). En este punto, los trabajos de Borges forman parte de un conjunto más amplio de publicaciones que a finales de los años 20 proliferan en la prensa periódica y cultural de Buenos Aires, configurando uno de los momentos más intensos en la historia de los debates sobre la lengua en Argentina. ${ }^{3}$

Capdevila, por su parte, entre sus columnas de temática asimismo literaria, o en torno a sus viajes por el país y la Península ibérica, daría a conocer en esta sección del periódico los trabajos que luego se integrarán en un volumen de larga trayectoria en el panorama glotopolítico argentino, Babel y el castellano (1928). Este libro, publicado por primera vez por la editorial Cabaut en Buenos Aires y distinguido con el Premio Nacional de Literatura en 1931, representa una intervención efectiva y duradera en el debate glotopolítico. Fue reeditado por Losada en 1940 (llegando a una tercera edición en esta misma casa en 1954), y también por la breve pero prestigiosa Compañía Ibero-Americana de Publicaciones con sede en Madrid, Barcelona y Buenos Aires (López Morel y Molina-Abril 2012) (esta edición carece de fecha). En referencia a su edición en Losada, Glozman (2015: 40) señala su lugar en una serie de publicaciones impulsada por Amado Alonso en esta pujante editorial, serie en la que se combinaba la difusión del saber lingüístico especializado y la discusión sobre la lengua, y en la cual al de Capdevila le seguirían volúmenes de gran impacto como La peculiaridad lingüística rioplatense y su sentido histórico (1941) de Américo Castro o Castellano, español, idioma nacional, del propio Amado Alonso (1943). Esta edición de Babel y el castellano vendría acompañada de sen-

3. Se reconoce así, por ejemplo, de acuerdo con las distintas perspectivas, en 1927 (Toscano y García 2019) y 1928 (Alfón 2013) los momentos claves de la polémica. Asimismo, dentro del proyecto en cuyo marco se desarrolla esta investigación (PICT 2017-1865: “Ideologías lingüísticas en la prensa escrita en Argentina, 1810-1855”) se está estudiando también otra serie, presente en La Prensa de la época, las “Gramaticales y filológicas” redactadas primero por Matías Calandrelli y luego por Florencio Garrigós (investigación a cargo de Esteban Lidgett y Guillermo Toscano y García). 
dos paratextos firmados por reconocidos escritores españoles de larga presencia en la prensa y el mercado editorial argentinos. El "Prólogo con versos" consistía en una carta de Miguel de Unamuno fechada el 31 de agosto de 1928, luego de haber recibido el ejemplar de Babel y el castellano que le remitiera su autor, y en la que agregaba dos poemas dedicados a él, que anunciaba irían incluidos en su poemario En la frontera (el Cancionero de su destierro en Hendaya, que no llegaría a publicar en vida). Como corolario del volumen, se reproducía parcialmente una nota de Guillermo de Torre, publicada el 5 de junio de 1932 en el folletón de la octava página de El Sol de Madrid. Originalmente titulado "Nuestro idioma y la Argentina", el artículo de De Torre, transformado en epílogo del libro reseñado, adquiría el nombre más elogioso de "La buena doctrina". Celebrando la defensa de la unidad del idioma con centro en Madrid realizada por Capdevila, De Torre denigra con él las diversas formas de nacionalismo lingüístico estereotípicas entonces para la Argentina, y se apoya sobre todo en la ya referida conferencia de Borges para reforzar sus argumentos.

Capdevila, lo mismo que Borges, no intervenía en la discusión como especialista acreditado por títulos académicos - un tipo de agente novedoso aunque ya asentado y visible de manera decisiva en el campo intelectual argentino y en las páginas de la prensa periódica y cultural (Toscano y García, 2009) - o reconocido por su expertise autodidacta al estilo de Arturo Costa Álvarez (Degiovanni y Toscano y García, 2010; Toscano y García, 2016; Ennis, en prensa). Sin embargo, lo que diferencia asimismo su intervención como literato de otras más próximas a la discusión de orden estético es la frecuencia del recurso a la autoridad de la cita filológica y de la historia lingüística, en un tono que combina el ensayo y la interpelación al lector con argumentaciones de índole diversa, siempre orientadas a la promoción de la unidad de la lengua española con centro en Castilla.

Esto quiere decir también que la serie de columnas que Capdevila publica en La Prensa y dan forma a un libro de intervención glotopolítica de eficacia tan duradera como se ha consignado más arriba, si bien cobra forma en las intervenciones periódicas de un letrado en materia de lenguaje, no proviene estrictamente de un espacio que podamos asociar a la chronaque linguistique en sentido estricto -ya que no se trata de un espacio asociado regularmente al tema- sino de la integración de la temática en el espacio del periódico, más precisamente en el de una firma de aparición regular en el espacio destinado a la literatura, la ciencia y la cultura en general, que contaba entre sus temas no el de la mera censura de usos inadecuados, sino reflexiones que invocaban la autoridad del discurso científico para proponer políticas lingüísticas de cierta precisión. ${ }^{4}$

Capdevila, entonces, no era ni un filólogo ni un gramático, sino un poeta y publicista de intereses y osadías múltiples. En su bosquejo biográfico lo retrata así Fermín Estrella Gutiérrez (1961: 26):

\footnotetext{
4. Remysen define la columna sobre la lengua del siguiente modo: "ensemble de discours sur la langue, plus particulièrement encore sur les bons et les mauvais usages de la langue. Elle est diffusée périodiquement sous forme de rubriques dans les médias écrits (articles de journal ou de revue) ou électroniques (émissions de radio ou de télévision). La chronique est signée par une même personne, physique ou morale, à laquelle on reconnaît une compétence en matière de langue" (Remysen, 2005, p. 271, cf. también Gagné et al., 2004, Remysen, 2009; Meier y Schwarze, 2020).
} 
Todo lo ha abarcado este hombre del Renacimiento, surgido como un milagro entre nosotros, en estos tiempos de la especialización y de la concentración rigurosa en una u otra disciplina. Pareciera como si él mismo no hubiera podido sustraerse a este destino múltiple y al parecer heterogéneo e incontrolado, de su ingente obra de creación.

Era abogado, había sido juez en su Córdoba natal, y estaba dedicado desde entonces a una carrera literaria que le había granjeado ya en 1920 y 1923 el Premio Nacional de Literatura, y en 1922 su ingreso a la Academia Nacional de la Historia. Al final de la primera edición del volumen se agrega una nota que menciona su incorporación como académico correspondiente a la RAE:

Este libro se imprimió en la Imprenta Mercatali (Avda. Acoyte, N. 271, Buenos Aires) y fue entregado a los libreros corriendo el mes de julio de 1928. Y por esos mismos días su autor fue designado miembro correspondiente de la Real Academia Española; siendo bueno que conste aquí, en mérito de cada uno, que ni el autor escribió este libro para que lo nombrasen académico, ni lo nombraron porque lo escribiera. (Capdevila, 1928: 191)5

La publicación en 1952 en Losada de Despeñaderos del habla, poco antes de la tercera edición de Babel y el castellano (1954), y luego de Consultorio gramatical de urgencia (1967) en la misma editorial, da cuenta de la persistencia del autor en estos afanes, así como de la sostenida vigencia de los mismos en el mercado del libro y, probablemente, también entre el público lector.

\section{El libro y los artículos}

El presente trabajo se propone como objetivo ofrecer un examen de las intervenciones de Arturo Capdevila en el periódico La Prensa entre 1925 y 1928, que desembocarán en su puesta en volumen en Babel y el castellano. El análisis de estos textos se realiza aquí tomando en consideración el modo en que los mismos se inscriben tanto en su contexto inmediato de publicación -caracterizado por un particularmente intenso debate glotopolítico- como en una tradición de debates sobre la lengua, que no solamente recuperan, sino que logran además imprimir una huella duradera en ella. De este modo, se pretende ofrecer un aporte al conocimiento de una zona específica del archivo de la que con Del Valle (2015) podemos Ilamar historia política del español, aquí específicamente en Argentina, que procure dar cuenta de las condiciones materiales de su emergencia y el complejo entramado de su circulación y recepción en distintos tiempos y ámbitos.

Babel y el castellano, así, es el libro de un escritor reconocido que a partir de 1925 comienza a dar lugar recurrentemente en sus columnas al debate histórico sobre la lengua en Argentina. El libro, el más conocido en esta materia de un autor ubicado en la línea del "nacionalismo de corte hispánico" (Di Tullio, 2003: 101), había sido precedido en 1925 por otro, sobre la base de textos previamente

5. En "La prodigiosa y díscola ciudad del idioma común" (La Prensa, 12 de junio de 1927), Capdevila lamentaba la falta de reciprocidad entre españoles y americanos a la hora del intercambio intelectual, refiriendo la escasa recepción del envío de docenas de ejemplares de Tierras nobles "a colegas y a periódicos"; quizás esta haya sido una forma de respuesta. 
aparecidos en La Prensa, que bajo el título de Tierras nobles. Viajes por España y Portugal (Buenos Aires, El Ateneo, 1925), desplegaba asimismo un panegírico de la madre patria.

Babel y el castellano reúne intervenciones de tres órdenes: en favor de la unidad del idioma, con centro en Castilla; en contra del voseo en Argentina, así como de las entonces nuevamente activas intervenciones en favor de una gestión autónoma de la identidad y la diferencia lingüística en Argentina, y también observaciones acerca de la lengua de los sefardíes, encomiando claro está la lealtad lingüística de estas comunidades para con el español.

En el siguiente cuadro se consignan los distintos capítulos que componen el volumen, junto con su fecha de publicación primera en La Prensa, el título original y algunas observaciones acerca de las variantes encontradas.

\begin{tabular}{|c|c|c|c|c|}
\hline $\begin{array}{l}\text { Número de } \\
\text { capítulo }\end{array}$ & $\begin{array}{c}\text { Título en Babel y el } \\
\text { castellano }\end{array}$ & $\begin{array}{c}\text { Título en La } \\
\text { Prensa }\end{array}$ & Fecha de publicación & Observaciones \\
\hline I & $\begin{array}{l}\text { Un gran imperio } \\
\text { espiritual }\end{array}$ & $\begin{array}{l}\text { Meditaciones } \\
\text { sobre el idioma } \\
\text { castellano }\end{array}$ & $\begin{array}{c}\text { Domingo } 27 \text { de diciembre } \\
\text { de } 1925\end{array}$ & $\begin{array}{l}\text { Se añaden algunos pá- } \\
\text { rrafos autobiográficos } \\
\text { en la última parte (pp. } \\
\text { 23-24 de la } 1^{2} \text { ed.) }\end{array}$ \\
\hline ॥ & La utopía & $\begin{array}{l}\text { Meditaciones } \\
\text { sobre el idioma } \\
\text { castellano }\end{array}$ & Viernes 1 de enero de 1926 & \\
\hline III & España y América & $\begin{array}{l}\text { Meditaciones } \\
\text { sobre el idioma } \\
\text { castellano }\end{array}$ & $\begin{array}{c}\text { Domingo } 17 \text { de enero de } \\
1926\end{array}$ & $\begin{array}{c}\text { En las ediciones pos- } \\
\text { teriores en Losada se } \\
\text { añade una nota con } \\
\text { respecto a la situación } \\
\text { del mercado editorial } \\
\text { tras la Guerra Civil } \\
\text { española. }\end{array}$ \\
\hline IV & En Castilla & En Castilla & $\begin{array}{c}\text { Sábado } 1 \text { de enero de } \\
1927\end{array}$ & \\
\hline V & $\begin{array}{c}\text { El embrollado problema } \\
\text { del tú y el vos }\end{array}$ & $\begin{array}{l}\text { El embrollado } \\
\text { problema del tú y } \\
\text { el vos }\end{array}$ & $\begin{array}{l}\text { Domingo } 16 \text { de enero de } \\
1927\end{array}$ & \\
\hline $\mathrm{Vl}$ & $\begin{array}{c}\text { El tú y el vos en los } \\
\text { clásicos }\end{array}$ & $\begin{array}{l}\text { El tú y el vos en } \\
\text { los clásicos }\end{array}$ & $\begin{array}{c}\text { Domingo } 13 \text { de febrero de } \\
1927\end{array}$ & \\
\hline VII & El tú y el vos en América & $\begin{array}{l}\text { El tú y el vos en } \\
\text { América }\end{array}$ & $\begin{array}{c}\text { Domingo } 20 \text { de febrero de } \\
1927\end{array}$ & \\
\hline VIII & El idioma en la Argentina & $\begin{array}{l}\text { El idioma en la } \\
\text { Argentina }\end{array}$ & $\begin{array}{c}\text { Domingo } 24 \text { de abril de } \\
1927\end{array}$ & $\begin{array}{l}\text { Coincide con el "día del } \\
\text { idioma" y el falleci- } \\
\text { miento de R. Monner } \\
\text { Sans }\end{array}$ \\
\hline
\end{tabular}




\begin{tabular}{|c|c|c|c|c|}
\hline $\begin{array}{l}\text { Número de } \\
\text { capítulo }\end{array}$ & $\begin{array}{l}\text { Título en Babel y el } \\
\text { castellano }\end{array}$ & $\begin{array}{l}\text { Título en La } \\
\quad \text { Prensa }\end{array}$ & Fecha de publicación & Observaciones \\
\hline IX & Los sefardíes & & & \\
\hline$x$ & El romancero sefardí & $\begin{array}{l}\text { El castellano de } \\
\text { los sefardíes, su } \\
\text { romance }\end{array}$ & $\begin{array}{l}\text { Domingo } 14 \text { de febrero de } \\
1926\end{array}$ & $\begin{array}{c}\text { La sección II de la edi- } \\
\text { ción en libro no está en } \\
\text { la edición en periódico } \\
\text { Intercala en la sección } \\
\text { I la mención a Wagner } \\
\text { (1914) }\end{array}$ \\
\hline$X I$ & $\begin{array}{c}\text { En Manila se ha puesto } \\
\text { el sol }\end{array}$ & $\begin{array}{l}\text { En Manila se ha } \\
\text { puesto el sol }\end{array}$ & $\begin{array}{c}\text { Domingo } 18 \text { de julio de } \\
1926\end{array}$ & \\
\hline XII & $\begin{array}{l}\text { La prodigiosa y díscola } \\
\text { ciudad del idioma común }\end{array}$ & $\begin{array}{l}\text { La prodigiosa y } \\
\text { díscola ciudad del } \\
\text { idioma común }\end{array}$ & $\begin{array}{c}\text { Domingo } 12 \text { de junio de } \\
1927\end{array}$ & \\
\hline XIII & $\begin{array}{l}\text { El inmenso mar del } \\
\text { castellano }\end{array}$ & $\begin{array}{l}\text { El inmenso mar } \\
\text { del castellano }\end{array}$ & $\begin{array}{c}\text { Domingo } 29 \text { de mayo de } \\
1927\end{array}$ & \\
\hline
\end{tabular}

Hasta el capítulo VIII se mantiene la correspondencia entre la sucesión de los capítulos y el orden cronológico de su aparición en el periódico. Como puede verse en las "Observaciones" de la última columna del cuadro, las variaciones son mínimas entre una y otra aparición. Sólo en el caso de "Los sefardíes" no he podido dar con su antecedente en La Prensa.

Los primeros tres capítulos aparecieron sucesivamente, los días 27 de diciembre de 1925, 1 y 17 de enero de 1926, siempre bajo el mismo título de "Meditaciones sobre el idioma castellano", que varía luego en el libro. En ellos se celebra la unidad de la lengua tal como venía haciéndose desde el comienzo de la política panhispánica encarada por la Academia al menos desde el ingreso de Juan Valera en 1862, recapitulando la historia de los debates sobre la lengua en Argentina, y subrayando, al igual que su fuente (Costa Álvarez, 1922), el carácter extendido de pecado de juventud que definiría el secesionismo lingüístico de la generación del 37.6 El segundo se ocupa de rebatir con argumentos diversos la necesidad de un idioma nacional para los argentinos, cerrando con una afirmación de la profunda identidad entre España y la Argentina fundada en el parentesco entre el Himno nacional argentino y el "Canto guerrero para los asturianos" de Gaspar Melchor de Jovellanos, señalada por Menéndez y Pelayo en su Historia de la poesía Hispanoamericana de 1911 (1948: 334).

6. El mismo Costa Álvarez, no obstante, le dedicaría una reseña especialmente crítica, poniendo límites justamente al alcance de este tipo de representaciones: "A mí me parece que los argentinos no nos hemos emancipado para andar requiriendo la tutela espiritual de la madre patria, como la criatura que se arrepiente de alguna rebeldía; y me parece también que es un acto poco digno de un pueblo libre transferir a otro pueblo la tarea de velar por su propia lengua y por su propia influencia" (Costa Álvarez, 1928: 288). 
El tercer artículo de este bloque inicial pasa de la celebración a la promoción económico-política de la unidad de la lengua, retomando el tópico -habitual también desde finales del XIX- de la incomunicación entre la producción letrada no sólo a uno y otro lado del Océano, sino sobre todo entre los países americanos, traduciendo lo que sería poco después una discusión por el meridiano intelectual (de Torre, 1927, v. Falcón, 2010a y b; Bosoer, 2008, Alemany, 1998; entre otros) en la más clara de -como se lo llamó posteriormente- un meridiano editorial:

Una vasta empresa editorial de obras en habla española, radicada en Madrid o en BarceIona, es cosa de suma urgencia. Agrego que tiene que ser un buen negocio. En cien años de literatura continental hay veinte o más autores dignos de difusión por el continente y la península. Es un absurdo el acantonamiento en que vivimos. No debe ser tolerado por más tiempo que un escritor del Perú o de la Argentina se reduzca a ser leído por sus compatriotas. No conozco un feudalismo más necio. Resultado: cifras humillantes e irrisorias. 1.500 acaso 2.000 ejemplares por todo tirar... irrisorio y humillante. jHay que haber nacido con misión de escribir para seguir escribiendo! (Capdevila, 1928: 53)

En la sección de la reseña de De Torre en El Sol no incorporada al epílogo de Babel y el castellano en su edición de Losada, este autor subrayaba de hecho esta como una reivindicación de su combatida propuesta (combatida entre otros por el propio Borges, v. Ennis 2008: 236), que generaría en 1927 la célebre polémica sobre Madrid como meridiano intelectual de Hispanoamérica: "No se trataba, empero, sino de poner en un pie de igualdad ante el mercado la producción española y la hispanoamericana; de otorgar a esta última el mismo trato de publicidad y de atención que merece ahí la nuestra. Y ése era, en definitiva-repito una vez más-, el supremo vértice adonde apuntaba aquella desnaturalizada pretensión del meridiano, no cultural, sino editorial, publicitario, empírico" (De Torre, 1932). En este punto cabe destacar el acierto de Falcón (2010) al resaltar a Babel y el castellano entre los "discursos sobre el llamado 'problema de la lengua en América" que "revelan los fundamentos económicos de las creencias lingüístico-culturales que procuran instalar", esto es, la expansión americana del mercado editorial español. El de la unidad de la lengua es un problema estratégico de un "nosotros" que debía encontrar en el mercado del libro un agente de cohesión y progreso:

Nadie se queje si mañana los yanquis se apoderan de esa formidable llave de las rutas del pensamiento hispanoamericano. Nadie se queje si mañana España pierde otro inexpugnable Gibraltar, desde el cual gobierne un extranjero invasor todas las corrientes editoriales del mundo hispánico: quiero decir nuestros sentimientos, nuestras ideas, nuestros anhelos, nuestra acción, dueños y señores de todo libro y árbitros de la real eficiencia de todo autor. (Capdevila, 1928: 54-55)

La única variación que se encuentra entre la edición en periódico y la edición en libro consiste en la actualización de la fecha del que probablemente constituya su postulado central (y también el de todo el libro), que pone de manifiesto el lugar que se otorgaba a la lengua en el discurso acerca de 
su unidad como avatar de un proceso de secularización en el cual la universalidad de la democracia liberal se daba también por fracasada:

Desnuda verdad fechada en 1928 [1926 en la primera versión]: no cuenta la América española con otra unidad que la del común idioma. La unidad religiosa no tiene ninguna eficacia actual (ni existe), y en cuanto a la unidad del régimen político, muchos de sus pueblos han renegado del inmenso bien de la democracia, ya que la dejaron ofender y profanar por menguados tiranuelos. No queda más que el idioma. (Capdevila, 1928: 50)

La postura de Capdevila coincidía aquí políticamente con la esgrimida entonces de diverso modo por los sucesivos representantes del Centro de Estudios Históricos madrileño en Buenos Aires. Si bien presentarían rasgos diferenciales individuales significativos, tanto Américo Castro como Amado Alonso promoverían en sus escritos más significativos una representación restrictiva de la lengua legítima y una mirada crítica sobre la relación entre la norma lingüística, la estratificación social y la cultura de masas en Argentina, fuertemente arraigada en el Ortega y Gasset de La rebelión de las masas (Ennis, 2008: 249; Arnoux y Bein, 1995: 190-191).

El cuarto ensayo -acompañado en el periódico por fotografías de la catedral y el alcázar de Segovia y la puerta de Fernán González en Burgos- funciona como reenvío al libro anterior, Tierras Nobles, postulando a Castilla como la Meca o "tierra santa de este portento", de un idioma tratado en la retórica cuasi-religiosa de la comunidad espiritual, incorporando el motivo recurrente hasta hoy de la creciente cantidad de hablantes del castellano: "No ha mucho, se calculaba en 85000000 la cifra de los que hablamos castellano por haberlo recibido en la materna leche. Ahora, la cifra debe rectificarse y ser elevada a más de los 90000 000. El castellano está triunfante en el mundo, y es una de las mayores fuerzas del espíritu sobre la tierra" (Capdevila, 1928: 59). Volviendo sobre la resignificación del canon liberal decimonónico, esta vez al releer los Viajes de Domingo F. Sarmiento por España, reivindica -como ya lo hacía Miguel de Unamuno (Ennis, 2008: 219)- el casticismo de la prosa de este último, para sostener en la anecdótica existencia de The Southern Star/La Estrella del Sur en Montevideo durante las invasiones inglesas de 1807 la superioridad, en los liberales que luego promoverían la emancipación, de la devoción por la lengua heredada sobre las convicciones políticas (Capdevila, 1928: 65).

Los siguientes cuatro artículos, publicados en La Prensa entre enero y abril de 1927, conforman un bloque sólido y quizás el verdadero núcleo de la intervención glotopolítica de Capdevila a través de la prensa y el libro. En ellos se abunda en lo que se ha descripto como su "fervorosa estigmatización del voseo" (Sztrum, 1992: 70), en un análisis de la historia y extensión de lo que entiende como "viruela del idioma" (Capdevila, 1928: 75), "cosa tan sucia" (ibid.: 107), "ignominiosa fealdad" (ibid.: 115), y que pretendía aún entonces desplazar del uso general a través del disciplinamiento del uso letrado y escolar. En la primera de estas columnas, "El embrollado problema del tú y el vos", presenta el tema indicándolo como una de las cuestiones de interés en materia lingüística para los hispanoamericanos, puesto que es de las que "conciernen a la suerte del castellano en América”, 
y especialmente para "nosotros los argentinos, enfermos de este sucio mal, que ojalá no resulte incurable" (ibid.: 71). La actitud de Capdevila no era en absoluto aislada, sino que encontraba eco en un sistema educativo que no solamente seguía enseñando exclusivamente el paradigma tuteante, sino que además lo estigmatizaba activamente. ${ }^{7}$

Sin embargo, la persistencia y el fervor del encono de Capdevila no dejan de otorgarle un lugar preeminente en este panorama. Hacia el final de los 1960, María Beatriz Fontanella de Weinberg, pionera de la sociolingüística en Argentina (v. Ennis, 2008), comenzaría a dar forma a un volumen nutrido y consistente de estudios en diacronía y sincronía sobre el voseo bonaerense. Al elaborar el estado de la cuestión del tema, destaca la presencia de Babel y el castellano:

La historia del voseo en Buenos Aires es un tema que ha suscitado diversas interpretaciones a lo largo de varias décadas. Curiosamente, una obra que ha tenido vasto eco y que se cita con frecuencia sobre la cuestión es Babel y el castellano, volumen carente de un enfoque lingüístico, publicado por Arturo Capdevila en 1928. En este libro Capdevila se deja llevar por un apasionamiento purista, según el cual el voseo constituye un "calamitoso rasgo" y una "ignominiosa fealdad" que conduce al caos espiritual, y señala que el uso de vos es síntoma de incultura y barbarie. De acuerdo con esto, sostiene que tanto la clase culta de la generación de Mayo, como la del período rivadaviano, desconocía el voseo, y que el oscurantismo instaurado durante el gobierno de Rosas fue el responsable de su difusión (Fontanella de Weinberg, 1971: 495)

Lo curioso del "vasto eco" de la obra de Capdevila se explica seguidamente al completar el estado de la cuestión con firmas autorizadas por su formación y prestigio filológico y lingüístico, que sin embargo retomaban las hipótesis de Capdevila, apoyándose en sus escritos como fuente de autoridad: se trata de Américo Castro, discípulo de Ramón Menéndez Pidal y primer director en 1923 del Instituto de Filología de la Universidad de Buenos Aires, de Berta Elena Vidal de Battini, formada en sus estudios de doctorado en la misma institución y responsable de un importante estudio de campo sobre el español en la Argentina (1964), y -ya en trabajos posteriores donde Fontanella (1976: 14) retoma esta misma crítica-, también de Bertil Malmberg (1973). ${ }^{8}$

La hipótesis que Fontanella de Weinberg venía a rebatir entonces a través de la evidencia documental no tenía que ver directamente con las diatribas de Capdevila, sino con la fundamentación histórica que proporcionaba a las mismas, en la cual combinaba el ejercicio de cierta erudición filológica (o al menos de la demostración del conocimiento de fuentes filológicas y literarias) apoyada en los fundamentos literarios prototípicos de un duradero relato de la historia y la identidad nacional, propio del liberalismo argentino. Este relato -que hemos llegado a encontrar aún vigente en fuentes más

7. Como botón de muestra, Sztrum (1992: 70) recuerda "que aún en 1939 una circular del Consejo Nacional de Educación prohibía el uso del voseo 'y demás formas bárbaras' en las escuelas primarias”.

8. Esto ha sido trabajado más ampliamente en un estudio anterior (Ennis, 2008: 327-328). El recorrido de esta hipótesis es examinado en detalle por López García (2015: 54-55) y sobre todo por Carricaburo (1999). 
recientes (Benavides, 2003: 619) - situaba al gobierno de Juan Manuel de Rosas en Buenos Aires, entre 1829 y 1852, como un factor clave en la imposición del voseo, consecuente con su política populista antiliberal. Adoptando las formas más maniqueas de esta verdadera fábula de identidad (Ludmer 1999), Capdevila comenzaba por dar cuenta de la expansión del fenómeno a partir de la mayor o menor expansión de la cultura letrada en las respectivas regiones americanas:

México y Lima fueron y son las grandes metrópolis del tú y los mayores centros de su expansión. La causa queda averiguada. En Lima y en México, tal como ocurriera en España, la adopción del tú fue un fenómeno de cultura y buena crianza, al paso que en lo restante de América el triunfo del voseo en las masas populares no fue sino una imposición del general atraso. Y tanto fue cosa de cultura el tutearse y tanto lo sigue siendo, que aún allí donde prepondera el voseo, como en la Argentina, la gente de mayor alcurnia intelectual dice de tú cuando otros emplearían el vos: y lo propio acontece en todas las otras zonas infectas por el voseo en América.

¿Un ejemplo? Monner Sans nos le ofrece: “En casa de Mitre no entró nunca el vos”... pues, ¡cómo había de entrar cosa tan sucia en tan limpia casa” (Capdevila, 1928: 107)

El linaje de los Mitre (presidente argentino entre 1862 y 1868, escritor, historiador y fundador del periódico La Nación), quintaesencia de la aristocracia liberal argentina, aparece como bastión para una alteridad voseante que en Babel y el castellano encuentra su raíz histórica en un período que la misma historiografía presidida por Mitre situaba como el de la barbarie y la oscuridad que precede a la "organización nacional". Los textos de los que Capdevila toma sus muestras son ejemplos centrales de la figuración literaria de la barbarie rosista afianzados en el canon de la literatura romántica argentina: Amalia de José Mármol o El matadero de Esteban Echeverría. "La librea es para vosotros, esclavos, y no para hombres libres”, desafía Eduardo Belgrano a los federales en la novela de Mármol, y Capdevila subraya esa ocurrencia como posible evidencia de una eventual supervivencia en las clases ilustradas porteñas (en su exilio montevideano) de una forma desaparecida de toda América. Sin embargo, inmediatamente destaca que lo más posible es que esto no sea más que un uso limitado a la literatura, para expresar un desideratum a esa altura ya sorprendentemente extemporáneo:

De esta suerte, este lindísimo vosotros familiar, gracioso y noble, que tanto suena, y tan bien, por casi toda España, ha venido a ser en la Argentina y lo restante de América mero tratamiento de oratoria; y apenas si empieza a ocupar algún sitio en el buen lenguaje epistolar. Dolámonos de esa ausencia. La intimidad del hogar y el corro de la genuina amistad han perdido sus más propios y fervorosos elementos de expresión. Ustedes: he ahí un vocativo frío, todo convencional, todo tercera persona... Vosotros: he ahí la vida misma de la pasión y la sinceridad (Capdevila 1928: 113-114)

Treinta y cinco años después, como se ha visto al comienzo, seguiría sosteniendo en la práctica esa peculiar convicción. 
La ponderación de la historia de los sefardíes y de la necesidad del estudio de su lengua y cultura y de su reconexión con el conjunto de la lengua española ocupa los siguientes dos ensayos en el libro, para los cuales se ha recuperado aquí el antecedente del segundo, "El castellano de los sefardíes, su romance", publicado en La Prensa el domingo 14 de febrero de 1926. El primer ensayo en el libro, "Los sefardíes". comienza nuevamente con el fundamento económico-político de la unidad de la lengua: "¿Cómo no ha de ser deseado, entre lo que más se anhela, la pureza del habla general y la comunicación de unas y otras naciones hispánicas mediante la difusión del libro de lengua española, si grandes son por muchas y variadísimas tierras, nuestros intereses espirituales, y todavía anda dispersa o se acabará de dispersar, si nada se hiciere, buena parte de la común familia?" (Capdevila, 1928: 123). Capdevila demuestra aquí un conocimiento al menos superficialmente amplio de la bibliografía existente, incrementado entre ambas publicaciones (la del periódico es de febrero de 1926, el libro aparece en 1928). Así, contradice las afirmaciones de Max Nordau recogidas por Pulido en su Españoles sin patria, acerca de la pobreza léxica del habla sefardí, contrastándolas con "averiguaciones recientes". Estas averiguaciones, en el artículo publicado en La Prensa, podían considerarse restringidas a las que declara en nota final (ausente en la edición en libro) como sus "fuentes principales" (Menéndez Pelayo, 1900; Pulido, 1905; Gil 1911), y a las que luego añadirá la referencia a Wagner (1914), sobre el cual lamenta que no pueda ser mejor conocido entre el público hispanohablante, ya que su libro estaba publicado en Viena y en alemán -aunque para entonces ya se contaba con contribuciones suyas en español y portugués (Wagner, 1923, 1924)- y a la Revista de la Raza de Manuel L. Ortega. En este mismo texto, junto a la fascinación por la supervivencia de la lengua y el acervo poético popular tras siglos de diáspora sefardí, se destaca su infantilización como recurso minorizador de los hablantes de la variedad (cfr. Heller, 2019).

Los últimos tres capítulos insisten con la unidad espiritual, con la retórica imperial hispanófila contra el avance norteamericano. En "En Manila se ha puesto el sol", publicado en La Prensa el 18 de julio de 1926, Capdevila pondera la grandeza imperial pretérita de España y retorna al clima de entresiglos, agitado por la guerra hispano-norteamericana, renovando la fórmula del nacionalismo hispanizante, al vincular ese pasado con el augurio de un futuro venturoso para Argentina:

Nosotros, por lo menos, queremos ser un pueblo de voluntad muy recia. De este modo, aceptamos sin el menor esfuerzo que en aquellas naves españolas se paseaba ya nuestro espíritu, según iba resonando nuestro idioma por nuevos y nunca surcados mares. (Capdevila, 1928: 151)

“La prodigiosa y díscola ciudad del idioma común", aparecido el 12 de junio de 1927 en La Prensa con el mismo título, abunda en la metáfora de la ciudad para referir al idioma, oponiendo al imaginario que evocaba el título del libro (el del "cosmopolitismo babélico" (Sarlo, 1996) demonizado por las élites dirigentes) el de una compleja y abigarrada comunidad de lengua. 
En el periódico, la intervención de Capdevila viene acompañada de una ilustración que adorna su firma y figura una ciudad luminosa, acorde con la descripción de la ciudad compartida por españoles y americanos que describe al comienzo, "ciudad alta, empinada sobre montes que miran al mar, muy esbelta, muy guarnecida, brillante al sol como si toda fuese de oro" (Capdevila, 1928: 167). El artículo celebra la "unidad espiritual" de "nuestra inmensa familia hispánica" (ibid.: 168) y vuelve sobre la polémica que en el cambio de siglos desatara el libro de Lucien Abeille (1900), actualizada entonces en los debates del día, desde Nuestra lengua de Costa Álvarez y la respuesta de Ernesto Quesada (1922) a ese mismo libro hasta las tensiones y polémicas generadas en torno a la instalación del Instituto de Filología de la Universidad de Buenos Aires en 1923 (Toscano y García, 2009, 2016), además de la inmediatez de la sonada encuesta del diario Crítica acerca de la posibilidad de un idioma nacional (Sztrum, 1998; Oliveto, 2010; Toscano y García, 2019; Ennis, Toscano y García y Santomero 2020) - el artículo de Capdevila aparece el 12 de junio de 1927, un día después de que lo haga la primera entrega de dicha encuesta. A tono con la dominante en la mayor parte de esas intervenciones (y entre ellas, la anteriormente mencionada de Borges, que tendría lugar tres meses después), esta actualización conecta, sin solución de continuidad, con el rechazo del lunfardo como base de una lengua local: "No, ya no hay quien dude entre la piltrafa de una lengua rioplatense, nacida de una jerga de ladrones, y esta hermosa solidaridad que nos vincula a millones y millones de hombres por toda la extensión del planeta" (Capdevila, 1928: 169). ${ }^{9}$ Luego de esto prosigue la lista de los "díscolos" de la lengua con la ya entonces plurisecular diatriba contra el galicismo, para pasar en la sección siguiente a la también recurrente queja por la falta de reciprocidad en el intercambio intelectual entre España y América, destacando la mayor importancia adquirida por Buenos Aires para la difusión del español, aun entre los hablantes de las demás lenguas de España: "En mira de Buenos Aires, no de Madrid, hay en este momento millares de hombres que aprenden castellano, así en Berlín como en Bruselas, así en el Japón como en el Canadá. En Buenos Aires, no en Madrid ni en Castilla entera, es donde se rinde al castellano el mayor número de gallegos, catalanes o vascos. Al Plata lo que es del Plata..." (ibid.: 172). De este modo, recriminando la poca receptividad hispánica para la producción intelectual americana, volverá a llamar al trabajo en la unidad americana, conjurando una hora de peligro inminente (ibid.:174) -en el que se adivina fácilmente el fantasma del imperialismo norteamericano- que demandaría tal unidad basada en el idioma común.

Resulta común a estas últimas columnas el recurso a la presentación del otro de la expansión de ese espíritu común del español como destinado a la desaparición, desprovisto justamente de esa capacidad de formar comunidad en el tiempo a través de la memoria común. Es el caso de las Filipinas, donde al recurso de la infantilización ("Chinos y malayos sueñan con alma cándida", ibid.: 153), se agrega el de esta carencia:

9. En la conferencia referida, Borges haría un razonamiento similar: "El lunfardo es un vocabulario gremial como tantos otros, es la tecnología de la furca y la ganzúa. Imaginar que esa lengua técnica -lengua especializada en la infamia y sin palabras de intención general- puede arrinconar al castellano, es como trasoñar que el dialecto de las matemáticas o el de la cerrajería puede ascender a único idioma" (Borges, 1998: 146-147). 
Tribus indígenas hay que viven como en el límite de análoga animalidad. No bajan nunca de la montaña. No les interesa la civilización. Épicos fueron los sucesos de la primera arremetida española. Magallanes mismo cayó a los golpes del indio. Reyezuelo hubo -el famoso Hamabar- que pudo considerarse el más glorioso capitán de su raza: el español, vencido, hubo de retirarse deshecho. Hamabar en Europa hubiera sido un héroe nacional y se le hubiera erigido estatua. En Cebú no fue así... Cuando a los cuarenta años de aquellos acontecimientos, los españoles retornaron, nadie recordaba nada, ni mozos, ni ancianos, ni sabía nadie cosa alguna de Hamabar (Capdevila, 1928: 154).

Esto se extiende a los pueblos originarios de América, donde la imagen del "inmenso mar del castellano" propicia la fantasía desbocada del homogeneísmo (Blommaert y Verschueren, 1998: 202204) u homo-hegemonía monoculturalista (Derrida, 1997: 105): de nuevo la metáfora más o menos evidente figura a las "antiquísimas lenguas de América" como silenciosas playas que se desvanecen ante el avance del idioma común. Su desaparición es también la de sus tradiciones e identidades: "A lo lejos, en el confín del horizonte, los apagados cráteres no son más que conos misteriosos. ¡Y no menos enigmáticos se elevan los monumentos que nadie sabe quién construyó! ¿Memorias de qué? Memorias de nada: son lo inmemorial. ¿Vaticinios de qué? Vaticinios de nada. Lo inmemorial carece de visión futura. Lo que no tiene memoria ignora la esperanza” (Capdevila, 1928: 186). Así, Capdevila recupera una imagen ya presente en Bello (v. Ennis y Pfänder, 2013: 62-63), la del monumento mudo, la damnatio memoriae que condena a la cultura del otro, junto con su lengua, a la ilegibilidad, en función de un progreso irrevocable:

¿Y las otras cien, y las otras mil lenguas aborígenes, de tribus, de clanes, de ayllus, que a manera de islotes se fue tragando el mar de la lengua nueva por todo lo que es América? Tal cataclismo espiritual fue aquel, que ese mismo de la sumergida Atlántida pálido parece a su lado.

Y todavía trabaja el mar, y lo que deba ser destruido, será destruido. [...] Hasta que todo sea mar: inmenso mar castellano. (Capdevila, 1928: 186-187)

Así el ensayo refuta en su cierre en todas las versiones, que será también el cierre del libro, lo postulado antes para Manila, reforzando la retórica imperial: "Y no se pone el sol” (ibid.: 189). 


\section{Consideraciones finales}

En estas páginas se ha procurado ofrecer una presentación y examen inicial de una serie de intervenciones que encuentran su manifestación más conocida en el volumen Babel y el castellano, pero que tienen su génesis en la prensa periódica y alcanzan un entramado institucional, material y discursivo complejo que integra el discurso y las instituciones de la literatura con las del discurso especializado sobre la lengua, la educación y la política. De este modo, el análisis propuesto para este corpus textual permite observar las diferentes y complejas alternativas de la circulación de este tipo de intervenciones sobre el lenguaje en el espacio público, desde el momento de su producción hasta las formas más tardías de su recepción.

Si bien la historia de los debates ideológico-lingüísticos en Argentina se abre desde las primeras décadas del siglo XIX, puede decirse que hasta los años 1920 esto no sucede a través de tradiciones sostenidas de intervención pública sobre la lengua, sino mediante la aparición de debates singulares en distintos momentos y de diversa intensidad y extensión. Es a lo largo de las décadas del 20 y 30 que puede observarse la emergencia y proliferación de formas diversas de la intervención pública sobre el lenguaje en la prensa escrita, y junto a procesos de institucionalización específicos (como la creación del Instituto de Filología de la Universidad de Buenos Aires en 1922 y la de la Academia Argentina de Letras en 1931), y la consolidación de firmas relacionadas directamente con la intervención en el espacio público del lenguaje, que a su vez empiezan a encontrar un lugar cada vez más notorio en un pujante mercado editorial. Esto no significa que en la exploración de la prensa escrita no podamos encontrar manifestaciones anteriores de este tipo de intervenciones, sino que es a partir de ese momento que se generan condiciones de posibilidad en varios aspectos para darle visibilidad y continuidad. Entre estos aspectos puede enumerarse de manera preliminar la complejidad del panorama de las competencias legítimas disponibles para intervenir sobre el tema a partir de la emergencia de espacios de profesionalización del saber sobre la lengua e incipiente formación de un campo científico relativamente autónomo, la extensión y diversificación de los periódicos metropolitanos (y del novedoso espacio de las conferencias públicas), y los rasgos específicos del desarrollo de la cultura impresa en Buenos Aires y la diversificación y tensiones en el campo literario.

Las dos escenas citadas al inicio, en las cuales Capdevila comparte el escenario con Borges, permiten, del lado de la literatura, observar el alcance y los límites del destacado lugar que asume un discurso de este tipo: cuando el joven escritor presenta en el escenario privilegiado del periódico más vendido de la época su discurso sobre la materia, la presentación será hecha por su firma más frecuente para esta temática; al mismo tiempo, cuando décadas después, en la Academia Argentina de Letras, Capdevila -aún en un plano destacado en las manifestaciones públicas de la cultura legítima- persista en sus afanes por corregir el español local y acercarlo al peninsular, será devuelto por ese mismo escritor, ahora de fama universal, discretamente al rincón de las preocupaciones baladíes. Esa parábola da cuenta bastante aproximada del destino de la firma de Capdevila en el 
horizonte de la literatura y los discursos legitimados sobre la lengua, desde la notoriedad de un escritor ampliamente reconocido hasta la reminiscencia anecdótica de un purismo militante.

Lo que el caso de Capdevila permite observar en la serie de textos aquí analizada es cómo en el momento en el cual emerge con fuerza la autoridad de un campo científico hegemonizado por los discípulos de Menéndez Pidal, del mismo modo que surgen formas de resistencia o alternativa frente a ese discurso hegemónico (Toscano y García, 2015, 2016), comienzan también a circular formas paralelas de autorización de un discurso sobre la lengua en el espacio público, propiciadas sobre todo por la prensa y su expansión y prestigio en la época - donde también encuentran lugar intervenciones provenientes de ese novedoso campo científico proveedor de autoridad discursiva en la materia, como es el caso por ejemplo con los artículos de Américo Castro en La Nación en la misma época. A partir de la articulación entre el discurso lego y el especializado (al menos al recurrir a este último como referencia obligada), entre el espacio de la prensa periódica y el mercado del libro, Capdevila logra agregar a su perfil de escritor los rasgos de un celoso y eficiente guardián de la lengua. Partiendo de su labor publicística en un diario de gran alcance, que articula con otra en los espacios que proporciona el propio periódico, sostiene su influencia en las sucesivas ediciones del libro, que logran incorporarse (a través de las incursiones de los lingüistas profesionales como A. Castro en la política lingüística, en la prescripción pura y dura) a una tradición presuntamente científica y le permiten ganar un alcance de otro modo difícil de imaginar para sus pareceres sobre la conducta lingüística de sus compatriotas. 


\section{Referencias bibliográficas}

Abeille, Lucien (1900), Idioma nacional de los argentinos, París, Bouillon.

Alemany, Carmen (1998), La polémica del meridiano intelectual de Hispanoamérica (1927). Estudio y textos, Alicante, Universidad de Alicante.

Alfón, Fernando (2013), La querella de la lengua en Argentina. Antología, Buenos Aires, Biblioteca Nacional.

Alonso, Amado (1943), Castellano, español, idioma nacional, Buenos Aires, Losada.

Arnoux, Elvira Narvaja de y Roberto Bein (1995), "La valoración de Amado Alonso de la variedad rioplatense del español", Cauce, nº 18-19, p. 183-194.

Benavides, Carlos (2003), "La distribución del voseo en Hispanoamérica”, Hispania, n 86, vol. 3, p. 612-623.

Blommaert, Jan y Jef Verschueren (1998). "The Role of Language in European Nationalist Ideologies", en Bambi Schieffelin, Kathryn Woolard y Paul Kroskrity (eds.), Language Ideologies. Practice and Theory, Nueva York y Oxford, Oxford University Press, p. 189-210.

Borges, Jorge Luis (1926), El tamaño de mi esperanza, Buenos Aires, Proa.

Borges, Jorge Luis (1998), El idioma de los argentinos, Buenos Aires, Alianza [1ª ed. 1928, Buenos Aires, M. Gleizer].

Borges, Jorge Luis (1962), “Discurso de Don Jorge Luis Borges en su recepción académica”. Boletín de la Academia Argentina de Letras, t. XXVII, nº 105-106, p. 303-312.

Bosoer, Sara (2008), 'Algo más que hispanismo-antihispanismo en la polémica por el meridiano: Lengua, nación y mercado a fines de la década de 1920', en Actas del I Congreso Internacional de Literatura y Cultura Españolas Contemporáneas, La Plata, Universidad Nacional de La Plata, 2008.

Capdevila, Arturo (1925), Tierras nobles. Viajes por España y Portugal, Buenos Aires, El Ateneo.

Capdevila, Arturo (1928), Babel y el castellano, Buenos Aires, Cabaut.

Capdevila, Arturo (1952), Despeñaderos del habla, Buenos Aires, Losada.

Capdevila, Arturo (1962), "Discurso de Don Arturo Capdevila en la recepción académica de Don Jorge Luis Borges”, Boletín de la Academia Argentina de Letras, t. XXVII, n 105-106, p. 297-302.

Capdevila, Arturo (1967), Consultorio gramatical de urgencia: Con algunos llantos y quebrantos o lances y percances del habla depor acá, Buenos Aires, Losada.

Carricaburo, Norma (1999), El voseo en la literatura argentina, Madrid, Arco. 
Castro, Américo (1941), La peculiaridad lingüística rioplatense y su sentido histórico, Buenos Aires, Losada.

Costa Álvarez, Arturo (1922), Nuestra lengua, Buenos Aires, Sociedad Editorial Argentina.

Costa Álvarez, Arturo (1928), Reseña de Babel y el castellano, de Arturo Capdevilla. Nosotros, vol. LXI, t. 22, n²3, p. 288-290.

Degiovanni, Fernando y Guillermo Toscano y García (2010a), "'Las alarmas del doctor Américo Castro': institucionalización filológica y autoridad disciplinaria”, Variaciones Borges, n 30, p. 3-42.

Degiovanni, Fernando y Guillermo Toscano y García (2010b), "Disputas de origen: Américo Castro y la institucionalización de la filología en la Argentina”, Nueva Revista de Filología Hispánica, vol. LVIII, no 1, p. 191-213.

Derrida, Jacques (1997), El monolingüismo del otro o la prótesis del origen, Buenos Aires, Manantial.

Del Valle, José (dir.) (2015). Historia política del español. La creación de una lengua, Madrid, Aluvión.

Ennis, Juan (2008), Decir la lengua. Debates ideológico-lingüísticos en Argentina desde 1837, Frankfurt et al., Peter Lang.

Ennis, Juan (en prensa), "La filología como profesión en la Argentina del 20: Arturo Costa Álvarez en la prensa", en Elvira Narvaja de Arnoux, Lidia Becker y José del Valle (eds.), Reflexiones glotopolíticas desde y hacia América y Europa, Berlín, Peter Lang.

Ennis, Juan y Stefan Pfänder (2013), Lo criollo en cuestión. Filología e historia, Buenos Aires, Katatay.

Ennis, Juan (2020), Guillermo Toscano y García y Lucila Santomero (eds.) (2020), La lengua argentina. Una encuesta del diario Crítica (1927), Santa Fe, Vera Cartonera.

Estrella Gutiérrez, Fermín (1962), Arturo Capdevila, Buenos Aires, Ediciones Culturales Argentinas.

Falcón, Alejandrina (2010a), "Un español sin patria ninguna: el idioma de los libros en tiempos de auge editorial", IX Congreso Argentino de Hispanistas, 27 al 30 de abril de 2010, La Plata. El hispanismo ante el bicentenario. Disponible en: http://www.memoria.fahce.unlp.edu.ar/trabeventos/ev.1069/ev.1069.pdf

Falcón, Alejandrina (2010b), "El idioma de los libros: antecedentes y proyecciones de la polémica "Madrid, meridiano 'editorial' de Hispanoamérica"', Iberoamericana, vol. X, n³7, p. 39-58

Fontanella de Weinberg, María Beatriz (1971), "El voseo en Buenos Aires en las dos primeras décadas del siglo XIX”, Thesaurus, vol. XXVI, n. ${ }^{\circ}$ 3, p. 495-514.

Fontanella de Weinberg, María Beatriz (1976): "Analogía y confluencia paradigmática en formas verbales de voseo”, en Thesaurus, vol. XXXI, n.ㄹ 2; p. 225-239. 
Gagné, F., Verreault, C., Mercier, L. (2004), “La base de données textuelles ChroQué: un nouvel outil pour élargir la description du français en usage au Québec", en Mercier, L. (ed.), Français du Canada - Français de France. Actes du sixième colloque international tenu à Orford, Québec, du 26 au 29 sept. 2000, 247-261. Tübingen: Niemeyer.

Gil, Rodolfo (1911), Romancero judeo-español, Madrid, Imprenta Alemana.

Glozman, Mara (2015), Lengua y peronismo. Políticas y saberes lingüísticos en Argentina, 1943-1956, Buenos Aires, Biblioteca Nacional.

Gómez, Hernán E. (2008), Los diarios como espacios públicos: La Prensa en la vida social de Buenos Aires a comienzos del siglo XX, Intersecciones en Antropología, n 9, p. 261-274.

Heller, Monica y Bonnie McElhinny (2017), Language, Capitalism, Colonialism. Towards a Critical History, Toronto, Toronto University Press.

Heller, Monica (2019), "Sociolinguistic Frontiers: Emancipation and Equality", Items. Insights from the social sciences, disponible en https://items.ssrc.org/sociolinguistic-frontiers/sociolinguistic-frontiers-emancipation-and-equality/

López García, María (2015), Nosotros, vosotros, ellos. La variedad rioplatense en los manuales escolares, Buenos Aires, Miño \& Dávila.

López-Morell, Miguel Ángel y Antonio Molina Abril (2012), "La Compañía Iberoamericana de Publicaciones, primera gran corporación editorial en castellano", Revista de Historia Industrial vol. XXI, n. 49, p. 111-145.

Ludmer, Josefina (1999), El cuerpo del delito. Un manual, Buenos Aires, Perfil.

Malmberg, Bertil (1973), "La situation linguistique de la République Argentine et du Río de la Plata”, en Linguistique générale et romane. Études en allemand, anglais, espagnol et francais, La Haya y París, Mouton, p. 319-334.

Meier, Franz y Sabine Schwarze (2020, en prensa), "CROM.net - una investigación de corpus contrastiva en torno a la epistemicidad y las tradiciones discursivas en las columnas del lenguaje en lenguas romance", en G. Goldchluk y J. Ennis (eds.), Las lenguas del archivo. Filologías para el siglo XXI, La Plata, EdULP.

Menéndez Pelayo, Marcelino (1900), Antología de poetas líricos castellanos, tomo X: Romances populares recogidos de la tradición oral, vol. III, Madrid, Viuda de Hernando.

Oliveto, Mariano (2010), "La cuestión del idioma en los años veinte y el problema del lunfardo: a propósito de una encuesta del diario Crítica”, Revista Pilquen vol. XII, n.ำ13, p. 1-9.

Pulido Fernández, Ángel (1905), Españoles sin patria, Madrid, Teodoro.

Quesada, Ernesto (1922), La evolución del idioma nacional, Buenos Aires, Mercatali. 
Remysen, Wim (2005), "La chronique de langage à la lumière de l'expérience canadienne-française: un essai de définition", en Remysen, Wim et al. (eds.), Les Journées de linguistique. Actes du $18^{e}$ colloque 11-12 mars 2004, Quebec: Centre interdisciplinaire de recherches sur les activités langagières, p. 267-281.

Remysen, Wim (2009), Description et évaluation de l'usage canadien dans les chroniques de langage: contribution à l'étude de l'imaginaire linguistique des chroniqueurs canadiens-français, Quebec, Université Laval.

Saítta, Sylvia (2013 [1998]), Regueros de tinta. El diario Crítica en la década de 1920, Buenos Aires, Siglo XXI.

Sarlo, Beatriz (1996), "Oralidad y lenguas extranjeras. El conflicto en la literatura argentina durante el primer tercio del siglo XX", Orbis Tertius vol. 1, n. ${ }^{\circ}$ 1, disponible en https://www.orbistertius.unlp. edu.ar/article/view/OT

Sztrum, Marcelo (1992), "Algunas relaciones entre 'lengua gauchesca' e 'idioma nacional de los argentinos', América. Cahiers du CRICCAL, n. ${ }^{\circ} 11$, p. 62-77.

Sztrum, Marcelo (1998), "¿Llegaremos a tener un idioma propio? Encuesta en el diario Critica, Buenos Aires, 1927", América: Cahiers du CRICCAL. Polémiques et manifestes auX XIXe et XXe siècles en Amérique latine, n²1, p. 219-225.

Torre, Guillermo de (1927), "Madrid, meridiano intelectual de Hispano-América", La Gaceta Literaria, ibérica, americana, internacional. Letras, artes, ciencia, t. I, n. ${ }^{\circ}$ 8, p. 1.

Torre, Guillermo de (1932), "Nuestro idioma y la Argentina. Babel y el castellano", El Sol XVI, 4623, 5 de junio de 1932, p. 8.

Torre, Guillermo de (1940), "La buena doctrina", en Capdevila, Arturo. Babel y el castellano, Buenos Aires, Losada, p. 165-171.

Toscano y García, Guillermo (2009), "Materiales para una historia del Instituto de Filología de la Universidad de Buenos Aires (1920-1926)", Revista Internacional de Lingüística Iberoamericana, vol. VII, n. ${ }^{\circ} 13$, p. $113-135$.

Toscano y García, Guillermo (2015), “'Antes que mentir exclusividad que no siento'. Saberes lingüísticos e instituciones reguladoras en Delfina Molina y Vedia", Estudios de Lingüística del Español, n. ${ }^{\circ} 36$, p. $25-56$.

Toscano y García, Guillermo (2016), "Debates sobre la lengua e institucionalización filológica en la Argentina durante la primera mitad del siglo XX”, en José del Valle (ed.), Historia política del español. La creación de una lengua, Madrid, Aluvión, p. 245-265.

Toscano y García, Guillermo (2019), "El futuro de la lengua, la lengua del futuro. Sobre la encuesta del diario Crítica (1927)", Olivar vol. 19, n. ${ }^{\circ} 29$, https://doi.org/10.24215/18524478e052 
Unamuno, Miguel de (1940), "Prólogo con versos”, en Arturo Capdevila, Babel y el castellano, Buenos Aires, Losada, p. 11-12.

Vidal de Battini, Berta Elena (1964), El español de la argentina. Estudio dedicado a los maestros de las escuelas primarias, Buenos Aires, Consejo Nacional de Educación.

Wagner, Max Leopold (1914), Beiträge zur kenntnis des Judenspanischen von Konstantinopel, Viena, Hölder.

Wagner, Max Leopold (1923), "Algunas observaciones generales sobre el judeo-español de Oriente", Revista de Filología Española, n. ${ }^{\circ}$ 10, p. 225-244.

Wagner, Max Leopold (1924), "Os judeos hispano-portugueses e a sua língua no Oriente, na Holanda e na Alemanha", Arquivo de história e bibliografia, vol. I, p. 257-272.

Zeballos, Estanislao (1915), "Acta de fundación del Instituto Popular de Conferencias", Anales del Instituto Popular de Conferencias Dr. Lisandro de la Torre, c. I, p. 3-6. 


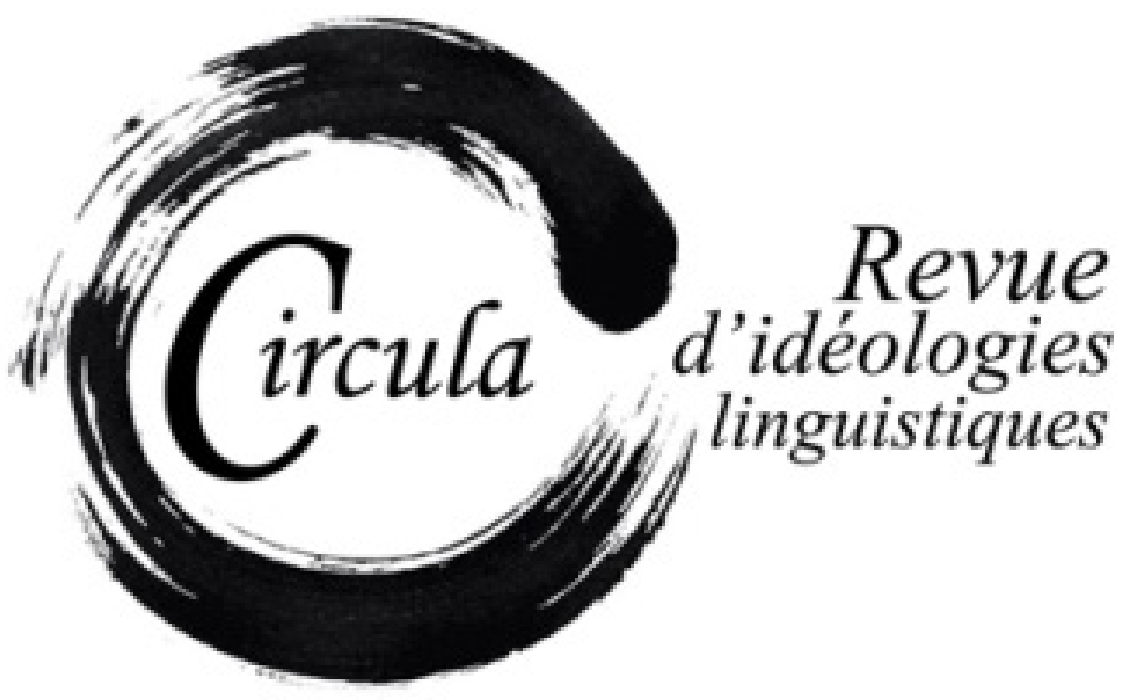

Titre: ACtiTUdeS haCIA LAS LENGUAS IndíGENAS POR ESTUdiANTES EN LEÓN, GUANAJUATO, MÉXICO Auteur: Felipe Canuto Castillo, Universidad de Guanajuato

RevUe: CIRCULA, NUMÉRO 11

PAGES: $24-45$

ISSN: 2369-6761

URI: HTTP://HDL.HANDLE.NET/11143/17839

DOI: HTTPS://DOI.ORG/10.17118/11143/17839 


\title{
Actitudes hacia las lenguas indígenas por estudiantes en León, Guanajuato, México
}

\author{
Felipe Canuto Castillo, Universidad de Guanajuato \\ felipe.canuto@ugto.mx
}

\begin{abstract}
Resumen: En este artículo se analizan las actitudes de estudiantes de bachillerato y licenciatura hacia los idiomas en general y los indomexicanos en particular para conocer la percepción de este sector de la población en torno al tema. Para llevar a cabo esta investigación, se aplicó un cuestionario a 83 jóvenes, de ambos sexos, que acudían a la Biblioteca Pública Estatal. El análisis de los datos lingüísticos se centró en las unidades de información en relación con las valoraciones hacia los idiomas indígenas y las situaciones sociales que comunicaban las respuestas. Los resultados que se obtuvieron muestran que, probablemente, debido a la "sensibilización" que reciben en la escuela acerca de la diversidad cultural, estos jóvenes se muestran favorables hacia las lenguas indígenas, pero sus deseos de aprender alguna de ellas se desvanecía cuando se confrontaban con sus intereses.
\end{abstract}

Palabras clave: lenguas indígenas; actitudes; estudiantes; asimetría; representaciones sociales

\begin{abstract}
This article analyzes the attitudes of students towards languages in general and particularly the indomexicans to know the perception of this sector of the population around these languages. To carry out this research, a questionnaire was applied to 83 young people, of both sexes, who went to the State Public Library. The analysis of the linguistic data focused on the units of information in relation to the attitudes towards the indigenous languages and the social situations that the responses communicated. The results obtained show that, probably, due to the "sensitization" they received at school about cultural diversity, these young people were favorable to indigenous languages, but their desire to learn some of them faded when they were confronted his interests
\end{abstract}

Key words: indigenous languages; attitudes; students; asymmetry; social representations 


\section{Introducción}

León, que se fundó como villa de españoles a finales del siglo XVI, se ubica en el Bajío, una región que, según Wright (2014), abarca desde el primer lugar citado hasta Querétaro capital y a la que se le podría sumar el oriente de los Estados de Jalisco y Aguascalientes; la ciudad se asentó en territorio de los guachichiles quienes, junto con sus vecinos guamares, ofrecieron resistencia a la colonización española y sus aliados indios ${ }^{1}$ que dio lugar a la llamada "guerra chichimeca" entre 1550 y 1590. Posterior al establecimiento de los hispanos arribaron purépechas de Acámbaro que fueron llevados como mano de obra y se asentaron en El Coecillo, el pueblo de indios. La población africana llegó también y contribuyó a los mestizajes biológico y cultural que se gestaron, lo cual dan cuenta los registros parroquiales de bautismos más antiguos que se conservan:

En dieciséis días del mes de julio de mil seiscientos treinta y seis años bauticé a María, mulata, hija de Antonia, esclava de Francisco Muñoz. Fueron sus padrinos Pedro Juan y María Pascuala, negros. Fray Álvaro de Acevedo².

Sin embargo, ese pasado que forjó el presente de México, se ignora o se niega; a pesar de que los indios y los negros fueron los grupos más numerosos de la población durante la época colonial, sus civilizaciones y aportes son negados: la primera, ha sido discriminada y, la segunda, invisibilizada; una glorificada en sus tiempos pretéritos para fines nacionalistas y la otra borrada de los libros de historia desde el siglo XIX; sólo a finales del XX comenzó a ser considerada la "tercera raíz" (Aguirre Beltrán, 1972; Bonfil Batalla, 1990; Gutiérrez y Valdés, 2015; Velázquez e Iturralde, 2016).

En algunas regiones se ha forjado un imaginario que considera que la población es de descendencia "pura" de españoles y que allí la presencia de indios y negros fue escasa o nula, como sucede en los Altos de Jalisco; sin embargo, las investigaciones recientes demuestran que desde principios del siglo XVII se forjaron sociedades multiétnicas y heterogéneas done la mayoría eran los indios, como lo confirma el trabajo de Becerra, quien culmina su obra señalando que "un alteño de esa época [últimas décadas del XVIII] se asombraría al escuchar las afirmaciones que con el pasar de los siglos se han vuelto comunes y que sostienen que la región alteña ha sido, desde sus orígenes, eminentemente hispana y mestiza" (2015: 154).

En el caso de León, junto al desconocimiento de su pasado indio y negro, la discriminación a los indígenas que han llegado de diferentes partes del país a partir de la segunda mitad del siglo XX es un continuum de olvido, negación y rechazo, pues a pesar de que son visibles y han hecho de esta ciudad su residencia permanente, se les considera extraños, "indígenas migrantes", y vistos como

1. En este caso se emplean las denominaciones de la época colonial: "indios" y "negros".

2. Archivo Parroquial del Sagrario de León, libro de bautismos, volumen 1, 1636-1682, sin número de folio ni partida, disponible en https://tinyurl.com/3m4fuhm. [Sitio consultado el 1 de febrero de 2020]. Se actualizó la ortografía y la puntuación del registro del bautismo. 
una alteridad no deseada de acuerdo con el imaginario de una sociedad clasista, racista y católica conservadora, como se considera a los leoneses.

Ser indígena en León, pero, sobre todo, evidenciar los rasgos diacríticos étnicos, entre ellos el idioma y la vestimenta, puede ser causal de discriminación. A nivel instituciones, la alcaldía ha contado con el mayor número de denuncias a nivel estatal ante la Procuraduría de los Derechos Humanos del Estado de Guanajuato por maltrato a indígenas; en particular, contra los que ejercían el comercio informal en determinados sitios (Canuto, 2017); además, en la ciudad, han sido vulnerables por desconocer la lógica de la cultura urbana, la pobreza y la falta de acceso a oportunidades laborales y educativas, así como por no entender “bien” el castellano ni saber leer y escribir (Jasso, 2011).

De acuerdo con notas periodísticas, los indígenas en León “son los más desprotegidos” y las miradas de la sociedad hacia ellos son de "desinterés, desprecio, otros con morbo y unos más que prefieren considerarlos invisibles”; de esta manera, su cultura se convierte en signo que permite identificar a sus portadores y ser sujetos de discriminación; por eso, no quieren hablar su idioma "por temor a que se rían de ellos, los excluyan o que los discriminen"3.

A pesar de la anterior situación desfavorable, que es una constante que se señala en relación con la pérdida de las lenguas indígenas, parece ser que la discriminación debe conjuntarse con otros factores para propiciar el desplazamiento, pues, según se ha observado, ante esta misma situación algunos indígenas en León optan por no hablar ni transmitir sus lenguas a sus descendientes, mientras que otros las emplean en su cotidianidad para demostrar su orgullo étnico y diferenciarse de los mestizos (Canuto, 2017).

Con el fin de revertir la situación descrita, en México se han promulgado leyes que buscan reconocer, fomentar y proteger los derechos y los idiomas de los pueblos indígenas. Según el artículo segundo de la Constitución Política del país, "la Nación tiene una composición pluricultural sustentada originalmente en sus pueblos indígenas" a los que se les reconoce y garantiza, entre otros derechos, el de "preservar y enriquecer sus lenguas, conocimientos y todos los elementos que constituyan su cultura e identidad"; además, corresponde al Estado mexicano establecer instituciones y determinar políticas "para promover la igualdad de oportunidades de los indígenas y eliminar cualquier práctica discriminatoria" (v. Constitución).

Por otra parte, en 2003 se decretó la Ley General de Derechos Lingüísticos de los Pueblos Indígenas que menciona que los idiomas indomexicanos son parte del patrimonio cultural y lingüístico del país y una de las principales expresiones de la composición pluricultural de la nación; esta legislación busca regular el reconocimiento y la protección de los derechos de los hablantes, así como promover el uso y desarrollo de los idiomas indígenas (v. Ley General).

3. El Heraldo León, Son los más desprotegidos en León, publicado el 20 de agosto de 2016, disponible en https://tinyurl. com/rzwa6t4. [Sitio consultado el 12 de enero de 2020.] 
Entre los derechos lingüísticos se encuentran los relativos a comunicarse en los idiomas indomexicanos en todas las actividades sociales, sea en los ámbitos públicos y privados, y de manera oral o escrita; además, los hablantes gozarán de la jurisdicción del Estado mexicano, el cual tomará en cuenta sus costumbres y cultura; también, accederán a educación bilingüe e intercultural en la que se asegure la práctica y uso de sus lenguas.

En esta ley se estipula la creación del Instituto Nacional de Lenguas Indígenas, llevada a cabo también en 2003, con el fin de "promover el fortalecimiento, preservación y desarrollo de las lenguas indígenas que se hablan en el territorio nacional, el conocimiento y disfrute de la riqueza cultural de la Nación". Una de las atribuciones de esta institución es la de estimular el aprecio de los idiomas indomexicanos "en los espacios públicos y en los medios de comunicación".

En lo que toca a la educación, también en el artículo segundo de la Constitución se señala que "para abatir las carencias y rezagos de los indígenas" se garantizará e incrementará el nivel de escolaridad de éstos y se favorecerá la educación bilingüe e intercultural; además, un aspecto que destaca es el relativo a que las autoridades tienen la obligación de "impulsar el respeto y el conocimiento de las diversas culturas existentes en la nación".

Con base en las políticas que "orientan la atención educativa de la diversidad cultural y lingüística" de México, en el Plan de estudios 1997 se incorporó la perspectiva de educación intercultural "para todos los mexicanos" a la formación de profesores de nivel primaria; el objetivo que se sigue es generar conocimiento, reconocimiento, valoración y aprecio por la diversidad cultural en un esfuerzo por forjar una sociedad unida en la diversidad "con una visión pluralista, democrática e incluyente" con el fin de revertir los efectos de la desigualdad y la discriminación (v. Educación); por lo que se espera que al egresar de la escuela, los estudiantes reconozcan "la diversidad individual, social, cultural, étnica y lingüística del país" (v. Aprendizajes).

Con estas leyes y con educación intercultural se busca combatir los prejuicios arraigados y naturalizados acerca de los indígenas en la sociedad, entre ellos, los que se propagan en los propios libros de texto gratuitos de la Secretaría de Educación Pública y por la televisión. De acuerdo con Corona y Le Mûr (2017), en las ilustraciones de los libros citados se reproduce un discurso racista que retrata al indígena de forma folklórica, en el medio rural y subraya su condición de pobreza y "atraso cultural", lo que constituye un paso previo al prejuicio que lleva a la discriminación.

Por su parte, según Muñiz, Marañón y Saldierna (2014), los estereotipos que se difunden en la televisión son un "indicador cultural" que permite observar su papel en la creación y transmisión de imaginarios, pues es un instrumento que socializa conductas y roles sociales; en su investigación encontraron que la presencia de personajes indígenas en la programación es reducida y desempeñan roles secundarios; además, suelen dedicarse al campo, a las labores domésticas y ser curanderos o parteras. 
En lo que toca a la condición étnica en México, se ha observado que ser indígena no representa ventajas, además de las "tradiciones"; en cambio, las desventajas se encuentran en relación con la discriminación, la marginación y la pobreza "por estar inscrito en un sistema y en una sociedad que reproduce comportamientos racistas en expresiones como la violencia, la burla y la ridiculización”; por lo cual, la vida "es más difícil para los indígenas" (Gutiérrez y Valdés, 2015: 148-149).

De acuerdo con estudios realizados acerca de la percepción que se tiene de los indígenas y sus manifestaciones culturales en las ciudades de México, la situación presenta claroscuros, pues, por un lado, se les considera una de las raíces de la identidad mexicana pero, por otro, se les señala como uno de los grupos sociales más vulnerables y discriminados y, por tanto, sujetos de estigmatización debido a que se les relaciona con el atraso, la ignorancia y la pobreza, y todavía se sigue empleando la palabra "indio" para insultar con una significación altamente racista (CDI, 2006).

Este es el contexto en el que se analizan las actitudes de estudiantes leoneses de nivel bachillerato y licenciatura hacia las lenguas del mundo, en general, y los idiomas indígenas de México, en particular, con el fin de conocer las representaciones socialmente compartidas por este sector de la población en torno al tema. Las preguntas que guiaron esta investigación indagaron en las ideologías y las actitudes lingüísticas, y se analizó el discurso a partir de lo declarado a favor o en contra de los idiomas y las intenciones de (no) aprenderlos.

La investigación partió de considerar que por lo mencionado anteriormente en relación con lo(s) indígena(s), en general, los estudiantes entrevistados dejarían ver en sus respuestas y comentarios un desconocimiento de la diversidad lingüística a nivel mundial, mayor interés por las llamadas "lenguas modernas" y, respecto de los idiomas indígenas, actitudes negativas y un cierto desprecio por los que comúnmente se denominan "dialectos" debido a que en la conciencia de la población aún sigue pesando un pasado de colonización y una de sus expresiones es el desinterés y, también, aversión hacia lo indígena; sin embargo, también se previó que la educación pudiera ser un posible factor de cambio en las actitudes, al menos a nivel discursivo, debido a la sensibilización que se realiza en la escuela en torno a la diversidad cultural.

\section{En torno a la investigación}

Las actitudes hacia los idiomas indomexicanos y sus hablantes es un tema que ya ha sido abordado en varios estudios; sin embargo, en éste se hará referencia a tres que se han llevado a cabo con jóvenes / universitarios cuyas preguntas son afines a las de esta investigación para observar de manera más amplia el fenómeno a partir de las semejanzas y diferencias en los resultados y conclusiones.

El primer trabajo (por año de aparición) es el de Caldera y Peredo (2014) quienes señalan que indagaron con estudiantes de nivel licenciatura de la Universidad de Guanajuato en torno a las "personas, pueblos y comunidades indígenas (PPCI)" a partir de los ejes "imagen", "empatía o identificación", 
"conocimiento" a nivel país y Estado, "derechos humanos" y "el tema" de los indígenas en la universidad con base en una encuesta aplicada en línea.

Una de las cuestiones que mencionan es el desconocimiento y escaso interés de los universitarios en las PPCl; aunque se identifica a los indígenas con aspectos positivos como la tradición y la cultura, siguen presentes "mitos" y estereotipos arraigados en el imaginario social que los relacionan con las artesanías, el campo, labores domésticas y mendicidad. Destaca el hecho de que para los entrevistados la palabra "indígena" no es sinónimo de atraso, ignorancia y carencia, y que ellos no son responsables de su discriminación.

Los jóvenes encuestados no conocen datos a nivel nacional y estatal del porcentaje de la población indígena, el número de pueblos que existen y las lenguas que se hablan, así como el nombre de éstas, ni las regiones donde habitan, además de otras cuestiones; sin embargo, 82.88\% mencionó interés en el aprendizaje de algún idioma indomexicano, de los que sólo mencionaron náhuatl, maya y otomí. ¿Cómo identifican a los indígenas? Por la vestimenta y la lengua o el modo de hablar, de otra manera, aunque alguien lo sea, si no se comporta de acuerdo con ciertos patrones estereotipados "no podrán percibirlo".

Por su parte, el texto de Sima y Perales (2015) tuvo como objetivo analizar las actitudes de un sector de población juvenil en Mérida hacia el maya y el inglés, las "contradicciones" entre la valoración y la elección de una lengua, y las presiones que hacen preferir el aprendizaje del idioma extranjero. Con base en una muestra de 16 informantes, de entre 15 y 30 años, exploraron las causas por las que hablantes de español como primera lengua preferirían estudiar inglés u otro idioma, pero no maya.

En el artículo citado se menciona que existen actitudes favorables hacia el maya y se le da importancia en relación con la identidad y las costumbres; además, existen motivaciones para aprenderlo, por lo que, al menos en el nivel del deseo, "la relación de ambos idiomas ocasiona entre ellos un equilibrio afectivo" y, aunque se prefiera el inglés, esta situación no implica que haya desprecio o que las actitudes sean negativas. Según los datos presentados, algunos diferencian entre lenguas "que se usan en la actualidad" y las que ya no se emplean "en el tiempo presente" o las hablaron "personas de otras generaciones".

Según los autores, la elección del inglés en lugar del maya se encuentra en relación con lo "utilitario" ya que las lenguas de "prestigio" se encuentran presentes en los espacios laborales, económicos, educativos, entre otros, mientras que el idioma indígena no genera expectativas profesionales o éstas son reducidas. De acuerdo con lo que mencionan, "las condiciones laborales y económicas [son] las que provocarían el detrimento de la lengua regional": el inglés genera incentivos monetarios o profesionales en el mundo globalizado y el maya no. 
Finalmente, Corral (2017) abordó las actitudes hacia los hablantes de lenguas indígenas en la Universidad Autónoma Chapingo con base en un cuestionario de 29 preguntas acerca de la identificación social, la identidad sociolingüística y las actitudes y creencias. Esta universidad, "donde ser indígena no es algo inusual", fue un espacio que consideró "ideal" para estudiar las actitudes lingüísticas debido a que interactúan diferentes culturas y se podría comprobar si existían diferencias debido a la categoría étnica de los informantes.

De los resultados que obtuvo Corral, se destaca el relativo a "la percepción de superioridad de unas lenguas sobre otras" que interpreta, desde una perspectiva actitudinal, como negativo hacia los idiomas indígenas ya que se considera que, en este caso el español y el inglés, son lenguas de prestigio o utilidad; sin embargo, a las lenguas indomexicanas se les confiere la identidad en el mundo global y mantienen las tradiciones de quienes las hablan.

En las conclusiones se destaca, en primer lugar, que los motivos de los estudiantes para aprender una segunda lengua están en relación con los beneficios instrumentales; en segundo, que las actitudes negativas hacia las lenguas indígenas y sus hablantes no son explícitas, lo que induciría a pensar que los prejuicios ya han sido superados, pero también se observan contradicciones que llevarían a desconfiar; en tercero, "apenas hay diferencias" entre las respuestas de los "indígenas" y los mestizos, y se observan actitudes negativas hacia la propia identidad etnolingüística que se relaciona con la discriminación y el menosprecio de que han sido sujetos los indígenas.

Como ya se mencionó, en este trabajo se abordan las actitudes de estudiantes de bachillerato y licenciatura hacia las lenguas, con énfasis en las que habla la población indígena en México. El concepto de "actitud" proviene de la sicología social y se encuentra en relación con el carácter evaluador que se construye a través de la experiencia social; cuenta con una estructura tripartita y sus componentes son de orden cognitivo, evaluativo y conductual (Castillo, 2006; Rojas, 2012; Sima, Perales y Be, 2014); las actitudes resumen comportamientos diferentes de una persona en relación con otra o con un objeto y reflejan la manera cómo se percibe el mundo que la rodea; los factores que desempeñan un papel esencial en su origen y evolución son los padres, los profesores, los camaradas, la escuela y la televisión (Lasagabaster, 2006).

Las actitudes lingüísticas son valoraciones que proyectan la percepción que se tiene de las personas que hablan una determinada lengua; por tanto, expresan de manera manifiesta o encubierta el prestigio de los idiomas y sus hablantes, por lo que también proporcionan datos en torno a las relaciones interculturales (Castillo, 2006; Corral, 2017); la enunciación de sentimientos positivos o negativos acerca de la lengua de los otros o la propia muestra lo que se piensa de sus hablantes (Lasagabaster, 2006).

El conocimiento de las actitudes lingüísticas permite comprender cómo a través del lenguaje se (re)crean ideologías e identidades, y cómo se forjan y perpetúan prejuicios sociales, lo cual permite observar la relación entre idioma y sociedad (Rojas, 2012); los valores acerca de las lenguas o sus 
variedades se encuentran motivados por la situación temporal en que se encuentran los idiomas y cambian de acuerdo con diversas circunstancias (Sima, Perales y Be, 2014); además, están determinados por creencias o ideas sobre ellas (Rojas, 2012) y se manifiestan a partir de una relación de oposición, por lo cual también es pertinente conocer quién, cómo y cuándo se dice lo que dice (Castillo, 2006).

Cabe mencionar que las actitudes lingüísticas son valoraciones con un sustento ideológico, por lo cual son parte de un constructo social que se (re)produce. Según van Dijk (2011), las ideologías son las creencias fundamentales de un grupo y de sus miembros que dan sentido al mundo y fundamentan las prácticas; por tanto, determinan lo que se dice y cómo se dice y pueden llevan a generar, según sea el caso, polarizaciones entre "nosotros" y "ellos", además de recursos para contrastar la otredad.

En particular, las ideologías lingüísticas son conceptualizaciones acerca del lenguaje y su uso; refieren a la calidad, valor, estatus, normas, funciones y pertenencia de los idiomas, y guían el comportamiento comunicativo de los hablantes; estos constructos son espacios de poder y autoridad, por lo que el uso de la lengua se encuentra estratificado y reglamentado (Blommaert, 2006); estas creencias y actitudes son colectivas, y dan forma a la relación de los hablantes con su propio idioma y los de otros en el marco de la práctica social de la lengua y las estructuras socioeconómicas y políticas (Cavanaugh, 2020). Skrobot (2014) señala que no se debe confundir ideología y actitud ya que la primera es mental e individual, aunque incluye el aspecto social, y es parte de la actitud y se verbaliza, en tanto que la segunda puede ser latente y no verbal.

Con base en lo anterior, se puede señalar que las opiniones y argumentos que emitieron los estudiantes a quienes se entrevistó para esta investigación parten de lo que se considera "correcto", de acuerdo con la sociedad donde se desenvuelven, respecto de la manera cómo es y debe funcionar el mundo. Por lo mencionado, el análisis se centró en los porqués de sus opiniones debido a que en ellos se observa el fundamento de sus ideas y creencias que comparten como grupo social, pues las representaciones sociales permiten conocer cómo se configuran las relaciones entre los diferentes grupos en contacto en un mismo territorio físico o en el imaginario.

¿Comparten los estudiantes la ideología de la "asimetría lingüística" que minusvalora las lenguas indígenas y por ello no les interesa su aprendizaje o, más aún, las menosprecian? Esta fue la pregunta que se trató de responder a partir de la "valoración" que realizaron acerca de lenguas "minorizadas" y las de "prestigio" con base en los argumentos a favor o en contra de ellas; así, se buscó de conocer la posición de los estudiantes acerca de la diversidad lingüística y las creencias que motivan una determinada actitud. 
Para llevar a cabo esta investigación ${ }^{4}$, se aplicó entre junio y julio de 2018 un cuestionario de 18 preguntas (además de los datos etarios, de escolaridad, etcétera) a 83 jóvenes que acudían a la Biblioteca Pública Estatal, ubicada en León, en torno a las lenguas que habían aprendido y por qué; en un segundo bloque se abordaba lo relativo a los idiomas que deseaban o no aprender y sus motivos; un tercero inquiría sobre el conocimiento y las actitudes hacia las lenguas indígenas. Para observar o no las asimetrías lingüísticas entre los idiomas indomexicanos y los de "prestigio" en los discursos de los estudiantes se incluyeron preguntas claves para confrontar aspectos valorativos con utilitarios.

La muestra estuvo integrada por 42 mujeres y 41 hombres; de ellos, 72 nacieron en León, cuatro en el vecino San Francisco del Rincón y los siete restantes en diversas partes del país; también, la mayoría de los progenitores de los estudiantes eran leoneses. La edad de los jóvenes se ubicó en el rango de los 15 hasta los 29 años; el mayor número se concentró en los de 17, 18, 1920 con 11, 14, 14 y 9 personas, respectivamente. En cuanto al nivel de estudios, 48 cursaban el bachillerato y 35 alguna licenciatura (13 de ellos una ingeniería) en instituciones públicas y privadas de la ciudad; por su parte, el nivel de estudios de sus padres era de secundaria (20 madres / 17 padres), preparatoria (14 / 20) y licenciatura (12 / 10), de acuerdo con los porcentajes más altos.

Debido a que unos de los recursos con que cuentan los jóvenes para obtener y compartir información, incluida aquélla que podría estar en relación con las lenguas y poblaciones indígenas, son las redes sociales, se preguntó a los entrevistados de cuáles hacían uso y las más mencionadas fueron Facebook (68 estudiantes), Instagram (42) y WhatsApp (38). Caldera y Peredo (2014) mencionan que las fuentes de los estudiantes universitarios de su investigación eran los libros, su casa y familia, y los medios de comunicación.

En general, las preguntas del cuestionario estaban conformadas de una parte "cerrada" y una "abierta", que correspondían a lo cuantitativo y lo cualitativo, respectivamente; la última era la principal, pues permitiría conocer la argumentación de los participantes y, a partir de ella, realizar el análisis. Los datos que se obtuvieron se conjuntaron con el fin de encontrar ciertos patrones o categorías en las variables estudiadas; de esta manera, por un lado, se conocieron cifras "duras" en torno a la situación lingüística y, por otro, la explicación de esos números.

\section{Datos linguiísticos}

Los datos que se mencionan a continuación son los que se encuentran en relación con las actitudes hacia las lenguas en general y en particular con los idiomas indígenas, así como el interés en el aprendizaje de ellos, y corresponden a una parte del total del cuestionario que se aplicó. En general,

4. Agradezco a Melissa Montserrat Castillo Ibarra, estudiante de la Universidad Veracruzana, quien durante su Verano de Investigación "Delfín” me apoyó con la sistematización de los datos. 
el análisis se centró en las unidades de información en relación con las actitudes de estos estudiantes hacia las lenguas y las "situaciones sociales" que comunicaban en sus respuestas.

En primer lugar, una situación que refleja un contraste entre el deseo y la "necesidad" de saber un idioma extranjero, principalmente el inglés, para ser parte de un idealizado mundo global y la realidad del sistema educativo y el compromiso por aprender alguno es el hecho que de los 83 entrevistados 31 (37.35\%) declararon que no sabían otra lengua además del español (se les denominó "monolingües"), 43 (51.81\%) que conocían una más, ocho (9.64\%) mencionaron que dos y sólo uno (1.20\%), tres.

De los entrevistados que dijeron "hablar" otro idioma aparte del español, 51 sabían inglés, 4 francés y las siguientes lenguas se mencionaron una vez: portugués, italiano, coreano, ruso, japonés y alemán; sin embargo, el conocimiento de éstas, de acuerdo con su propia percepción, evidencia que los menos poseen competencia "avanzada" (B2 en adelante): de los 51 "angloparlantes" sólo 14 dijeron poseer un nivel "nativo", "avanzado", "profesional" o porcentajes de 70 o más; en las demás lenguas, únicamente el hablante de portugués declaró que su competencia era "muy buena" y uno de francés que su nivel era B2; en el resto, la competencia lingüística de 21 era media y la de 24 baja. Por tanto, si se suman los 31 "monolingües" y los 24 de la escala baja, 55 no hablan un segundo idioma y 21 se encuentran en el "umbral” (B1), según el Marco Común Europeo de Referencias para las Lenguas.

El aprendizaje de una lengua extranjera, principalmente inglés y francés, se encuentra en relación con un fin instrumental, pues los entrevistados mencionaron que saber la primera de ellas es importante debido a su carácter "universal" e "indispensable en la vida cotidiana" y ambas brindan oportunidades en el campo laboral; un aspecto que destaca es el relativo a que 26 estudiantes mencionaron que "aprendieron" inglés porque "te lo inculcan desde pequeño" en la escuela y es parte del currículo académico, y esta dinámica continúa en los estudios superiores: "Io tienes que tener para titularte"; por esta razón, se genera un cierto rechazo a su aprendizaje: "no es un idioma de aquí, por lo tanto, no tendrían por qué estar poniéndolo en alto, exigiendo que uno lo aprenda". Por otra parte, tener una madre que hable ruso no garantiza su dominio, pues, según declaró el "hablante", su nivel era "básico".

Las razones por las que los estudiantes aprenderían o no una determinada lengua son diversas y corresponden a valoraciones realizadas a partir de lugares comunes, imaginarios colectivos e, incluso, gustos personales y expresaron actitudes tanto positivas como negativas acerca de una misma lengua; por ejemplo, el alemán fue el que recibió más intenciones de saberlo por cuestiones laborales y académicas, pero también porque "suena bien" y "es bonito"; en cambio, quienes no lo aprenderían dijeron que "se me hace muy complicado en fluidez" y "suena muy agresivo".

En lo que corresponde a las lenguas indígenas, ninguno de los entrevistados declaró saber o estar aprendiendo alguna a pesar de que, al menos siete, mencionaron que alguno de sus familiares sí las hablaban. En esta muestra se observa el corte generacional en la transmisión de los idiomas 
indomexicanos, pues dos personas señalaron que sus bisabuelos hablaban náhuatl y zapoteco, respectivamente, una que desde su bisabuela hasta su mamá y sus tías sabían náhuatl, una más que sus "abuelos sí tienen conocimiento de lenguas indígenas", otra que sus tíos "hablan totonaca", una que contó que uno de sus hermanos estaba aprendiendo náhuatl y alguna que supuso que en su familia debían "hablar una lengua porque son de Oaxaca"5.

El desconocimiento de la diversidad lingüística es notorio entre los estudiantes entrevistados, pues 50 no supieron cuántas lenguas se hablan en México, además de español: "desconozco, pero sé que son bastantitas. Bueno, más que nada por algunas lenguas que, obviamente, ya casi no se usan y que se quedan en los contornos de las ciudades, sobre todo... Desconozco por completo"; por su parte, 33 dieron una respuesta tratando de "adivinar" el número: "eh, no, no sé cuántas lenguas se hablan... solamente sé que son varias... te puedo mencionar, no sé, unas diez, pero son unas doscien... no... ¿ 74 ? No sé, la verdad".

En este mismo contexto, el término "dialecto" apareció en los discursos para diferenciar las lenguas de acuerdo con niveles que suponen superioridad según su importancia en el contexto sociopolítico: "sé que hay muchísimos dialectos, eh, pero lenguas, como tal, pues náhuatl, otomí, eh... zapoteco... o no sé si esos ya son como... ¿cómo se llaman?... dialectos; sí, no sé si ya entra en dialecto o qué”.

El número de lenguas indígenas de las que han oído hablar los entrevistados también es reducido; cuando respondieron a la pregunta del número de éstas las más citadas fueron náhuatl (9 veces), otomí (5), maya (4) y wixárika, zapoteco, purépecha y totonaca (una vez cada una); cuando se les solicitó específicamente que mencionaran nombres, dijeron náhuatl (21 veces), maya (9), otomí (6), zapoteco (3), mixteco (2) y totonaco, tarahumara, purépecha, tarasco, wixárika, huichol, tepehuano y cora una sola vez.

Respecto del interés por aprender una lengua indígena, las respuestas de los estudiantes fueron positivas en la mayoría de los casos: 62 contestaron afirmativa y 21 negativamente; de los estudiantes a favor, 23 dijeron que estudiarían "cualquier" idioma; luego, el náhuatl fue preferido con 22 "interesados", el maya con 12 y el "azteca”, chichimeca, zapoteco, huichol, wixárika, "oaxaqueño" y otomí con una mención cada uno.

Entre los motivos que mencionaron quienes mostraron cierto interés en aprender un idioma indígena se encuentran los relacionados con la identidad, el conocimiento y deseo de perpetuar la "raíz ancestral", la manera de conectarse con el pasado, la cultura y, también, la posible relación con sus estudios, principalmente; además de lo anterior, se señalaron ciertas cualidades de las lenguas, como que son "interesantes" y "bonitas", y "estaría chido saber de qué hablan"; el contacto personal o indirecto con hablantes también ha despertado el interés, así como la lectura de poesía y, en un

5. Oaxaca cuenta con el mayor porcentaje de población hablante de lenguas indígenas, 32.2\%, según la Encuesta Intercensal de 2015, disponible en https://tinyurl.com/y9trbxlw. [Sitio consultado el 1 de febrero de 2020]. 
caso particular, el hecho de que "llega mi familia de visita y hablan ese idioma y no les entiendo", entre otros.

Quienes no aprenderían una lengua indígena dijeron, en primer lugar, que no existe necesidad de saberlas debido a que, aunque existe gente que las habla, "pero como que ya hablan todavía más español"; en segundo, la supuesta "dificultad" que implica su dominio: "se me hace muy difícil de aprender porque se me hace mucho más complicado que el inglés o cualquier otro idioma"; en tercero, la cuestión utilitaria, pues para ellos si no les beneficia en lo laboral o económico, aunque tenga importancia "yo lo veo como que no le encontraría una aplicación". En el último caso también pueden entrar idiomas extranjeros de "prestigio": "¿para qué me serviría hablar francés aquí cuando nadie lo habla?".

Respecto de considerar que existan lenguas más importantes que otras, los números indican que 48 (57.83\%) estudiantes mencionaron, en general, que "todas tienen su valor y cultura", por tanto, son iguales; los argumentos a favor versaron acerca de la cultura, identidad e historia de los pueblos y la función comunicativa de los idiomas; consideraron que la situación de asimetría tiene qué ver con el empleo de algunos en ciertos contextos y por esta razón "les dan más importancia", pero "el hecho de a lo mejor reducir a nivel de importancia una lengua es de alguna manera discriminar a esa gente que la habla".

Por su parte, el mismo número de estudiantes que declaró que no aprendería una lengua indígena (21 que equivalen al 25.30\%) fue el mismo que sostuvo que algunas lenguas sí son más importantes que otras porque son necesarias para ciertos estudios y profesiones y, sobre todo, "abren las puertas" y ayudan a conseguir un mejor trabajo; además, consideraron que existen lenguas que "la mayoría de la gente ya las conoce" y por eso son "internacionales", "universales": en siete de las respuestas se mencionó al inglés como poseedor de estas características. El retorno a un pasado anterior al mítico Babel parece rondar en la mente de algunos jóvenes: "es más entendible que todos puedan hablar un mismo idioma y que todos se vayan más por ese mismo idioma”.

Un tercer grupo de 12 estudiantes (14.46\%) mencionó que sí existen lenguas más importantes que otras, pero hay otros factores por los que no se les podría considerar así o que "depende del enfoque de la persona"; así, las respuestas fueron del tipo "el inglés sería como el más importante, pero en el sentido de conservar las, no sé, las tradiciones [...] creo que ninguna es más importante", "creo que es relativo", "no hay lenguas más importantes, sólo unas más necesarias" y aquéllas que, aunque admitían la situación, no estaban de acuerdo con ella: "sí, por la globalización; sin embargo, no debería haber lenguas más importantes que otras porque es sólo comunicación”. Dos de los entrevistados no respondieron esta pregunta.

Con el fin de observar si las actitudes positivas en torno a la igualdad de las lenguas y la intención manifestada por la mayoría de los estudiantes de aprender un idioma indígena se mantenían, se les preguntó: entre maya e inglés, ¿qué estudiarías? Y, entonces, los números se invirtieron y la lengua 
indígena tuvo menos partidarios que argumentaran a favor de la importancia, necesidad o gusto de estudiarla, o el interés por conocer el "idioma de los antepasados" no fue suficiente. Los números indican que 20 aprenderían maya (24.10\%), tres ambos idiomas (3.61\%), 50 inglés (60.24\%) y 10 no respondieron (12.05\%).

Los discursos a favor siguen manifestando que estudiarían el idioma indomexicano porque es parte de la propia cultura y se debería conocer antes que otras; el orgullo de ser mexicano desempeña un papel fundamental en la elección de la lengua a aprender, pues el interés es conocer las raíces, el origen y la historia. Cabe destacar que se asocia a las lenguas indígenas con el pasado porque, al parecer, no se sabe que en el presente algunas mantienen su vitalidad en ciertas regiones; para ellos, aprender maya es "conocer la forma en que los mexicanos se comunicaban anteriormente", "es como aprender un idioma de México, pero de tiempo atrás”: es un pasado idealizado.

Los que manifestaron que no aprenderían maya sino inglés también esgrimieron los mismos argumentos acerca de que este idioma es parte de la formación académica; al ser "universal", "internacional", "importante", "necesario", "prioritario", ayuda y se usa y es más útil; por tanto, les "abre las puertas" en el mundo laboral. En cambio, el maya ya no se usa y es difícil: "el maya se ve que está más perro". Aunque algunos seguían recalcando la igualdad e importancia de las lenguas, el factor utilitario prevalecía sobre el cultural: "no sé, este... el inglés, la verdad. Sé que es importante el maya, pero, pues... el inglés porque es el que más ocuparía. Entonces, el inglés".

Finalmente, las tres personas que mencionaron que aprenderían ambos idiomas, mencionaron argumentos de una y otra posición; en este caso se conjuntan lo instrumental y el deseo de "conectarse" con la raíz: "los dos, pues el maya porque... ¿cómo te diré?, pues, es como ir hacia atrás de todos nuestros antepasados y el inglés es como abrirte puertas, ya es como un idioma básico que tienes que aprenderlo". Nuevamente, se observa el interés de aprender maya por el hecho de conocer el pasado, a los antepasados.

Una de las preguntas finales hizo retornar las valoraciones positivas en relación con las lenguas indígenas. Cuestionados acerca de si a los niños, en general, se les debería enseñar un idioma indomexicano en la escuela, además de uno extranjero, 73 opinaron que sí, seis que no y cuatro no supieron; las respuestas a favor, en general, estuvieron en torno, una vez más, de la conservación de la cultura y los orígenes, las tradiciones y "para que no se pierda la raíz" que viene de los antiguos y se conozca; sin embargo, dos respuestas pusieron el acento en que una política de este tipo contribuiría a combatir la discriminación y fomentar el respeto, la inclusión, la tolerancia y se pondría a las lenguas indígenas a la par del inglés, por ejemplo. Los que no se mostraron en pro de esta iniciativa presentaron los mismos argumentos utilitarios debido a que "es más importante que aprendan una lengua que les pueda ayudar en el futuro". La siguiente gráfica muestra un resumen acerca de las actitudes en torno a las lenguas indígenas. 


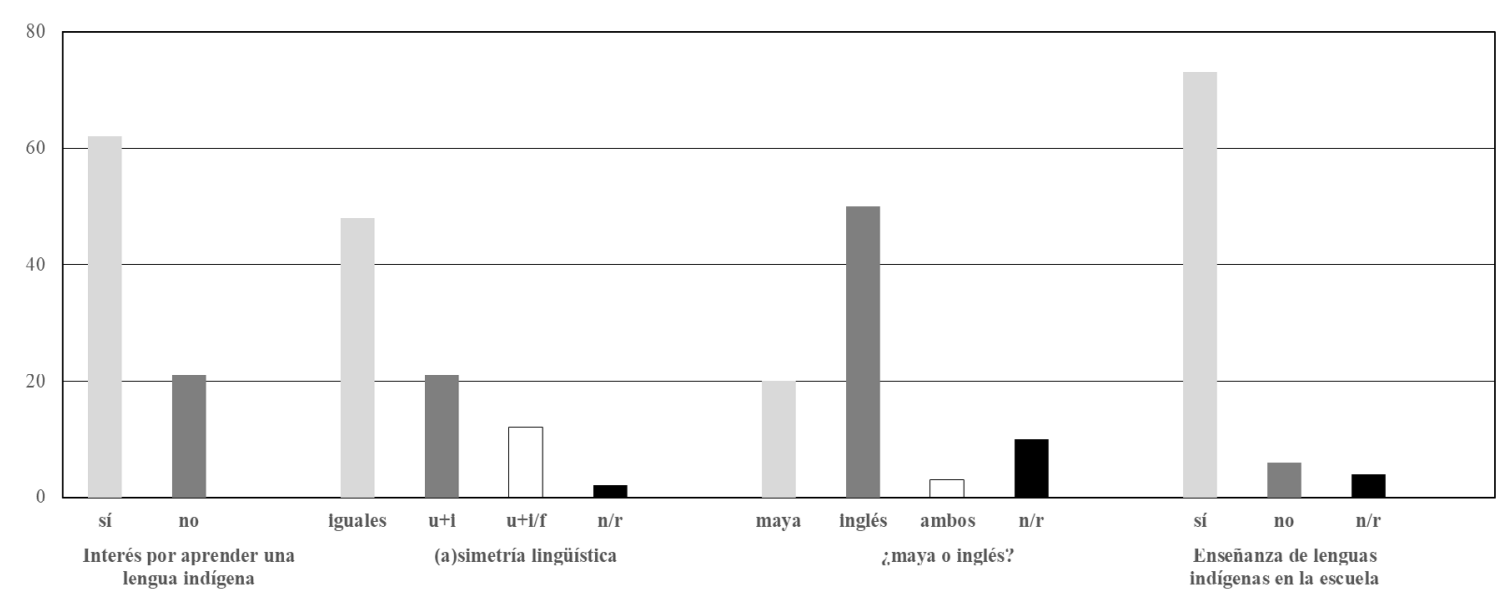

Gráfica 1. Actitudes hacia las lenguas indígenas mexicanas

FUENTE: ELABORACIÓN CON BASE EN LOS RESULTADOS CUANTITATIVOS OBTENIDOS EN LAS 83 ENTREVISTAS

ABREVIATURAS: U+I: UNAS LENGUAS SON MÁS IMPORTANTES, U+I/D: UNAS LENGUAS SON MÁS IMPORTANTES DEPENDIENDO DE LOS FACTORES QUE SE OBSERVEN, N/R: NO RESPONDIERON

La gráfica muestra cuatro variables del análisis: en la primera, se presenta el interés por aprender una lengua indígena; en la segunda, lo relativo a la (des)igualdad de los idiomas; en la tercera, la preferencia entre maya e inglés; finalmente, en la cuarta, si estaban a favor o no de la enseñanza de una lengua indomexicana en la escuela, además de una extranjera. La primera barra de cada variable (en tono gris claro) indica las actitudes a favor de los idiomas indígenas, mientras que la segunda (en gris oscuro) son las negativas o en pro de otro idioma; la barra blanca corresponde a respuestas que indicaron que aprenderían ambos idiomas o la igualdad de las lenguas según se considere la situación y la negra, por su parte, cuando no supieron qué responder.

Como se puede observar en la gráfica, las actitudes hacia las lenguas indígenas fueron contrastantes según el orden que se formularon las preguntas: de 62 personas interesadas en aprender una se pasó a 48 que mencionaron la igualdad de los idiomas y sólo quedaron 20 que declararon preferir el maya sobre el inglés; sin embargo, regresaron a un nivel positivo más alto con 73 menciones a favor de la enseñanza de un idioma indomexicano en la escuela. En las reflexiones siguientes se analiza este fenómeno contradictorio. 


\section{Reflexiones finales}

Como se ha podido observar, los resultados obtenidos en esta investigación son semejantes a los de las tres que se citaron, entre ellos, el relativo a que el aprendizaje de una segunda lengua se encuentra en relación con un factor instrumental / pecuniario, pues los estudiantes lo mencionaron como sus motivaciones; sin embargo, parece ser que éstas no han sido suficientes para lograr una competencia "avanzada" en un idioma debido a que la mayoría de los entrevistados (67 = 80.72\%) no la poseía.

El sistema educativo no parece ser óptimo en cuanto a su cometido en la enseñanza de segundas lenguas o en exigencia en cuanto al nivel de adquisición y, más bien, lo que está produciendo es rechazo, sobre todo al inglés, porque algunos lo consideran una imposición. Los números indican que para estos jóvenes el aprendizaje de un segundo idioma, aunque sea de "prestigio", obligatorio en la formación escolar o "que les abra las puertas laborales", no es importante ni indispensable o, a pesar de ello, no lo dominan. Un ejemplo de la aversión hacia el inglés, una actitud negativa, es la siguiente:

No me gustaría aprender el inglés, definitivamente. Yo creo que como no me di la oportunidad de generar un interés por el idioma, de niño me dijeron tienes que aprenderlo y lo he aprendido porque me lo han dicho; entonces, se volvió para mí un idioma tedioso. Si algún día llego a despertar el interés por él, pues lo aprendería con gusto. Lo poquito que sé es porque me han dicho que lo tengo que aprender no porque de verdad yo quiera hacerlo.

En las respuestas de los bachilleres y universitarios se observa un cierto conocimiento de la historia mexicana y la "sensibilización" que reciben en la escuela acerca de la diversidad cultural que les permitió considerar lo indígena como la "raíz" y, por esta razón, optar por un discurso "a favor" de los idiomas indomexicanos; a éstos, la mayoría los ponderó en igualdad frente a otros y declararon que aprenderían uno.

Sin embargo, la mención de la "raíz" en el discurso no es sino la presencia y actualización del mito fundador de la nación mexicana en el siglo XIX que ensalzaba al indio muerto y despreciaba al vivo, pues, como señalaron los estudiantes, aprender un idioma indomexicano era para conectarse con un pasado que, aunque idealizado, no remite a las poblaciones indígenas actuales, lo cual, como señalan Corona y Le Mûr (2017), es una representación abstracta, construida por y para la retórica; la interculturalidad ha quedado en el plano verbal, pero no en la cotidianidad, y no existen espacios para vivirla (Skrobot, 2014).

La pregunta clave para detectar "contradicciones" en las respuestas fue la relativa a la elección del aprendizaje entre maya o inglés, pues permitió que surgieran las ideologías compartidas socialmente en "situaciones concretas" y se manifestó la oposición utilitarismo versus "las raíces", pero, sobre todo, la asimetría lingüística, pues, aunque se observan "matices positivos" en el discurso, la 
ideología de la "jerarquía lingüística" se conserva en lo fundamental, se refleja en las valoraciones y repite prejuicios:

[Aprendería] el maya [y no el inglés] porque, en primera, a mí sí me enorgullece ser mexicano; entonces, conocer la forma en que los mexicanos se comunicaban anteriormente y, en segunda, porque me da la oportunidad de conocer un poquito más a fondo mi cultura; no sólo con conocer el idioma, sino con ver qué hay escrito a través de él.

Cuando se confrontaron las intenciones de aprender un idioma indígena con los intereses académicos, profesionales o laborales se dejaron ver actitudes negativas: aunque la mayoría de los entrevistados no lo declararon abiertamente, en sus argumentos se observa la descalificación de las lenguas indígenas pues no se les considera a la par de las que les "abren las puertas" y aunque se les da la concesión de ser parte de "nuestra raíz" se les niega como parte de la modernidad y se les relega a un pasado; es decir, se realiza una contrastación. Como menciona Corral, "no existe un rechazo explícito a las lenguas originarias, pero sí un menosprecio velado" (2017: 49). Skrobot (2014) observó en el contexto de la educación a nivel primaria que profesores y hablantes afirmaban el valor de los idiomas indomexicanos, pero sus conductas no se encontraban en relación con lo declarado (Skrobot, 2014).

En el caso que aborda este texto se estaría ante un "juego de la negación”, como lo llama van Dijk, en el cual sólo la primera parte "niega los sentimientos negativos o el racismo respecto de un grupo, mientras que el resto del discurso afirma aspectos muy negativos de los Otros" (2011: 64). Las negaciones de "concesión aparente" se ven reflejadas en la construcción de una ideología que se resumiría en una frase del tipo "las lenguas indígenas son la raíz, pero prefiero otras que abren las puertas laborales".

Si se considera que las actitudes lingüísticas manifiestan el prestigio de los idiomas y de sus hablantes, y muestran datos en torno a las relaciones interculturales, como señalan Castillo (2006) y Corral (2017), las valoraciones negativas de los estudiantes hacia las lenguas indomexicanas no son sino el resultado de los siglos de discriminación contra los pueblos y sus culturas, y una ideología compartida que se encuentran interiorizadas aun en el imaginario de la población indígena, sea hablante o no del idioma, como señalan Sima y Perales (2015) y Corral (2017). Como han señalado Velázquez y Terborg (2018) en relación con los medios, los estereotipos se forman con base en la relación histórica y aunque los discursos pueden ser multiculturales, manejan una oposición indígena-mestizo.

El "ciclo del discurso correcto de la asimetría lingüística" (velado por un matiz de empatía intercultural) mostraría los siguientes pasos (declaraciones): a) igualdad de las lenguas, b) interés en el aprendizaje de un idioma indígena, c) "contradicciones" en la elección de una lengua (interés vs igualdad), d) preferencia de una lengua de prestigio (aprendizaje por fines utilitarios): es decir, se regresa a la discriminación, a las actitudes negativas, debido a que se prefiere un idioma con base 
en una valoración diferenciada, por contraste, definida por cuál es de más utilidad y se desplaza la supuesta "igualdad lingüística".

Se puede retornar a la "igualdad de lenguas" cuando se realiza una pregunta "neutra", el aprendizaje de un idioma indígena en la escuela, como en el caso que se presenta. El paso a través de los niveles a, b, c y d del ciclo va diluyendo la simetría lingüística para llegar a las actitudes negativas en un discurso que parece formulaico y permite observar "Ios modelos mentales de representaciones sociales e ideologías" (van Dijk, 2011: 79).

Las conclusiones de Corral se encuentran en semejantes términos respecto de esta situación: las actitudes hacia las lenguas indígenas suelen ser negativas, pero es común que estas no se expresen abiertamente debido a que "lo habitual son las respuestas políticamente correctas en las que el informante suaviza su opinión” (2017: 52). En el discurso se siguen reproduciendo estereotipos y conservando la ideología de la "asimetría lingüística" que minusvalora las lenguas indígenas porque son del pasado y no generan ganancias, y por ello no interesa su aprendizaje. Como señala Skrobot (2014), un profesor indígena puede tener actitudes favorables hacia su lengua, pero pensar que no sirve y demostrarlo no enviando a sus hijos a la escuela bilingüe.

Los resultados que se obtuvieron en esta investigación comprueban una situación que se previó al inicio: un discurso "correcto" por parte de los estudiantes acerca de los idiomas indomexicanos que veladamente encubría la posición asimétrica donde los ubican. Lo anterior confirmaría que debido a la "sensibilización" que reciben en la escuela acerca de la diversidad, los jóvenes son empáticos con la otredad, pero con preguntas que confrontaban sus intereses emergió la discriminación que sigue en la conciencia colectiva hacia la población indígena, aquélla que identifican con base en estereotipos y es parte de la discriminación histórica hacia sus culturas y forja y perpetúa prejuicios mediante la lengua. 


\section{Referencias bibliográficas}

\section{Fuentes primarias}

Aguirre Beltrán, Gonzalo (1972), La población negra en México, México, Fondo de Cultura Económica.

Becerra Jiménez, Celina (2015), Indios, españoles y africanos en los Altos de Jalisco. Jalostotitlán, 1650 - 1780, Guadalajara, Universidad de Guadalajara.

Blommaert, Jan (2006). "Language policy and national identity", en Thomas Ricento (ed.), An introduction to language policy: Theory and method, Oxford, Blackwell, p. 238-254.

Bonfil Batalla, Guillermo (1990), México profundo. Una civilización negada, México, Consejo Nacional para la Cultura y las Artes / Grijalbo.

Caldera González, Diana y Karina Peredo Barrientos (2014), "Percepción de los jóvenes universitarios acerca de los indígenas”, en David Wright y Daniel Vega (coord.), Los pueblos originarios en el estado de Guanajuato, México, Pearson / Universidad de Guanajuato, p. 57-76.

Canuto Castillo, Felipe (2017), "Lenguas indígenas de México en contexto urbano. Una aproximación al caso de León, Guanajuato, México”, Universos. Revista de lenguas indígenas y universos culturales, no 14, disponible en https://tinyurl.com/v2lbnkz. [Sitio consultado el 14 de enero de 2019].

Castillo Hernández, Mario (2006), "El estudio de las actitudes lingüísticas en el contexto sociocultural: el caso del mexicano de Cuetzalan", Anales de Antropología, vol. 40, n 1, disponible en https:// tinyurl.com/r4dwghh. [Sitio consultado el 14 de agosto de 2019].

Cavanaugh, Jillian R. (2020), "Language ideology revisited", International Journal of the Sociology of Language, vol. 263, disponible en https://tinyurl.com/y5s3fyrp. [Sitio consultado el 17 de septiembre de 2020].

Comisión Nacional para el Desarrollo de los Pueblos Indígenas (CDI) (2006), Percepción de la imagen del indígena en México. Diagnóstico cuantitativo y cualitativo, México, CDI, disponible en https:// tinyurl.com/y9t6cl6c. [Sitio consultado el 30 de enero de 2020].

Corona Berkin, Sarah y Rozzen Le Mûr (2017), "Racismo en la imagen de los indígenas en los libros de texto gratuitos (2012-2015)", Comunicación y sociedad, n²8, disponible en https://tinyurl.com/ vcoyx3n. [Sitio consultado el 29 de agosto de 2019].

Corral Pérez, Isabel (2017), “Cómo le gustaría que fuese la educación en lo referente a las lenguas? Actitudes lingüísticas del alumnado mexicano", Onomázein. Revista de lingüística, filología y traducción, número especial III, disponible en https://tinyurl.com/s24ymbq. [Sitio consultado el 25 de agosto de 2019].

Dijk, Teun A. van (2011), Ideología y discurso, Barcelona, Ariel.

Gutiérrez Chong, Natividad y Luz Valdés (2016), Ser indígena en México. Raíces y derechos, México, Universidad Nacional Autónoma de México. 
Jasso Martínez, Ivy (2011), "Vulnerabilidad y población indígena en León, Guanajuato", Ide@s CONCYTEG, vol. 6, n 75, disponible en https://tinyurl.com/uvq4nhr. [Sitio consultado el 16 de enero de 2020].

Lasagabaster, David (2006), "Les attitudes linguistiques: un état des lieux", ÉLA. Études de linguistique appliquée, vol. 4, nº 144, disponible en https://tinyurl.com/yy29jc4p. [Sitio consultado el 17 de septiembre de 2020].

Muñiz, Carlos, Felipe Marañón y Alma Saldierna (2014), "¿Retratando la realidad? Análisis de los estereotipos de los indígenas presentes en los programas de ficción de la televisión mexicana", Palabra clave, vol. 17, no 2, disponible en https://tinyurl.com/uo5hmsx. [Sitio consultado el 16 de enero de 2020].

Rojas, Darío (2012), "Actitudes lingüísticas de hispanohablantes de Santiago de Chile: creencias sobre la corrección idiomática”, Onomázein. Revista de lingüística, filología y traducción, n²6, disponible en https://tinyurl.com/ukjw39d. [Sitio consultado el 14 de agosto de 2019].

Sima Lozano, Eyder y Moisés Perales Escudero (2015), "Actitudes lingüísticas hacia la maya y la elección del aprendizaje de un idioma en un sector de población joven de la ciudad de Mérida", Península, vol. X, n 1, disponible en https://tinyurl.com/te3wa7v. [Sitio consultado el 14 de agosto de 2019].

Sima Lozano, Eyder, Moisés Perales Escudero y Pedro Be Ramírez (2014), "Actitudes de yucatecos bilingües de maya y español hacia la lengua maya y sus hablantes en Mérida, Yucatán”, Estudios de cultura maya, vol. XLIII, disponible en https://tinyurl.com/qr4d8hv. [Sitio consultado el 25 de agosto de 2019].

Skrobot, Kristina (2014), Las políticas lingüísticas y las actitudes hacia las lenguas indígenas en las escuelas de México, tesis de doctorado, Barcelona, Universitat de Barcelona, disponible en https:// tinyurl.com/y6h8o7hp. [Sitio consultado el 17 de septiembre de 2020].

Velázquez, Elisa y Gabriela Iturralde Nieto (2016), Afrodescendientes en México. Una historia de silencio y discriminación, México, Consejo Nacional para Prevenir la Discriminación / Instituto Nacional de Antropología e Historia.

Velázquez, Virna y Roland Terborg (2018), "El otro México, estereotipos sobre el México indígena", en Zuzana Erdösová (ed.), La imagen estereotipada de México. Perspectivas internas y externas, Toluca, Universidad Autónoma del Estado de México, p. 91-109.

Wright Carr, David (2014), "La prehistoria e historia temprana de los pueblos originarios del Bajío", en David Wright y Daniel Vega (coord.), Los pueblos originarios en el estado de Guanajuato, México, Pearson / Universidad de Guanajuato, p. 1-40. 


\section{Documentos en internet}

Cámara de Diputados, Constitución Política de los Estados Unidos Mexicanos, disponible en https:// tinyurl.com/ruevp3s. [Sitio consultado el 1 de febrero de 2020].

Cámara de Diputados, Ley General de Derechos Lingüísticos de los Pueblos Indígenas, disponible en https://tinyurl.com/qvhtzcp. [Sitio consultado el 1 de febrero de 2020].

Secretaría de Educación Pública, Educación intercultural para todos. La interculturalidad en el Plan de Estudios 1997, disponible en https://tinyurl.com/qmwgpmf. [Sitio consultado el 1 de febrero de 2020].

Secretaría de Educación Pública, Aprendizajes clave para par la educación integral. Plan y programas de estudio para la educación básica, disponible en https://tinyurl.com/ttla82r. [Sitio consultado el 1 de febrero de 2020].

\section{Apéndice: cuestionario}

Sexo / edad:

Nivel de estudios / carrera / escuela

Lugar de nacimiento / de sus padres:

Nivel de estudios de sus padres:

Redes sociales que emplea:

1. ¿Cuántos idiomas hablas además de español? (si habla otro[s] aparte de español, realizar la pregunta 2; si no, pasar a la 7)

2. ¿Cuál es tu nivel en ese (esos) idiomas?

3. ¿Por qué aprendiste ese (esos) idioma(s)? (si es más de uno, continuar con la 4; si no, pasar a la 6)

4. ¿En qué orden los aprendiste?

5. ¿Por qué en ese orden?

6. ¿Dónde (o con quién) y cuándo (edad) aprendiste ese (esos) idioma(s)?

7. ¿Cuál consideras que es un idioma importante para tu carrera / escuela (en caso de los de bachillerato)?

8. ¿Qué idioma extranjero te gustaría / no te gustaría aprender?, ¿por qué?

9. ¿Sabes cuántas lenguas (en general) se hablan en México, aparte del español?, ¿cuáles? 
10. ¿Sabes cuántas lenguas indígenas se hablan en México?, ¿cuáles conoces o has oído de ellas?

11. ¿Hablas alguna lengua indígena?, ¿cuál?

12. ¿Sabes si en tu familia alguien habla / hablaba (padres o abuelos) alguna lengua indígena?

13. ¿Te interesaría aprender una lengua indígena?, ¿cuál?, ¿por qué? (en caso de que la respuesta sea negativa, también preguntar por qué)

14. ¿Consideras que algunas lenguas son más importantes que otras?, ¿por qué?

15. ¿Entre inglés y maya, cuál estudiarías?, ¿por qué?

16. ¿Crees que es importante que a los niños se les enseñe una lengua indígena en las escuelas, además de una extranjera?, ¿por qué?

17. ¿Crees que a los niños indígenas se les debería enseñar en la escuela en español o en su propia lengua?, ¿por qué?

18. En León hay unas calles (cerca del estadio de futbol) que se llaman "otomíes" y "chichimecas" (grupos indígenas asentados históricamente en la región), ¿sabes qué o quiénes eran o son? 


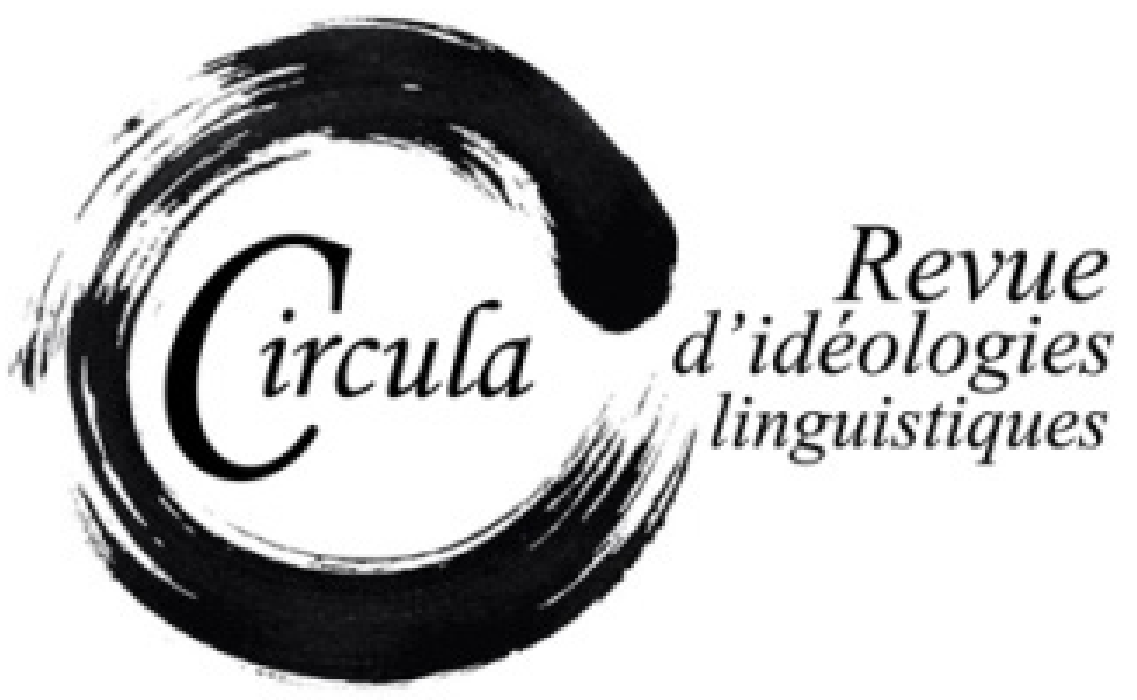

TITRE: IL COMMENTO LINGUISTICO COME TRADIZIONE DISCORSIVA NELLA STAMPA PERIODICA DI METÀ SETTECENTO

Auteur: RAPHAEL MERIDA, UnIVERSITÀ DEGLI STUdI DI MESSINA

Revue: CIRCULA, NUMÉRO 11

PAgES: $46-62$

ISSN: 2369-6761

URI: HTTP://HDL.HANDLE.NET/11143/17840

DOI: HTTPS://DOI.ORG/10.17118/11143/17840 


\section{Il commento linguistico come tradizione discorsiva nella stampa periodica di metà Settecento}

Raphael Merida, Università degli studi di Messina rmerida@unime.it

Riassunto: La pratica del commento linguistico all'interno della stampa periodica comincia a diffondersi prevalentemente nell'Ottocento. Gli articoli di cronaca, le recensioni bibliografiche o le semplici novità, però, offrono uno spunto di riflessione linguistica già all'interno di molti periodici della metà del Settecento. In particolare, polemiche o apologie rivolte al conservatorismo dell'Accademia della Crusca, l'innovazione del lessico specialistico tramite nuove traduzioni di opere straniere e gli influssi dei francesismi nel lessico italiano, permettono ai compilatori delle varie riviste letterarie e delle gazzette di discutere, talvolta ampiamente, dei problemi linguistici dell'epoca. La ricerca quindi si propone di individuare una prima forma di commento linguistico all'interno di alcuni periodici a stampa di metà Settecento.

Parole chiave: commento linguistico, Settecento, periodici, Crusca, lessico tecnico.

Abstract: The practice of linguistic commentary within the periodical press began to spread mainly in the 19th century. The news articles, bibliographical reviews or simple news, however, offer a starting point for linguistic reflection already in many periodicals of the mid-eighteenth century. In particular, controversies or apologies addressed to the conservatism of the Accademia della Crusca, the innovation of the specialized lexicon through new translations of foreign works and the influences of the French into the Italian lexicon, allow the compilers of the various literary magazines and journals to discuss, sometimes widely, of the linguistic problems of the time. The research therefore aims to identify a first form of linguistic commentary within some printed periodicals of the mid-eighteenth century.

Keywords: linguistic commentary, 18th century, press, Crusca, special lexicon. 


\section{Introduzione}

Molti importanti studi hanno messo in luce l'evoluzione del giornalismo dalla fine del Seicento ai giorni nostri e ne hanno esaminato i fenomeni lessicali, sintattici e morfologici, dimostrando quanto sia complessa la struttura di un periodico a stampa: infatti, «non si può parlare del linguaggio giornalistico come di una lingua speciale: il giornale è un coacervo di lingue speciali» (De Mauro, 1976: 510) che rappresentano lo specchio dei linguaggi presenti nella società (cf. Beccaria, 1973: 64). Oltre a configurarsi come modello esemplare per l'analisi linguistica, i giornali si rivelano una fonte preziosa per la ricostruzione del dibattito culturale cominciato nei primi anni del Settecento e costantemente portato avanti nei secoli. Basti citare solo alcuni titoli per rendersi conto dello spessore dei nomi circolanti nelle varie redazioni di giornali, riviste e gazzette. Si prendano, per esempio, la Gazzetta di Milano, sulla quale scrisse anche Parini (cf. Bonomi, 2010: online), oppure la Galleria di Minerva e il più famoso Giornale de' letterati d'Italia, all'interno dei quali si era formato un circolo di intellettuali del calibro di Scipione Maffei o Apostolo Zeno (cf. Di Brazzà, 2012). Ben più note, anche per via della forte personalità dei loro fondatori, le vicende del Caffè e della Frusta Letteraria. Il celebre articolo-manifesto dei fratelli Verri Rinunzia avanti notaio degli autori del presente foglio periodico al Vocabolario della Crusca, che fa parte di uno degli articoli di carattere linguistico del Caffè, rappresenta un punto apicale dell'«avversione settecentesca alla politica linguistica della Crusca» (Giovanardi, 1987: 401) e mostra apertamente l'ideologia linguistica dei due autori. Allo stesso modo l'intera impostazione della Frusta Letteraria nasconde, sotto le vesti di domande e risposte fittizie, il pensiero critico di Giuseppe Baretti². I pochi esempi appena citati sono un'importante testimonianza dell'evoluzione del periodico a stampa: tuttavia, la caratura ideologica che si manifesta attraverso le figure di spicco di intellettuali famosi fa sì che l'interesse alla lingua faccia parte del fermento culturale di quel periodo.

Facendo riferimento al concetto di «tradizione discorsiva» di Koch/Oesterreicher (1990: 190-198), ci siamo chiesti se la pratica del commento linguistico, inteso come genere giornalistico autonomo, abbia avuto origine nel giornalismo settecentesco. Gli spunti per questa riflessione teorica derivano dagli studi che negli ultimi anni si sono concentrati sulle cronache linguistiche all'interno dei periodici a stampa (e ultimamente anche nei quotidiani in rete). Infatti, come nota Schwarze (2015: 2) «sin dalla sua nascita come mezzo di comunicazione di massa nel primo Ottocento la stampa italiana non ha mai cessato di commentare i problemi legati alla questione della lingua».

1. I preziosi contributi di Bonomi (2002), Bonomi/Morgana (2003; 2016), Dardano (1973; 2002), Gatta (2014), Gualdo (2017), Scavuzzo (1988), Castronovo/Ricuperati/Capra (1976), oltre a fornire l'esame linguistico di alcuni quotidiani in varie epoche, offrono una panoramica generale dell'evoluzione del giornalismo dal Settecento ai giorni nostri.

2. L'importanza dei fratelli Verri e di Baretti nel panorama del giornalismo settecentesco è stato recentemente oggetto di due convegni: Giuseppe Baretti, i fratelli Verri, Cesare Beccaria, e i periodici del Settecento. Lingua e storia (Milano, 12-13 dicembre), organizzato presso l'Università degli Studi di Milano da Daniela Marcheschi, Silvia Morgana, Giuseppe Polimeni, Massimo Prada, Sabine Schwarze, Giuseppe Sergio; Giuseppe Baretti scrittore europeo (Torino, 5-6 dicembre 2019), organizzato dall'Accademia delle Scienze di Torino con il patrocinio dell'Università degli Studi di Torino, del Dipartimento di Studi Umanistici dell’Università di Torino e dell'Università Italo-Francese. 
Per familiarizzare con il concetto di «tradizione discorsiva» prendiamo in prestito le parole di Wilhelm (2005: 157):

Chiamiamo tradizione discorsiva l'insieme dei testi, orali o scritti, che vengono prodotti secondo una precisa norma discorsiva [...]. Se parliamo della tradizione discorsiva 'articolo di fondo' ci riferiamo, quindi, all'insieme dei testi prodotti nel tempo secondo questa specifica norma discorsiva, cioè a una serie di testi storicamente determinata. Questo ci fa capire che possiamo fondare una teoria dei tipi di testo solo se prendiamo in considerazione la dimensione storica. Le norme discorsive sono sottomesse a un continuo divenire storico, a un costante cambiamento, vale a dire un continuo riassettarsi e adattarsi ai cambiamenti sociali e culturali nel senso più ampio.

La periodizzazione che proponiamo di seguito si pone sulla scia tracciata da Folena (1986: 194) che, già quarant'anni fa, individuava quattro fasi corrispondenti ai quattro quarti del secolo diciottesimo: il primo periodo era stato denominato età dei «filosofi-critici ed eruditi o dei letterati», seguito dall'età dei «filosofi enciclopedici»; successivamente, si indicava il terzo quarto di secolo come età dei «filosofi-economisti», per poi concludere con l'ultimo quarto caratterizzato dai «filosofi-politici, dei patrioti e dei giacobini». Per semplificare lo spoglio dei periodici, dato che un secolo come il Settecento è caratterizzato da profondi cambiamenti politici e scientifici, abbiamo deciso di raggruppare le quattro fasi storiche di Folena in due metà: la prima, che va dal 1701 al 1750, è contrassegnata dal giornalismo erudito (maggioritario nella prima metà del secolo, cf. Merida 2017), la seconda, che sarà quella su cui ci concentreremo, va dal 1751 al 1796 e si diversifica per la quantità di riviste letterarie, gazzette, fogli e avvisi di stampo economico e politico. Occorre precisare però che i confini tra prima e seconda metà spesso tendono ad allargarsi o a restringersi come nel caso del Nuovo giornale enciclopedico, fondato a Venezia nel 1774 come Giornale enciclopedico per opera di Domenico Caminer e della figlia Elisabetta.

\section{Le note di lingua nei periodici di cronaca}

Senza allargare l'indagine ai periodici più famosi del Settecento, il contributo si propone di individuare una base culturale, ideologica e linguistica ampia e continuativa all'interno dei periodici meno noti. Chiariamo subito che con l'etichetta di periodico a stampa intendiamo quei testi che con una cadenza più o meno regolare vengono stampati e pubblicati nelle varie città d'Italia. Allo stesso modo tratteremo di giornali (quotidiani, settimanali, ecc.) e riviste letterarie, ma con una necessaria premessa che ci permetta di distinguere preliminarmente due fattori: contenuto e cadenza. Le riviste letterarie si occupano quasi esclusivamente di teorie letterarie e scientifiche, senza mai occuparsi di cronaca e politica; hanno, inoltre, una cadenza a lungo termine (mensile, trimestrale, annuale ecc.). I 
giornali, invece, prediligono, a vario titolo, le notizie politiche, economiche e, talvolta, scientifiche; a differenza delle riviste letterarie hanno una cadenza a breve termine (quotidiana, settimanale ecc.) ${ }^{3}$.

La nostra "dimensione storica" di riferimento si avvicina a quella del giornale ottocentesco in cui si assiste a un abbandono della forma elitaria in favore di un giornalismo rivolto a un più ampio pubblico (cf. Masini, 1977: 2-5; Serianni, 1989: 35-36). Tuttavia, l'apice del giornalismo politico si sviluppa in una forbice temporale assai stretta che va dal 1796 al 1799, un triennio denominato dagli storici Triennio repubblicano, nel quale si assiste alla nascita di varie repubbliche dopo le campagne napoleoniche in Italia. Prima di allora le ideologie politiche, che racchiudevano anche una forte ideologia linguistica da parte del giornalista ${ }^{4}$, avevano un loro spazio all'interno delle gazzette, ma senza avere ancora la fisionomia del giornale inteso in senso moderno. Citiamo, solo a titolo d'esempio, due giornali pubblicati con lo scopo di testimoniare le politiche locali: la Gazzetta Patria, già dal secondo numero rinominata Gazzetta toscana (1766-1811), e la Gazzetta urbana veneta (1787-1798), continuatrice del settimanale /l sognatore italiano fondato da Gaspare Gozzi nel 1768. L'azione divulgativa diventava cosi il principale motore dell'editore che avesse voluto stampare un foglio periodico, così come ci dice nell'introduzione del primo numero della Gazzetta Patria Anton Giuseppe Pagani:

E cosa certamente stravagante e vergognosa che nel paese medesimo, dove una volta gli abitatori erano sì diligenti nel raccogliere e trasmettere alla posterità i fatti più memorabili, e quelli ancora che meglio sarebbe stato tacere, sieno al presente cosi trascurati e indolenti che lascino scorrere un secolo per la Toscana cotanto avventuroso senza notarne i più luminosi avvenimenti; di tal maniera che tutta l'istoria patria si riduce in oggi a una semplice gazzetta, la quale non può in verun conto imporre sullo spirito degli uomini, ed acquistare quel credito che volentieri si accorda ad un istorico grave (Gazzetta Patria, 1766: I)

Di là dalla questione meramente ideologica, lo stampatore Pagani offre preziose notizie in merito alla composizione di una gazzetta, non meritevole di essere considerata dagli ambienti intellettuali un foglio contenente «cose frivole e puerili bagattelle» (Gazzetta Patria, 1766: 1) e adatta al grande pubblico per via della sua notevole sveltezza argomentativa data dalla conoscenza dettagliata degli argomenti e della terminologia specialistica:

3. Sono gli stessi giornalisti a darci preziose informazioni relative alla cadenza periodica di un giornale: si veda, per esempio, l'introduzione al Giornale de' letterati d'Italia (1710: 46) in cui si mette in discussione l'appartenenza al genere giornalistico della Galleria di Minerva, pubblicata dal 1696: «Vero è che non è affatto cessata la Galleria di Minerva, la quale cominciò a stamparsi in foglio in Venezia nel 1696. Ma non può questa tener luogo di giornale, così perché non si dà regolarmente di mese in mese, onde in 14 anni appena compiè il sesto tomo».

4. Sul rapporto tra ideologia politica e ideologia linguistica si rinvia alla seconda parte di questo contributo, che tratterà specificatamente dei periodici del periodo giacobino (1796-1799). 
Le Gazzette [...] dagl'ingegni però cari a Minerva son tenute per la specie di composizioni la più dura, e la più utile al pubblico, che sia comparsa in abbigliamento di serva ed accorda a' componitori delle medesime quella stima che meritano; mentre elleno esigono perizia dei linguaggi e di tutti i loro termini: facilità e franchezza di scrivere; una precisione di dettaglio per narrare le cose nettamente, senza superfluità di parole (Gazzetta Patria, 1766: 1).

Pagani continua il suo elenco di elementi utili per la composizione della gazzetta proponendo alcune considerazioni in merito alla conoscenza dello scrittore la cui bravura risiede nell' "esser abile a parlare di guerra; essere appieno informato di tutto quello che riguarda la geografia, l'istoria del tempo e quella delle famiglie più luminose» (ib.). Le parole di Pagani rivelano un fatto finora rimasto in ombra e utile per la costruzione del pensiero settecentesco in merito alla circolazione delle gazzette: in particolare, si nota che una parte di intellettuali considerava tali periodici a stampa semplici notiziari senza alcun pregio. È noto, e lo stesso Pagani lo scrive più volte, che al compilatore di un foglio periodico era necessaria una cultura ampia e la padronanza di un lessico dettagliato.

L'interesse ad allargare la platea di lettori proviene anche da un altro periodico, il Magazzino italiano, stampato a Livorno nel 1752 per i tipi di Antonio Santini. Sul modello dei magazines inglesi (Gremigni, 2008: 164), il Magazzino italiano si fece portavoce, pur per brevissimo tempo, delle tendenze culturali italiane ed europee. Anche in questo caso è di notevole importanza l'azione divulgativa dei redattori, che dichiarano di scrivere per il pubblico e non «per i dotti» (Magazzino italiano, 1752: 3). Un pubblico che non ha avuto la possibilità di approfondire gli studi nelle scienze e che, di norma, opera in altri settori, non appartenenti al sapere tecnico-scientifico. L'introduzione alla rivista è particolarmente vivace e mostra gli intenti che mossero gli autori alla fondazione e pubblicazione del Magazzino italiano:

Noi scriviamo per quelle persone che distratte da impieghi o da cure più utili alla società non posson consacrare che una piccola parte del tempo alla lettura. Scriviamo per quelli che non hanno potuto darsi alle scienze, che si lamentano di non possederle, e che ne sospirano qualche notizia. Per questi servirà mirabilmente la nostra opera, quale se non fosse altro darà loro la definizione di molte cose, che prima di leggerla potrebbero spaventarli (Magazzino italiano, 1752: 3).

Pur mantenendo una configurazione di «un centone di notizie ufficiali, feste, cerimonie, partenze e arrivi di personaggi illustri, di spettacoli teatrali» (Bonomi, 2010: online), le gazzette permettono di leggere notizie preziose relative ad alcune indicazioni pratiche da parte degli organi politici di varie città o delle accademie culturali. A differenza dei periodici politici giacobini, quelli pubblicati tra gli anni '50 e '90 del Settecento sono privi di giudizi ideologici dei redattori e offrono quasi esclusivamente la semplice notizia di cronaca. Un caso particolare è offerto dal seguente articolo: «Si ordina ai medici, riguardo ai medicamenti da somministrarsi agli ammalati, di scrivere le ricette intieramente distese in idioma italiano, col nome del fisico in carattere chiaro, e non colla cifra come si praticava in passato» (Notizie del mondo, 97: 16 dicembre 1786), in cui si informa il lettore di un'importante novità 
riguardante la decisione del governo degli Asburgo d'Austria in merito alla concessione all'Istituto Pio di Santa Corona di Milano di poter scrivere in italiano le ricette mediche: un elemento degno di nota che ci consente di mettere in evidenza la scelta editoriale del giornale.

Per cogliere gli interventi dei redattori delle Notizie del mondo occorre guardare le note di commento, puntualmente segnalate da un asterisco e inserite a piè di pagina. L'importanza del commento redazionale è evidente quando in una traduzione di un articolo politico si giustifica la voce arresto, dal francese arrêt 'decisione di un tribunale o di un organo legislativo; sentenza, decreto' (cf. GDLI: S.v. arresto) $)^{5}$ :

Il vocabolo Arresto, in significato di Decisione, di Sentenza, di Pronunzia, è toscanissimo, come quello ch'è riportato in tal significato non solo dall'Antonini, dall'Abate Alberti, dagli altri Dizionarj, ma eziandio dalla Crusca, la quale, sotto la voce di cui si tratta, dice precisamente Arresto in alcun luogo usasi per lo stesso che Sentenza, Decreto. Si usa poscia in questi foglj per esprimersi le Risoluzioni del Parlamento, a fine di distinguersi queste Risoluzioni d'una Corte Suprema non sottoposte ad alcun appello, così dalle Sentenze dalle Corti subalterne soggette all'appello a Tribunali Superiori ed in ultima istanza al Parlamento medesimo, come dai Decreti del Consiglio in cui risede l'autorità reale. (Notizie del mondo, 75: mercoledì 19 settembre 1787).

Il ricorso ad alcuni dei più importanti vocabolari settecenteschi per spiegare una parola che a quell'altezza cronologica era già entrata nell'uso da circa un secolo (la voce arresto entra già nella Ill edizione della Crusca) e la definizione di «vocabolo [...] toscanissimo» somigliano a una difesa preliminare alle possibili critiche che l'uso del francesismo avrebbe potuto provocare.

Anche le novità bibliografiche offrono ai compilatori un'occasione per ragionare sull'importanza di alcune traduzioni italiane di opere straniere. Il fatto che le traduzioni di opere tecnico-specialistiche richiamino l'attenzione degli studiosi è già evidente nel primo Settecento in riviste come il Giornale de' letterati d'Italia, che sottolineava l'importanza di accrescere il lessico scientifico italiano attraverso le traduzioni: un'eredità culturale ben accolta anche dalle Notizie del mondo. All'indomani della pubblicazione della Biblioteca di Gius nautico, stampata a Firenze nel 1785, un redattore delle Notizie del mondo descriveva cosi l'opera:

5. Il passo in questione è il seguente: «Questi sono i principi che il Parlamento, attualmente in Troyes, vuole applicarsi a sviluppare. II medesimo, in continuazione dell'Arresto del di 27 dello scorso agosto, ne fece un altro, nel 28, contro le Lettere di Sigillo». (Notizie del mondo, 75: mercoledì 19 settembre 1787). 
Era desiderata in Italia una copiosa raccolta di leggi e di moderni trattati delle più culte nazioni riguardanti il commercio e le questioni marittime. [...] All'opera finalmente darà termine un vocabolario, in cui saranno spiegati con la possibile esattezza tutti i termini di commercio e di nautica, non solo in lingua italiana, ma ancora in lingua francese, inglese, olandese e spagnuola. È manifesta l'utilità di un si fatto vocabolario; perocché per mezzo di esso potranno evitarsi le molte questioni che nascono dagli equivoci e sbagli enormi presi spesso dai traduttori intorno al vero significato de' termini rozzi ed antiquati, che formano un linguaggio particolare delle genti di mare nei consolati, contratti polizze ecc. (Notizie del mondo, 21: sabato 12 marzo 1785).

L'importanza di un trattato che contenesse al suo interno un vocabolario formato da un lessico tecnico è, per il redattore, la notizia più importante da offrire al pubblico.

\section{Gli interessi linguistici del giornalismo erudito}

A proposito dei giornali veneti del Settecento, Folena (1986: 200) confermava quanto fosse rapida «la circolazione e l'assimilazione di idee e di parole nuove». Tale affermazione può essere estesa, più genericamente, alla situazione dei giornali italiani. In particolar modo, le pagine delle riviste letterarie descrivono due fatti importanti: 1) una circolazione del sapere scientifico ampia e continuativa; e in questo panorama ricorrono quasi sempre gli stessi nomi: Galileo, Magalotti, Zendrini, Vallisneri, Redi; 2) la lingua in cui codificare tale sapere. Senza dover scavare a fondo, sfogliando le pagine del Giornale d'Italia (1764-1797) è possibile leggere alcuni articoli interessanti per la ricostruzione del pensiero linguistico e scientifico settecentesco. Specifichiamo subito che spesso le opinioni linguistiche dei giornalisti provengono dalle recensioni di libri. Così un redattore nel decimo numero del 1766 del Giornale d'Italia, in una recensione alla Meccanica sublime di Domenico Bartaloni, informava vivacemente i lettori intorno alla possibilità, da parte degli scrittori italiani, di scrivere di meccanica, geometria o algebra in italiano, notando come molti scienziati italiani non fossero in confidenza con i trattati in latino?.

Sempre nella prima metà del Settecento si cominciano a stampare diverse riviste esclusivamente rivolte alle cosiddette novelle letterarie. Le informazioni date dai giornalisti sono molto chiare e già nell'introduzione al Giornale de' letterati d'Italia (1710: 13) si annunciano metodi e finalità dei periodici eruditi, definiti opere «che regolatamente di tempo in tempo ragguaglio danno de' varj libri, ch'e-

6. Il Giornale d'Italia spettante alla scienza naturale e principalmente alle arti e al commercio fu un settimanale di otto pagine legato alle accademie agrarie venete.

7. Giornale d'Italia, n. X, 1766, p. 76: «ll dotto autore dice nella prefazione d'aver trattato della meccanica sublime in lingua italiana, perché la nostra lingua non manca d’ogni espressione per qualunque arte o scienza; e di più non si fa vedere, perché, conforme riflette il Viviani, addomesticar non debbasi per queste dottrine la nobilissima favella nostra, avvalorati maggiormente al suo esempio e da quello degli altri autori sommi [...]. Io aggiungerei che conosco de' meccanici, de' geometri e degli algebristi stimabili, tutti italiani, o dimoranti in Italia, i quali non sono addomesticati col latino; onde per loro sarebbe anche bene di tradurre i trattati matematici latini in lingua nostra volgare». 
scono di nuovo in luce». Le stesse finalità arrivano anche in alcune riviste fondate nella prima metà e protratte fino alla seconda metà del Settecento: le Novelle della repubblica delle lettere pubblicate da Angelo Calogerà, pubblicate fra il 1729 e il 1776, e le Novelle letterarie pubblicate in Firenze curate da Giovanni Lami dal 1740 al 1769, per poi continuare fino al 1791 sotto altri due diversi direttori. Com'è già stato notato (cf. Castori, 2010: 73-80; Merida 2017: 17-18), il periodico fondato da Lami si configura come un importante strumento ideologico per due motivi: da una parte segue l'impostazione dei giornali veneziani precedenti; dall'altra vanta una forte tradizione linguistica e culturale. L'elogio della fiorentinità riecheggia già nella prefazione al primo numero della rivista in cui, oltre a elencare i migliori ingegni che Firenze produsse fino a quell'epoca, si tessono le lodi delle accademie; di particolare interesse il commento all'Accademia della Crusca: «la celebratissima Accademia della Crusca, non mai bastevolmente lodata, e sempre temerariamente ed inutilmente assalita» (Novelle letterarie, 1740: VIII). Le novità bibliografiche del Lami, corredate da veri e propri giudizi critici, riportano costantemente notizie relative alle attività della Crusca e dei suoi accademici. Ampio spazio è dedicato alla pubblicazione del Compendio del Vocabolario degli Accademici della Crusca da parte Domenico Maria Manni nel 1739. La posizione ideologica di Lami nei confronti di quest'opera è abbastanza evidente se messa a confronto con la segnalazione che nello stesso anno, il 1740, compare nel Giornale de' letterati d'Italia. Nelle parole di Lami, a differenza di quelle del Giornale de'letterati, si intravede un'operazione di promozione data dal fatto che l'Accademia della Crusca ha sede a Firenze: ecco che, per le Novelle letterarie, la quarta impressione del Vocabolario è considerata «magnifica» e che l'opera del Manni è considerata «scrupolosa fatica»; nella frase di chiusura, infine, è racchiusa l'azione propagandistica delle Novelle letterarie8.

Qualche anno dopo la fine della direzione di Lami delle Novelle letterarie, uscivano le Efemeridi letterarie, una rivista erudita stampata a Roma dal 1772 al 1798. L'impostazione del periodico è simile a tutte le altre riviste, ma la densità e la qualità delle segnalazioni bibliografiche al suo interno rivelano ampi interessi linguistici. Ancora una volta il quadro è occupato dal recensore, che sfoggia il proprio punto di vista ogni qual volta l'occasione lo permetta. Esemplare, quanto alle commedie, il comportamento nei confronti delle opere scritte in italiano da Goldoni. Lo spunto per parlare di lingua è offerto dalla notizia della premiazione di due commedie teatrali da parte della Reale Accademica

8. Giornale de' letterati d'Italia (1740: 440): «È già uscito il Compendio del Vocabolario della Crusca formato sull'edizione quarta del medesimo, e stampato dal Sig. Domenico Maria Manni in Tomi V. Nella prefazione assicura l'Autore di questo Compendio di non aver omesso dizione alcuna di quelle che si portano nell'ultima edizione del Vocabolari»; Novelle letterarie pubblicate in Firenze (1740: 148-150): «Essendo restata felicemente terminata nell'anno scorso la magnifica quarta edizione del gran Vocabolario degli Accademici della Crusca; e considerando il Sig. Domenico Maria Manni, che quest'opera da esso con somma esattezza ed eleganza stampata essendo riuscita molto voluminosa, e dispendiosa, non poteva esser utile sennon ad alcuni generi di persone [...]. Ė stato altresì animato a tale impresa dall'osservare che utilità grande era avvenuta agli Studiosi dal Compendio dell'Edizione terza del medesimo Vocabolario, pubblicato da un illustre Letterato Veneto, e con sommo applauso ricevuto, di modo tale che fu duopo farne, alle universali richieste, molte ristampe. Abbenché siasi affaticato il Sig. Manni di far questo suo Compendio più breve che fosse possibile; nientedimeno egli è stato necessario di allargarsi in cinque tomi in quarto, perché non ha voluto omettere dizione nessuna [...]. Quantunque la grand'opera del Vocabolario abbia sopra questa del Compendio i suoi particolari pregi a lei sola riservati; tuttavia la perizia del Sig. Manni in questo genere di sapere ben nota al Mondo Letterario, e la gran diligenza, e scrupolosa fatica impiegata nel far questo Compendio, ci fanno sperare, che egli sarà ricevuto con applauso universale». 
Deputazione di Parma, il Prigioniero di Francesco Albergati Copacelli (vincitore del primo premio nel concorso del 1773) e la Marcia dell'abate Francesco Marucchi (vincitore del secondo premio nello stesso concorso). Il giornalista, in due recensioni distinte, tesse le lodi del primo autore e lamenta l'assegnazione del secondo posto attribuito a Marucchi, sostenendo che l'opera in questione «sia stata onorata della seconda corona unicamente per animare la gioventù e per la scarsezza di concorrenti» (Efemeridi letterarie, 1773: 285). La critica, che si rivela abbastanza aspra nei confronti del modo con cui si tratta l'intreccio, spende una parola positiva nei confronti dello stile «migliore di quello che usa il Goldoni» (Efemeridi letterarie, 1773: 285). Contrariamente alle critiche di ascendenza gozziana, l'effemeridista elogia la maestria con cui Goldoni colora di umanità le scene, ma non ne apprezza (quando è presente) l'uso dell'italiano al posto del veneziano:

A proposito del Goldoni, oh se quest'uomo studiata avesse davvero la lingua italiana e un poco più nobilitate le idee! [...] Aggiungeremo una osservazione sopra l'illustre Sig. Goldoni, poeta che noi pregiamo assaissimo: quando egli scrive nel suo natio dialetto veneziano, è purissimo, originale, e si legge dagl'intendenti con infinito piacere, ma guai allora ch'egli pretende di scrivere in italiano! La nostra riflessione è tanto vera che il Cerloni stesso, autore, se altri mai, di stravaganti commedie [...], ove scrive ancor'esso nel suo dialetto napoletano, diletta infinitamente, dipinge gli originali al naturale. (Efemeridi letterarie, 1773: 285).

Per accrescere il valore dialettale dell'opera goldoniana, il recensore fa un richiamo anche all'autore napoletano Francesco Cerlone ${ }^{9}$.

Com'è ben noto, il rinnovamento linguistico e culturale che stava avvenendo in Italia durante il Settecento (cf. Folena, 1983: 7-10; Matarrese, 1993, 41; Serianni, 1998: 187) portò con sé un ventaglio di innovazioni lessicali e sintattiche non estranee agli occhi dei giornalisti. Nel numero XXXIX delle Efemeridi del 1774 una recensione al Saggio filosofico sul matrimonio di Melchiorre Delfico rivela la posizione del periodico nei confronti di alcuni usi lessicali (cf. Dardi 1992: 296):

In fine non meneremo mai buono all'Autore che faccia il torto alla nostra Italia di crederla così scarsa e meschina d'espressioni, che abbia a prenderne imprestito non poche dalla Francia, come regrettare, disabusare etc. Ciò non ostante siam sicuri che la sua opera incontrerà gradimento. Noi certamente ci dichiariamo non essere schiavi delle severe leggi della crusca, la quale non ammette che le parole bagnate nell'Arno, ed autorizzate da fra Guitone o dal Passavanti, ma non approviamo che se ne adoprino delle nuove quando abbiamo le loro corrispondenti nella nostra lingua, e talvolta più eleganti di quelle, che affettatamente andiamo ad accattare dai nostri avversari. (Efemeridi letterarie, 1774:311-312).

9. Il paragone tra Cerlone e Goldoni non è usuale. Cerlone, infatti, non ebbe un buon riconoscimento per le traduzioni napoletane dell'autore veneziano che anzi descrisse così la sua opera versificatoria: «Se sei ricamator come poeta / poveri drappi e sventurata seta». Cf. Giovanardi (1979). 
Siamo su un piano ben diverso rispetto alle vivaci parole che si possono trovare nei periodici a stampa posteriori di qualche anno. In questo caso, anche se non si assiste a una demonizzazione nei confronti dei francesismi usati da Delfico, viene dichiarata una preferenza verso le corrispettive parole italiane definite «più eleganti»» ${ }^{10}$. Un giudizio, quello dell'eleganza e della bellezza della parola, che vive durante tutto il Settecento e continua fino ai giorni nostri, ma con una ovvia differenza: chi scrive la recensione non disapprova tutti i prestiti, ma soltanto quelli non necessari alla lingua italiana. Si aggiunga, inoltre, che l'apertura linguistica di un periodico a stampa settecentesco contrario alle imposizioni dell'Accademia della Crusca si inserisce nel solco della «lingua comune» individuata da Folena (1983: 7-10).

Ben altra messe si potrebbe raccogliere guardando a due recensioni su uno stesso tema pubblicate su due diverse riviste: le Novelle letterarie e le Efemeridi. Nelle Novelle letterarie del 27 ottobre 1780 vengono riportati alcuni versi dell'«anonimo traduttore» seguiti da un breve commento linguistico (corsivo nel testo):

Il verso ha dell'armonia e lo stile avrebbe dell'eleganza se non fosse asperso di qualche negligenza grammaticale, come possin per possano (p. 8), testimonio invece di testimone (p. 35), voi vorresti in cambio di voi vorreste (p. 52). Non approveranno neppure i lettori di gusto purgato che si adopri il mai in senso negativo senza il non (p. 11). Madama invece dell'italiano vocabolo Donna, o Signora (p. 12) ed altre simili disattenzioni che non tolgon però il pregio sostanziale della traduzione. (Novelle letterarie, 1780: 675).

Gli esempi indicati dal recensore vengono puntualmente ripresi e giustificati dall'articolo apparso qualche mese dopo nelle Efemeridi letterarie (precisamente nel numero XIII del 31 marzo 1781): una prova di quanto ampia fosse la diffusione dei giornali nel territorio extraregionale. II tono polemico, rivolto all'articolo delle Novelle letterarie, si rivela nella seconda metà della recensione, dopo aver esteso il nome del traduttore, cioè il canonico Orazio Maccari. In generale il redattore si mostra sensibile all'eterogeneità linguistica che emerge dalla traduzione dei versi. Non c'è nessuna sorpresa nell'uso del mai usato negativamente senza il non; né fa specie l'occorrenza di testimonio al posto di testimone. Sono notevoli, semmai, le rapide incursioni storico-linguistiche del giornalista, il cui impegno è dimostrare l'uso letterario di alcune forme considerate scorrette: si passa dalle citazioni di Machiavelli a quelle di Dante, Boccaccio o Ariosto anche per giustificare il sostantivo madama in luogo di donna. L'apertura nei confronti di madama e di altri fenomeni dà prova di una coscienza

10. Un appunto sulla voce disabusare, prestito dal francese désabuser. La prima attestazione, secondo il GDLI (s.v.), è datata 1669 nella Vita di Sisto V di Gregorio Leti: «Credeva che non vi fosse differenza tra l'uno e l'altro de' Cardinali, havendo già inteso ch'erano insieme fratelli e per ciò s'era imaginato che tra di loro si dividevano la rendita della Chiesa, e volse per disabusarsi esser meglio informato» (Leti, 1669: 292). A distanza di un secolo, secondo gli autori delle Efemeridi, il termine disabusare rientra ancora tra le parole da non usare e viene messo sullo stesso piano di regrettare, voce nuova che fa la sua prima apparizione in un testo di Lione Pascoli, databile al 1741 (cf. GDLI, s.v.). Sul verbo disabusare si leggano le parole di Dardi (1982: 111-112): «Calco infrequente nei secoli XVII e XVIII [...], tuttavia deve aver avuto un qualche corso, se lo troviamo satireggiato dal Maffei [...] e, più di un secolo dopo, biasimato dai puristi». 
linguistica maturata grazie a una conoscenza diretta delle fonti letterarie e veicolata anche dall'uso del Vocabolario della Crusca:

Fracassi, precipizj perché nell'Irene si adopera la parola Madama. Ma perché non fanno fracasso col loro dizionario della crusca, il quale dice che cosi si chiamano le donne di grand'affare, e che cosi l'hanno usata il Boccaccio, l'Ariosto ed altri infiniti? La voce certamente è d'origine francese, ma è divenuta anche essa nostra nazionale, com'è divenuta italiana la voce Monsignore da che tornò la corte romana da Avignone. Guai a noi poveri Efemeridisti romani, se i Signori Novellisti fiorentini ci pesassero con questa loro delicata bilancia, perché malgrado i decreti d'Apollo, i nostri stampatori si direbbe che vogliono accostumare assolutamente gli orecchi di S.M. a peggiori eleganze, nelle quali non è certamente capace di cadere il Sig. canonico Maccari. (Efemeridi letterarie, 1781: 103).

All'Accademia della Crusca rimandano anche alcune pagine del Nuovo giornale de' letterati d'Italia (1773-1790) diretto da Girolamo Tiraboschi ${ }^{11}$. Di particolare interesse la decisione editoriale di pubblicare in cinque puntate, dal 1787 al 1789, la prima edizione delle Lettere di Diodoro Delfico a Lesbia Cidonia sopra gli epigrammi del gesuita mantovano Saverio Bettinelli (cf. Dillon Wanke, 1998: 125-147). La pubblicazione di un'opera letteraria all'interno di una rivista, pur essendo una pratica comune, specie durante un secolo come il Settecento caratterizzato dalla forte presenza di riviste letterarie, denota un intento non solo divulgativo ma anche ideologico (cf. Gallo 2017: 499). Le Lettere di Bettinelli, infatti, non sono prive di riferimenti al contesto culturale dell'epoca: per esempio, la Lettera X, pubblicata nel tomo XXXVIII nel 1787, si intrattiene sullo «spinaio grammaticale della differenza tra i linguaggi» (Nuovo giornale de' letterati d'Italia, 1787: 19). Nel condurre l'argomento, Bettinelli fa riferimento anche all'altalenante fortuna dell'Accademia della Crusca, affermando che in quel periodo «sembra nascere un'anarchia su le rovine dell'Accademia della Crusca e sul fondamento della filosofia dominante, la quale sdegna l'antiche leggi in ogni cosa anche più grave». La lettera continua con il confronto fra italiano e francese: seguendo il dibattito linguistico contemporaneo, Bettinelli fa cenno all'ordo verborum e ai possibili problemi che scaturiscono dall'inversione. Insomma, è importante non tanto l'intero contenuto del testo, quanto la sua presenza all'interno di un periodico a stampa che esibisce «tutta l'attenzione e tutta l'acutezza del Tiraboschi al riguardo delle tendenze più avanzate della letteratura contemporanea» (Mari, 2013: 66).

Entro il recinto della teoria linguistica può rientrare l'atteggiamento di Tiraboschi quando indossa i panni di apologeta della lingua italiana nell'articolo relativo alla traduzione dell'/liade di Cesarotti. È questo uno dei casi in cui si assiste a un dibattito teorico traduttologico in cui l'ideologia linguistica del giornale è chiara. La risposta di Tiraboschi all'intervento dello scrittore spagnolo Esteban Arteaga

11. Sulla preparazione alla pubblicazione delle Lettere di Diodoro Delfico a Lesbia Cidonia si veda il carteggio TiraboschiBettinelli riportato da Mari (1988: 228-279). Inoltre, Dillon Wanke (1998: 133) riporta un'informazione importante sulla ricostruzione dell'opera di Bettinelli: «La lettera del 18 novembre 1878 [...] ci lascia credere che Bettinelli non fosse pienamente soddisfatto dell'edizione tiraboschiana». Più in generale, sulle lettere di Bettinelli cf. Forner (2019) e Cappelletti (2019). 
è caratterizzata da toni pacati e da una lunga ed esauriente analisi rivolta alla difesa della lingua italiana:

Non è qui nostra intenzione di fare l'Apologia della nostra lingua, e di difenderla dalle taccie, che l’Ab. Arteaga le appone, né di rammentare alcune traduzioni che abbiamo degli Autori greci e latini, le quali a noi sembran molto pregevoli. Ma se la difficoltà anzi l'impossibilità di tradurli adeguatamente mostra la povertà della lingua, ci dica egli di grazia, qual sia la lingua d’Europa che possa dirsi abbondante e copiosa. [...] La ragione che rende sì rare e sì difficili le buone versioni, deesi ripetere, secondo la nostra opinione, dalla somma difficoltà di ben conoscere il genio e l'indole delle due lingue da cui e in cui si traduce, e dal saper adattare le espressioni dell'una a quelle dell'altra, in modo che il sentimento, l'affetto, l'immagine, l'armonia dell'originale nulla venga a soffrirne. (Nuovo giornale de' letterati d'Italia, 1787: 93).

Per spiegare le critiche di Arteaga alla lingua italiana è necessario far presente che la traduzione di Cesarotti si inserisce nel secolare dibattito della traduzione introdotta già a inizio secolo da Maffei e portata avanti da personalità come Torelli e Pompei. D'altro canto, la libera interpretazione dell'/liade rompe con la tradizione di traduzioni fedeli all'originale (cf. Mari, 1990: 1-75); lo stesso Tiraboschi, mediante il concetto del "genio e l'indole delle due lingue", sostiene la scelta di Cesarotti, che l'anno precedente, nel «Ragionamento preliminare storico-critico» all'/liade, aveva affrontato la questione della traduzione dei classici (cf. Battaglia, 1971:431). La polemica, tutta svolta nell'arco di pochi anni, vedrà anche una successiva testimonianza di Cesarotti nella traduzione dell'/liade pubblicata nel 1795, nella quale si fa riferimento alle critiche mosse durante gli anni precedenti dagli «Omerolatri e [...] Fidelisti» (Cesarotti, 1795: IX) (cf. Schwarze, 2020). La recensione dell'lliade, inoltre, offre a Tiraboschi l'opportunità di inquadrare le innovazioni stilistiche di Cesarotti all'interno del canone proposto dalle varie edizioni del Vocabolario della Crusca, rispondendo, passo dopo passo, alla polemica mossa da Arteaga ${ }^{12}$, che definiva «adeguata» la traduzione cesarottiana di Ossian per via della sua rottura con i «ceppi dell'autorità»:

Qual è questa autorità, i cui ceppi ha infranti l'Ab. Cesarotti? Sembra ch'ei voglia intendere qui dell'Accademia della Crusca, che da alcuni, e da lui stesso ci si rappresenta come dichiarata nimica di ogni novità nella lingua italiana. Ma in ciò ancora ei s'inganna di molto. E basti il riflettere che in ogni nuova edizione del Vocabolario si sono aggiunte parole ed espressioni che alle precedenti mancavano, e che da autori recenti erano state introdotte. Né è questo privilegio accordato a' soli toscani, ma l'Accademia ne è stata cortese anche agli stranieri. Così ella ammise già tra scrittori che facean testo di lingua, l'Ariosto, il Bembo, il Tasso, il Caro, il Guarini, il Castiglione; così più recentemente adottò il P. Segneri, e le nuove voci da essi introdotte, ricevette non altrimenti che sue. Se dunque l'Ab. Cesarotti ha creato nuove attitudini nello stile, ha usato di un diritto, che la ragione e l'autorità gli accordavano. E questo

12. Pochi anni prima, nel 1784, Arteaga lamentava la crisi della prosa, dovuta alla mancanza di un modello unitario per la letteratura (cf. Serianni, 2012: 108). 
anzi torna a nuova gloria della lingua italiana, e ne fa conoscere l'abbondanza, perciocché egli usando pure di questa lingua e non creandone una nuova, e servendosi comunemente di parole e di espressioni in essa già approvate, un nuovo stile ha saputo in essa introdurre. (Nuovo giornale de' letterati d'Italia, 1787: 94-95).

L'articolo appena citato si mostra, da un lato, particolarmente precoce nel presentare alcune tendenze linguistico-letterarie dell'epoca (nella fattispecie, la difesa di un nuovo modo di tradurre i classici greci e latini), come per esempio la traduzione dall'inglese dei Canti di Ossian, tradotti da Cesarotti con un nuovo metodo, in grado di «far parlare i personaggi dell'Ossian come avrebber parlato se conosciuta avessero la nostra lingua» (Nuovo giornale de' letterati d'Italia, 1787: 96), oltreché l'influenza che da lì a poco avrebbe avuto anche sulle traduzioni dalle lingue classiche ${ }^{13}$; dall'altro dimostra, ancora una volta, l'importanza dell'Accademia della Crusca, ancora tacciata di essere «nimica di ogni novità nella lingua italiana». Resta notevole che a movimentare (e ad inserirsi) nel dibattito linguistico e culturale dell'epoca siano periodici a stampa, continuamente esposti alle novità del Settecento e iniziatori di un processo divulgativo che fungerà da base per la stampa ottocentesca.

\section{Prime conclusioni}

Gli articoli qui presentati sono la testimonianza dell'attenzione dei periodici a stampa al naturale processo evolutivo della lingua e ciò che più colpisce è la tendenza a inserire le discussioni linguistiche anche al di fuori degli articoli di critica letteraria. Come si è visto, si tratta di commenti linguistici anche minimi che rivelano tuttavia l'eccezionale capacità divulgatrice della stampa, rivolta anche a chi non poteva entrare a far parte del dibattito intellettuale dell'epoca. D'altronde quasi tutte le riviste letterarie e i giornali sono chiari su questo punto: riportare notizie letterarie e tradurre dai giornali esteri per offrire a chiunque la possibilità di entrare in contatto con la realtà contemporanea. In linea con gli articoli presenti nella stampa di primo Settecento (cf. Merida 2017), quelli qui analizzati aggiungono un ulteriore tassello necessario alla ricostruzione di un periodo storico-culturale in cui la questione della lingua era l'argomento principale per tutta la stampa europea.

Nei periodici presi in esame si intravedono già le prime caratteristiche dei giornali ottocenteschi, che mischiano politica e letteratura anche attraverso il commento linguistico (si veda per esempio il giornale diretto da Elisabetta Caminer); tuttavia, la loro configurazione condivide ancora i caratteri del giornalismo erudito del Settecento. Come si dimostrerà in una seconda parte di questa ricerca, interamente dedicata alla stampa giacobina, bisognerà attendere l'arrivo di Napoleone in Italia, e la conseguente diffusione dei giornali, per vedere quanto l'ideologia politica e l'ideologia linguistica siano al centro del dibattito giornalistico.

13. Sulla traduzione di Cesarotti dei Canti di Ossian si vedano almeno i recenti lavori di Bianco (2016: 10-28, 2018: 261292) e Roggia (2013: 109-220). 


\section{Bibliografia}

Battaglia, Salvatore (1971), «La critica classicista di Vincenzo Gravina», Filologia e Letteratura, n 17 , p. 427-449.

Beccaria, Gian Luigi (1973), «ll linguaggio giornalistico», in Gian Luigi Beccaria (ed.), I linguaggi settoriali in Italia, Milano, Bompiani, p. 61-89.

Bianco, Francesca (2016), «Traduzioni a confronto: "I canti di Ossian” di Le Tourneur e Cesarotti», Testo, n 71 , p. 10-28

Bianco, Francesca (2018), «Le poesie di Ossian. Osservazioni critiche di Cesarotti a Le Tourneur», Critica letteraria, vol. 179, n² 2, p. 261-292.

Bonomi, Ilaria (2002), L'italiano giornalistico. Dall'inizio del Novecento ai quotidiani online, Firenze, Cesati.

Bonomi, Ilaria (2010), Lingua dei giornali, in Enciclopedia dell'italiano, disponibile su http://www. treccani.it/enciclopedia/lingua-dei-giornali_(Enciclopedia-dell'Italiano)/. [Sito consultato il 15 giugno 2020]

Bonomi, Ilaria, Stefania De Stefanis Ciccone e Andrea Masini (ed.) (1990), /l lessico della stampa periodica milanese, Firenze, La Nuova Italia.

Bonomi, Ilaria e Silvia Morgana (2003), La lingua italiana e i mass media, Roma, Carocci.

Bonomi, Ilaria e Silvia Morgana (2016), La lingua italiana e i mass media, nuova edizione, Roma, Carocci.

Cappelletti, Cristina (2019), «Saverio Bettinelli tra libri di lettere e “romanzi”», Testo, n 77, p. 119-134.

Castori, Loredana (2010), «Le novelle letterarie dei giornali del Settecento», Misure critiche. Nuova serie, a. $9, n^{\circ} 1$, p. 64-85.

Castronovo, Valerio, Massimo Ricuperati e Carlo Capra (ed.) (1976), La stampa italiana dal Cinquecento all’Ottocento, Roma-Bari, Laterza.

Cesarotti, Melchiorre (1786), «Ragionamento preliminare storico-critico», in L'lliade d'Omero recata poeticamente in verso sciolto italiano insieme col Volgarizzamento letterale del testo in prosa, vol. 1, Padova, Brandolese, p. 1-235.

Cesarotti, Melchiorre (1795), «Avvertimento preliminare», in L'lliade o la morte di Ettore. Poema omerico ridotto in verso italiano, Venezia, Tipografia Pepoliana presso Antonio Curti, p. V-XI.

Dardano, Maurizio (1973), Il linguaggio dei giornali italiani, Bari-Roma, Laterza.

Dardano Maurizio (2002), «La lingua dei media», in Valerio Castronovo e Nicola Tranfaglia (ed.), La stampa italiana nell'età delle TV. Dagli anni Settanta a oggi, Roma-Bari, Laterza, p. 243-285. 
Dardi, Andrea (1982), "L'influsso del francese sull'italiano tra il 1650 e il 1715 (IX). Calchi formali», Lingua nostra, vol. XLIII, nº 4, p. 107-116.

Dardi, Andrea (1992), Dalla provincia all'Europa: l'influsso del francese sull'italiano tra il 1650 e il 1715 , Firenze, Le Lettere.

De Mauro, Tullio (1976), «Giornalismo e storia linguistica dell'Italia unita», in Valerio Castronovo e Nicola Tranfaglia (ed.), La stampa italiana del neocapitalismo, Roma-Bari, Laterza, p. 455-505.

De Stefanis Ciccone, Stefania (1971), La questione della lingua nei periodici letterari del primo Ottocento, Firenze, Olschki.

Di Brazzà, Fabiana (2012), "Apostolo Zeno dalla "Galleria di Minerva" al "Giornale de' Letterati"» in Enza del Tedesco (ed.), Il "Giornale de' letterati d'Italia» trecento anni dopo. Scienza, storia, arte, identità (1710-2010), Atti del convegno, Padova, Venezia, Verona 17-19 novembre 2010, PisaRoma, Fabrizio Serra, p. 155-164.

Dillon Wanke, Matilde (1998), «"Bagatellando”. Le lettere di Diodoro Delfico a Lesbia Cidonia sopra gli epigrammi», in Ilaria Crotti e Ricciarda Ricorda (ed.), Saverio Bettinelli. Un gesuita alla scuola del mondo, Atti del Convegno (Venezia, 5-6 febbraio 1997), Roma, Bulzoni, p. 125-147.

Folena, Gianfranco (1983), L'italiano in Europa. Esperienze linguistiche del Settecento, Torino, Einaudi.

Folena, Gianfranco (1986), «"Alla vigilia della rivoluzione francese”. L'italiano due secoli fa tra riforme e rivoluzioni», Lettere italiane, vol. 38, n², p. 193-216.

Forner, Fabio (2019), «Bettinelli scrittore di lettere: precettistica, prassi e letteratura», Testo, n 77, p. 105-117.

Gallo, Valentina (2017), «La critica letteraria in forma epistolare», in Fabio Forner, Valentina Gallo, Sabine Schwarze e Corrado Viola (ed.), Le carte false. Epistolarità fittizia nel Settecento italiano, Roma, Edizioni di Storia e Letteratura, p. 491-500.

Gatta, Francesca (2014), «Giornalismo», in Giuseppe Antonelli, Matteo Motolese e Lorenzo Tomasin (ed.), Storia dell'italiano scritto, vol. 3, Roma, Carocci, p. 293-347.

Giovanardi, Stefano (1979), «Cerlone Francesco», in Dizionario Biografico degli Italiani, Roma, Istituto dell'Enciclopedia Italiana, vol. XXIII, p. 765-768.

Gremigni, Elena (2008), «La stampa periodica a Livorno nel secolo dei Lumi», in Silvia Capecchi (ed.), Giornali del Settecento fra Granducato e legazioni, Roma, Edizioni di Storia e Letteratura, p. 143176.

Gualdo, Riccardo (2017), L'italiano dei giornali, Roma, Carocci (I ed. 2007).

Koch, Peter e Wulf Oesttereicher (1997), «Zur Fundierung von Diskurstraditionen», in Barbara Frank, Thomas Haye e Doris Tophinke (ed.), Gattungen mittelalterlicher Schriftlichkeit, Tübingen, 1997, p. 19-41. 
Mari, Michele (1988), «Tiraboschi e Bettinelli: un'amicizia erudita», Giornale Storico della Letteratura Italiana, vol. CLXV, n530, p. 228-279.

Mari, Michele (1990), «Le tre lliadi di Melchiorre Cesarotti», Giornale storico della letteratura italiana, vol. CLXVII, n539, p. 1-75.

Mari, Michele (2013), La critica letteraria nel Settecento, Milano, Ledizioni.

Masini, Andrea (1977), La lingua di alcuni giornali milanesi dal 1859 al 1865, Firenze, La Nuova Italia.

Matarrese, Tina (1993), /l Settecento, Bologna, il Mulino.

Merida, Raphael (2017), «Questioni intorno alla lingua nelle riviste letterarie del primo Settecento», Circula, n 5, p. 7-24.

Roggia, Carlo Enrico (2013), La lingua della poesia nell'età dell'illuminismo, Roma, Carocci.

Scavuzzo, Carmelo (1988), Studi sulla lingua dei quotidiani messinesi di fine Ottocento, Firenze, Olschki.

Schwarze, Sabine (2020), «“Il traduttore a chi legge”. La fenomenologia della prefazione alle traduzioni italiane del Settecento», inTRAlinea, numero speciale La traduzione e i suoi paratesti, disponibile su http://www.intralinea.org/specials/article/il_traduttore_a_chi_legge. [Sito consultato il 15 giugno 2020].

Serianni, Luca (1989), Storia della lingua italiana. Il primo Ottocento: dall'età giacobina all'Unità, Bologna, il Mulino.

Serianni, Luca (1998), «La lingua italiana dal cosmopolitismo alla coscienza nazionale», in Enrico Malato (ed.), Storia della letteratura italiana, vol. VI, Roma, Salerno, p. 187-237.

Serianni, Luca (2012), Italiano in prosa, Roma, Carocci.

Sironi, Francesco (2018), «La 'Batracomiomachia' di Alessandro Garioni tra greco, italiano e milanese», Italiano LinguaDue, vol. 10, n² 2, p. 310-318.

Wilhelm, Raymund (2005), «Diskurstraditionen», La lingua italiana, vol. I, p. 157-161. 


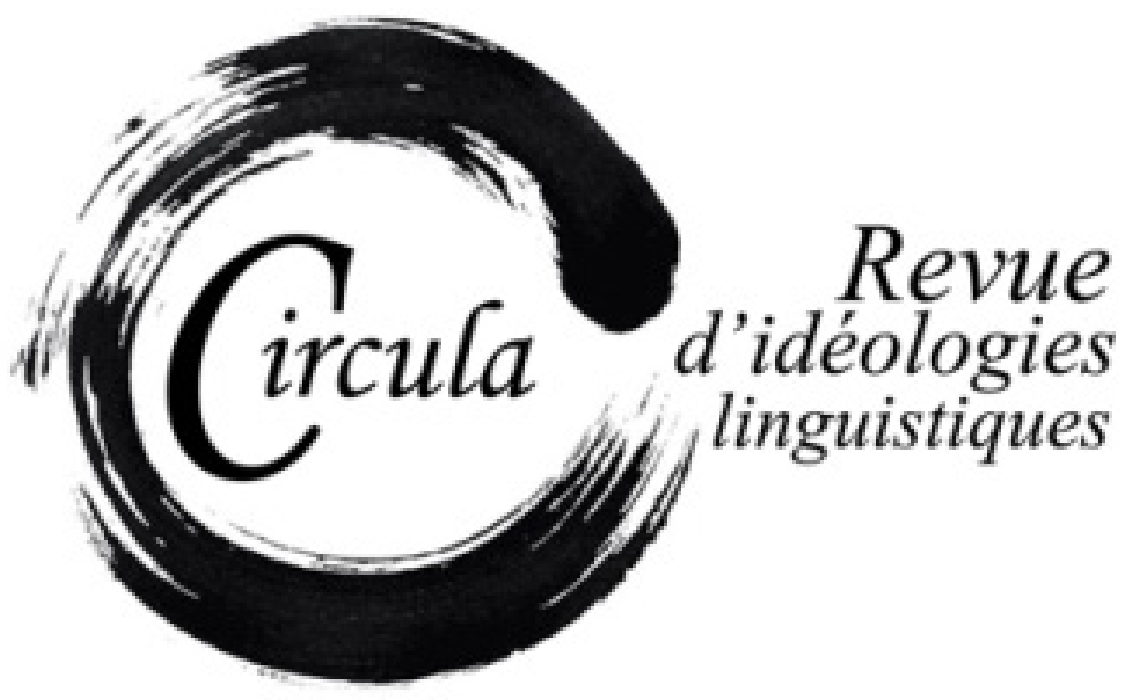

TITRE: SUR QUELQUES PRINCIPES D'ARGUMENTATION NÉOLIBÉRALE DANS L'ENSEIGNEMENT DU FRANÇAIS EN ACADIE

Auteur: Samuel Vernet, Aix-Marseille Université

Revue: CiRcula, NumÉRO 11

PAgES: $63-84$

ISSN: 2369-6761

URI: HTTP://HDL.HANDLE.NET/11143/17841

DOI: HTTPS://DOI.ORG/10.17118/11143/17841 


\section{Sur quelques principes d'argumentation néolibérale dans l'enseignement du français en Acadie}

Samuel Vernet, Aix-Marseille Université samuel.vernet1@gmail.com

Résumé : Cet article propose quelques réflexions sur l'influence d'un cadre idéologique néolibéral sur l'enseignement du français en Acadie du Nouveau-Brunswick, région francophone minoritaire du Canada. Il s'appuie sur une enquête ethnographique menée en 2013-2014 au sein des cours de français à l'Université de Moncton. Après avoir présenté le terrain, la méthodologie d'analyse critique et problématisé la situation des cours de français universitaires, le texte s'arrête sur la notion de néolibéralisme et analyse le corpus en fonction de deux de ses figures types majeures : l'individu-entrepreneur et l'individu-manager.

Mots-clés : enseignement du français; Acadie ; néolibéralisme ; individu-entrepreneur ; individu-manager

Abstract: This paper offers some reflections on the influence of a neoliberal ideological framework on the teaching of French in Acadia, New Brunswick, the French-speaking minority region of Canada. The article is based on an ethnographic inquiry conducted in 2013-2014 within French courses at the Université de Moncton. After introducing the field, the methodology of the critical analysis and problematizing the situation of university French courses, the text stops on the notion of neoliberalism and analyzes the corpus according to two of its major figures: that of the Entrepreneur and the Manager.

Keywords: French teaching; Acadia, neoliberalism; Entrepreneur; Manager 


\section{Introduction}

Le présent texte propose quelques réflexions sur un ancrage idéologique de l'enseignement du français en Acadie du Nouveau-Brunswick, au Canada. Il s'intéresse plus particulièrement à l'Université de Moncton, un des principaux établissements d'enseignement supérieur en français dans les régions francophones minoritaires du Canada. En 2013 et 2014, j'ai investi les lieux pour observer, dans une approche sociolinguistique ethnographique et critique, le déroulement des cours de français obligatoires (un de communication écrite, l'autre de communication orale) donnés à l'ensemble du corps étudiant en baccalauréat ${ }^{1}$. Cette recherche examinait notamment le type de français enseigné, comment il l'était et pourquoi ; elle interrogeait les tensions éventuelles entre standard et vernaculaire, les discours et les idéologies linguistiques circulant à la fois dans l'équipe enseignante, dans l'administration et chez les étudiants. Le corpus de cette recherche était constitué de l'ensemble des échanges en classe, des documents pédagogiques, d'entretiens avec l'équipe pédagogique de français et de documents administratifs.

Durant le travail de terrain, j'avais été interpelé par l'usage d'un certain champ sémantique concentré en particulier dans les documents pédagogiques et certains échanges du cours d'oral : évaluer ses forces et ses faiblesses, améliorer ses compétences, relever des défis, des termes comme leader, leadership, modèle à suivre, etc. J'avais à l'époque lié ce vocabulaire à un discours de la performance et une idéologie néolibérale sans prendre le temps de développer l'analyse (Vernet, 2016 : 287-293). C'est ce que je souhaite faire dans cet article, en m'intéressant à la façon dont on s'adresse aux étudiants dans le discours pédagogique.

Dans la suite de ce texte, une première partie présentera l'Acadie du Nouveau-Brunswick et les données auxquelles cet article s'intéresse. Cette partie ouvrira sur une contextualisation de la problématique de l'article dans un ensemble plus vaste examinant la circulation des discours et des idéologies dans l'enseignement du français en Acadie. Une partie de théorie suivra, s'attachant à préciser la notion d'« idéologie néolibérale » et son application au milieu universitaire. Les analyses du corpus, qui constituent le corps du texte, seront divisées en deux parties insistant chacune sur une figure type : l'interpellation des étudiants en sujets-entrepreneurs et l'interpellation des étudiants en sujets-managers.

1. Équivalent, à peu de choses près, de la Licence européenne. 


\section{Terrain et méthode}

\subsection{L’Acadie du Nouveau-Brunswick, contexte historique et linguistique}

L'Acadie est une région historique du Canada francophone, située au bord de l'Atlantique sur les actuelles provinces du Nouveau-Brunswick, de la Nouvelle-Écosse et de l'île-du-Prince-Édouard. Les Français ont commencé à coloniser cette région au tout début du $17^{\mathrm{e}}$ siècle avant de la céder en grande partie aux Anglais, par le traité d'Utrecht, en 1713². Les Acadiens furent massivement déportés à partir de 1755 à la faveur d'une nouvelle guerre franco-britannique; un épisode marquant resté dans la mémoire collective acadienne sous le nom de Grand Dérangement (LeBlanc, 2005). Ils quittèrent leurs foyers (à l'époque essentiellement situés dans l'actuelle Nouvelle-Écosse), pour rentrer en Europe ou se disséminer en Nouvelle-Angleterre, jusqu'en Louisiane et aux Antilles ou, au nord, sur les côtes qui seront plus tard celles du Nouveau-Brunswick. Si bien qu'aujourd'hui, l'Acadie n'est pas une région administrative officielle du Canada, elle n'a pas de frontières claires. Elle correspond plutôt aux foyers de peuplement francophones qui subsistent dans ces régions, c'est-à-dire, en fait, surtout le Nouveau-Brunswick (Arseneault, 1999) et à une mémoire commune réactivée.

Cela fait donc un peu plus de trois-cents ans que les Acadiens se trouvent officiellement en territoire anglais, minorisés sinon en nombre, du moins en poids politique. À partir de la fin du $19^{e}$ siècle, un processus d'émancipation politique s'enclenche à travers la création de journaux en français (L'Évangéline, Le Moniteur acadien), d'associations religieuses qui permettent à une petite partie de la population de bénéficier d'une éducation en français, puis la mise de place de conventions, réunissant les notables acadiens et officialisant la création de certains symboles nationaux : hymne, drapeau, fête nationale, etc. Ces évolutions permettent de gagner une certaine stabilité. Elles se poursuivront, notamment au Nouveau-Brunswick, tout au long du $20^{e}$ siècle.

Au chapitre linguistique, le français acadien parfois appelé « traditionnel » trouve très probablement ses racines dans certaines variétés régionales de l'ouest de la France (Massignon, 1962 ; Péronnet, 1989). Celui-ci a suivi sa propre évolution, déconnectée de l'ancienne métropole depuis fort longtemps, mais toujours influencée par elle : un français normatif exogène, dit «standard », est celui qui est enseigné et vers lequel tendent en général les formes d'expression publique (dans les médias, par exemple). Dans le même temps, le contact permanent avec les anglophones depuis des siècles a teinté le français vernaculaire d'anglais dans des proportions variables (Perrot, 1995). La situation actuelle peut être vue comme une double minorisation, à l'égard de l'anglais d'un côté, du français «standard» de l'autre.

2. Pour une histoire globale de l’Acadie, lire par exemple Daigle (1993), Landry et Lang (2014) ou Thériault (1999). 
Dans un tel contexte, la création de l'Université de Moncton, au début des années 1960, sonne comme un acquis considérable pour la population (Cormier, 1975) ; et, de fait, elle est dès le départ un haut lieu de l'émancipation politique acadienne (Boudreau, 2016 : 29-34). Former son public en français est alors une de ses missions revendiquées et renouvelées jusqu'à aujourd'huỉ. Pour y contribuer, des cours de français à destination de l'ensemble du public étudiant ont été instaurés depuis au moins les années 1980. Ils ont pour objectif la maitrise d'un français «standard » : une variété bien sûr difficile à définir mais qui, dans ce contexte, renvoie à un ensemble de variantes recommandées dans des supports de référence publiés en France ou au Québec 4 , à l'exclusion des formes vernaculaires de français. Ces cours ont plusieurs fois fait l'objet d'une réévaluation, de réajustements, en particulier du fait de la perception persistante de l'administration et du corps professoral d'un « manque » dans la maitrise du standard (Arrighi et Violette, 2013 ; Vernet et Määttä, à paraitre).

\subsection{L'enquête et les données}

En 2013-2014, date à laquelle a été menée l'enquête sur laquelle s’appuie le présent article, deux cours de français sont obligatoires pour l'ensemble du corps étudiant inscrit en baccalauréat : un cours de communication écrite et un cours de communication orale, dans lesquels les étudiants sont en général répartis selon leur filière. En outre, l'inscription à l'Université passe par un test de classement en français, qui classe les individus selon leur niveau et détermine si un ou plusieurs cours de français complémentaires sont nécessaires ${ }^{5}$. Les cours de français obligatoires se donnent pour mission d'enseigner les usages écrits et oraux d'un français dit standard. Ils sont constitués de nombreux exercices pratiques et interactifs menant les étudiants vers l'écriture normée de textes, de préférence liés à leur domaine, et la prise de parole. Le contenu des cours est à priori identique d'un groupe à un autre, avec une part de liberté pédagogique qu'il est difficile de mesurer. J'ai pu suivre et enregistrer un semestre complet des deux cours obligatoires, récolter le matériel pédagogique, interviewer une grande partie du corps enseignant en français, quelques étudiants, et obtenir les documents administratifs relatifs à la mise en place des cours de français dans cette université. Seule une petite partie de cet ensemble sera analysée ici. Il s'agit d'analyses secondaires, empiriques, d'un corpus qui n’y était pas spécifiquement destiné initialement, ce qui apporte son lot de contraintes et de limitations.

3. https://www.umoncton.ca/notreumoncton/a-propos (consulté le 16 avril 2020).

4. On parle des dictionnaires Larousse, Robert, du Multidictionnaire, de manuels et de sites Internet, comme ceux du TLF et de l'Office québécois de la langue française. J'emploierai désormais l'expression « français standard » sans guillemets, sans oublier pour autant que la nomination d'un tel ensemble aux contours abstraits contribue à son essentialisation.

5. Au moment de l'enquête, environ 60 \% des étudiants et étudiantes doivent suivre un ou deux semestres de français supplémentaires au parcours obligatoire. 
Je me focaliserai donc sur le matériel pédagogique du cours de français oral - j'expliquerai plus loin pourquoi - en proposant une analyse de ce matériel suivant les principes de la critical discourse analysis posés par Fairclough (1992). Il s'agit à la fois d'analyser un corpus dans ses aspects linguistiques (lexicaux, syntaxiques, énonciatifs...), mais aussi comme pratique discursive et sociale, en étudiant les aspects idéologiques. Cette branche de l'analyse du discours s'est développée pour examiner les " taken-for-granted practices that in their very ordinariness 'do ideological work' every day on the ground in unremarkable ways » (Kelly-Holmes, 2016 : 162), et en particulier, pour observer la pénétration de l'idéologie néolibérale dans les pratiques quotidiennes perçues comme neutres (Fairclough, $2001: 204)$.

\section{Cadre théorique}

\subsection{Rapport à la langue et idéologies linguistiques}

Cet article s'inscrit dans une réflexion plus large qui porte sur le rapport à la langue et aux normes linguistiques des intervenants (professeurs, étudiants et administration). D'autres points ont été développés ailleurs, qui méritent d'être succinctement rappelés pour cadrer ce propos-ci.

Tout d'abord, dans les cours qui ont été analysés, le français vernaculaire acadien trouve sa place dans une catégorie nommée « diversité linguistique ». Celle-ci est entourée d'un ensemble de discours mélioratifs, liés aux aspects identitaires et au rôle de socialisation qu'ont les variétés acadiennes de français. Elle est, dans le même temps, explicitement cantonnée aux sphères intimes, privées, et à certaines niches culturelles. En classe, cela se traduit par des attitudes prescriptives, où les éléments de français local font l'objet de nombreux exercices visant à les repérer et les remplacer, et sont en général sanctionnés dans les examens (Vernet, 2019). Parallèlement, cet argumentaire autour des pratiques vernaculaires se couple à une défense du standard comme compétence technique apportant une valeur ajoutée aux étudiants, c'est-à-dire un capital symbolique potentiellement convertible en capital matériel. En un mot, le standard est présenté comme une variété de langue instrumentale. Les deux argumentaires (celui portant sur le vernaculaire et celui portant sur le standard) sont compatibles à la condition que le vernaculaire reste cantonné aux sphères privées, tandis que le standard peut, lui, jouer un rôle politique et public - renouant par là avec les plus anciennes théories de la diglossie (Ferguson, 1959) : sur le terrain, ce rapport entre standard et vernaculaire est envisagé et présenté explicitement comme une cohabitation consensuelle. Consensualité d'apparence, car ces deux variétés se partagent les mêmes espaces sociaux où elles sont en tension (Vernet, 2021). Les discours mélioratifs tenus sur les pratiques vernaculaires pouvaient alors être vus comme un renfort de la situation diglossique en lui apportant des justifications. Ainsi, pour reprendre les termes de Duchêne et Heller (2012), sur ce terrain on pouvait observer deux types de discours, l'un ayant une fonction identitaire, lié au trope de la fierté et concernant le vernaculaire, l'autre une fonction instru- 
mentale, lié au trope du profit et concernant le standard. Dans les données issues de cette enquête, l'inversion de ces rôles est résiduelle.

Dans le présent article, je ne souhaite pas analyser le rôle du français standard en Acadie dans l'outillage néolibéral ; n’ayant pas été recueillies dans cet esprit, les données dont je dispose ne le permettent pas $^{6}$. Je souhaite plutôt m'interroger sur le rôle du discours pédagogique lié au standard (c'est-à-dire celui des professeurs en classe et du matériel pédagogique) dans la diffusion d'une idéologie néolibérale. Pour ce faire, j'utiliserai la notion d’interpellation développée par Althusser (1976 : 110-115), qui part du principe que la manière dont les institutions s'adressent aux individus (les interpellent) tend à diffuser subrepticement une idéologie, voire imposer à petit feu sa domination. Dans les données analysées plus loin, je souhaite montrer que les étudiants sont incités à une certaine conduite et un certain rapport à leur subjectivité en phase avec une idéologie néolibérale, et ce, notamment par la manière dont le discours pédagogique s'adresse à eux.

\subsection{Qu'est-ce que le néolibéralisme?}

Il s'agit maintenant de préciser ce que j'entends par « néolibéral », ce que je ferai en deux temps. D’abord, en expliquant ce que recouvre cet adjectif dans le champ théorique de l'économie ainsi que sa filiation avec le libéralisme ; ensuite, en essayant de décrire le néolibéralisme comme une idéologie globale, c'est-à-dire aussi comme un mode de gouvernance hors de la sphère économique. Ce second point fera un lien direct avec les données analysées dans ce texte.

Je ne peux évidemment pas donner ici de définition simple, courte et consensuelle du néolibéralisme. Un tel courant de pensée est lu, alimenté et débattu depuis fort longtemps. Partons déjà du fait que le préfixe néo- indique une évolution du corpus idéologique libéral ; il faut donc d'abord s'arrêter sur ce dernier. Globalement, lorsque le terme libéral est appliqué à la sphère des activités économiques, il désigne le marché libre et le non-interventionnisme de l'État, vus comme conditions d'une plus grande efficience dans les échanges économiques et donc d'une plus grande prospérité et d'un plus grand progrès (technique, scientifique, idéologique...). Les racines de cette idéologie sont incarnées par la figure tutélaire d’Adam Smith. La pensée de Smith, très essentialiste, considère que la nature humaine a une « propension à permuter, troquer et échanger une chose contre une autre » (2000 [1776] : 19). Il ajoute, et cela nous intéresse plus dans ce texte, que c'est la recherche de l'intérêt particulier qui est le moteur de l'intérêt général ${ }^{8}$. De cette réflexion étendue à l'ensemble

6. Je me suis toutefois intéressé, dans un autre texte, à la volonté du corps enseignant de transmettre un français standard en insistant sur sa fonction instrumentale au moyen d'un argumentaire utilitariste (Vernet, 2021).

7. Je dis « incarnées », car j’ai conscience que les racines de la théorie économique libérale sont à trouver avant Adam Smith, notamment chez les physiocrates (lire à ce sujet Citton, 2000).

8. «Ce n'est pas de la bienveillance du boucher, du brasseur ou du boulanger que nous attendons notre dîner, mais de l'attention qu'ils portent à leur propre intérêt. Nous nous adressons non à leur humanité mais à leur amour d'eux-mêmes, et nous ne leur parlons jamais de nos propres besoins mais de leur avantage » (2000 [1776] : 20). 
de la société vient l'idée fameuse de la «main invisible » qui régule le marché de manière autonome ou de la « loi des débouchés » de Say stipulant que l'offre crée sa propre demande. Ces éléments doctrinaux ont nourri le capitalisme industriel du $19^{e}$ siècle.

Après le krach boursier de 1929 et les crises économiques successives des années 1930 (Kindleberger, 1988), différents courants économiques ont cherché à tenir compte des problèmes posés par la doctrine libérale pour la réinventer (Turner, 2008). C'est ainsi qu'en Europe, l'ordolibéralisme allemand insiste sur le rôle de l'État pour créer les conditions favorables à un marché libre - tout en s'en méfiant (Commun, 2016 ; Foucault, 2017 : 823). En Amérique du Nord, Friedman tente de défendre l'appellation de « libéralisme », mais un changement a bien eu lieu, portant précisément sur le rôle « limité » de l'État:

First, the scope of government must be limited. Its major function must be to protect our freedom both from the enemies outside our gates and from our fellow-citizens: to preserve law and order, to enforce private contracts, to foster competitive markets. (1982 [1962] : 10-11)

L'État, dans son rôle « limité », doit par exemple assurer la pérennité et la stabilité de la monnaie, garantir la propriété privée des moyens de production, s’assurer juridiquement de la concurrence libre et non faussée, étendre le marché aux secteurs non marchands, etc. Puisqu'il faut pouvoir préserver et garantir tout ceci, par la force si nécessaire (Cusset, 2018), l'État doit gérer les structures juridiques, policières et militaires adéquates.

Foucault explique que le but des penseurs néolibéraux américains est d'étendre le fonctionnement du marché à des sphères non marchandes de l'activité sociale, telles que la famille (2017: 824). Il explique, par ailleurs, que la liberté des individus (induite dans l'idée de « libéralisme ») est surtout assujettie à la liberté économique, cette dernière s'accompagnant nécessairement d'un certain «dressage ${ }^{9}$ ». D’une certaine façon, c'est aussi la question soulevée par Harvey (2005) qui s'interroge sur la construction du consentement à ce cadre idéologique.

Par « idéologie néolibérale », j'entends donc un ensemble de croyances et de discours organisés en système, institutionnalisés, et qui conduisent à l'instauration d'un marché libre, reposant sur la concurrence libre et non faussée et la compétition entre individus-entrepreneurs. J'entends également que cet ensemble de croyances et de discours agit comme un mode de gouvernance sociale, qui s'inscrit jusque dans les attitudes mêmes que nous, en tant qu'individus, sommes sommés d'adopter.

Si je dis «sommés », cela ne doit pas nécessairement nous faire penser à une quelconque contrainte physique ou verbalement explicite. Althusser (1976) explique l'importance capitale de l'État dans la fabrication du consentement à un système. C'est à travers ses institutions (politiques, juridiques,

9. Je substantive ici la formule suivante de Foucault : «On ne pouvait évidemment pas libérer les individus sans les dresser» (2017: 911). 
scolaires...) qu'un cadre idéologique peut être construit et reproduit. Et c'est parce que « l'institution » s'adresse aux individus d'une manière précise, les interpelle d'une manière précise (Althusser, 1976 : 110-115), qu'elle les construit en sujets sociaux idéologiques. Dans notre contexte, c'est parce que l'institution universitaire (l'administration, le corps professoral, mais aussi les contenus pédagogiques) s'adresse aux étudiants comme à de futurs entrepreneurs ou à de futurs managers qu'elle les construit en partie comme sujets sociaux néolibéraux. C'est un argument pour s'intéresser au milieu universitaire comme terrain d'enquêtes ethnographiques, l'institution universitaire étant vue comme un appareil idéologique (Fairclough, 1993).

Ici, je ne m'intéresserai donc pas directement à la façon dont les pratiques linguistiques sont intégrées au cadre néolibéral comme produit marchand ou comme avantage comparatif pour les individus. De nombreuses recherches ont illustré que les pratiques linguistiques se fondent à merveille dans l'économie globale des échanges (v. par ex. Blommaert, 2010 ; Coupland, 2010 ; Duchêne et Heller, 2012), y compris dans le milieu universitaire (Chun, 2009) et en particulier dans l'enseignement des langues (Block, Gray et Holborow, 2012 ; Piller et Cho, 2013). Pour ce qui est de l'Acadie et du Canada francophone, plusieurs recherches ont montré qu'un nouveau rapport aux langues se dessinait, mettant l'accent sur les pratiques linguistiques comme capital et atout économique (v. par ex. Heller, 2011 ; Arrighi, 2013). Les données qui seront analysées ici sont en continuité avec ces travaux, car le français standard y est présenté comme une compétence marchandable (apportant, en tout cas, une valeur ajoutée à l'individu apprenant), mais dans une optique plus « althussérienne », je chercherai surtout à savoir comment les individus sont interpelés en sujets néolibéraux par l'institution universitaire.

En effet, McElhinny explique bien comment le cadre néolibéral a développé une nouvelle manière " d'être soi », et comment celle-ci se traduit dans le discours. Elle évoque les «new regimes of self associated with neoliberalism, in which the ideal adult person is self-governing, responsible, autonomous, self-sufficient, independent, and entrepreneurial » (2012 : 250). Insistons sur cette liste de termes, car nous la retrouverons plus tard : individu autonome, responsable, entrepreneur, qui gouverne sa propre vie. Or, j'ai rappelé plus haut l'importance de la langue dans sa forme standardisée comme compétence technique : c'est donc autour de cette variété que l'on va trouver, dans l'enseignement de la langue, un ensemble de traces discursives, argumentatives, de cette interpellation néolibérale.

\section{L'interpellation des individus en sujets néolibéraux}

\subsection{Des données qui concernent le cours de communication orale}

Lorsque l'ensemble du corpus de la recherche fut transcrit, j'ai cherché à connaitre les contextes d'apparition des termes qui avaient piqué ma curiosité et qui sont évoqués rapidement en introduction. Je me suis rendu compte que la quasi-totalité venait du cours d'oral. Un compte précis, effectué 
sur la base des 28 documents pédagogiques distribués et d'environ 40 heures de cours d'oral et d'écrit enregistrées et transcrites, nous informe que les termes « forces » et « faiblesses » apparaissent à 151 reprises dans le cours de français oral, contre 8 dans le cours d'écrit ; l'idée de l'amélioration de soi (verbe pronominal «s'améliorer » et formulations superlatives de type « devenir meilleur ») est présente 37 fois durant le semestre d'oral, une fois seulement en écrit. Certaines formulations qui nous intéressent ici sont totalement absentes du semestre de cours de français écrit et abondent dans le cours d'oral, en général dans les documents pédagogiques distribués : l'idée de se lancer des défis (16 occurrences), de suivre un modèle (16 occurrences), les termes «leader/leadership » (12 occurrences), etc. Cette liste n'est pas exhaustive.

Ces nombres n'ont pas de signification en eux-mêmes, ils sont intéressants pour souligner la présence de ce champ sémantique dans le discours pédagogique. Quant à expliquer les raisons pour lesquelles ce vocabulaire se concentre dans le cours de communication orale plutôt que dans celui de communication écrite, je poserai d'abord une hypothèse que je n'ai pas les moyens de vérifier: l'enseignement du français à l'écrit répond peut-être à des habitus pédagogiques très anciens et très ancrés dans le corps enseignant, là où l'enseignement du français à l'oral, n'étant pas si ancien (à Moncton, une douzaine d'années), répond à des besoins de pédagogie plus « innovante » (Lemaître, 2018), qui vont dès lors avoir tendance à s'inscrire dans les idéologies dominantes en circulation. Audelà de cette hypothèse, le cours de communication orale propose entre autres choses de préparer le public étudiant à une insertion sur le marché du travail, l'un des objectifs est ainsi formulé : «être capable de produire un discours oral dans un registre de langue neutre-soutenu, dans une forme structurée liée à son domaine d'études et/ou au marché du travail associé à ce domaine » (plan de cours). Il est constitué de nombreux exercices pratiques d'expression (orale le plus souvent) ou de mise en situation. Comme fil rouge du semestre, un manuel est utilisé en classe. Intitulé « A l'aise à l'oral », rédigé par Besson et D'Ornano, il est à l'époque publié chez ESF Editeur dans la collection «Management - Les cahiers (D’Ornano et Besson, 2011).

L'analyse du vocabulaire employé à destination des étudiants dans le cours montre que, dans le discours pédagogique (les documents, les manuels, ainsi que les adresses de l'enseignante), on s'adresse aux étudiants tantôt comme à de futurs entrepreneurs, tantôt comme à de futurs managers. Ces deux figures, celle du sujet-entrepreneur et celle du sujet-manager, ont chacune des caractéristiques observables, que je m'attacherai à décrire dans la prochaine section, mais soulignons, et c'est important, qu'elles sont profondément imbriquées et que j'opère cette distinction de façon quelque peu artificielle dans le but de mettre en évidence qu'un discours d'apparence neutre « do[es] ideological work» (Kelly-Holmes, 2016). 


\subsection{Le sujet-entrepreneur}

Désormais, sauf mention contraire, les extraits présentés sont tirés de documents pédagogiques utilisés en classe de français oral. Les documents sont copiés dans leur forme d'origine à la virgule près, format de présentation jugé préférable à des documents numérisés. Lorsque des modifications ont été apportées (mise en gras de certains éléments, par exemple), elles sont signalées.

Lors de la toute première séance, le jour de la rentrée, le premier document distribué sert à chacun à se présenter devant la classe. II s'agit d’une demi-feuille intitulée « Je me présente », constituée de quatre questions ainsi libellées:

(1, document complet)

1. Qui je suis, d'où je viens...

2. Ce que j'ai fait cet été : ex. projets, passe-temps, travail, découvertes, décisions...

3. Mes projets à long terme (plans futurs) ou à court terme (cette année).

4. Les moyens que je veux prendre pour atteindre mes buts.

Le document est anodin, même banal. Pourtant, d'emblée l'étudiant est placé devant deux axes qui s'avèreront majeurs durant l'ensemble du semestre : le parcours individuel et les réalisations individuelles. À l'appui du premier axe, on peut observer que l'étudiant est inscrit tout de suite dans un projet professionnel (question 3) liant le court terme (le cours de français lui-même, par exemple) au long terme (les objectifs de vie). Cet exercice d'introduction insiste sur un parcours de vie : le propos de présentation doit commencer par d'où vient la personne (question 1) et finir par où elle va. Sur le second axe, la question 2 demande de mettre en avant les réalisations qu'elle a déjà à son actif ("projets » ${ }^{10}$, « décisions », « découvertes »). Il est également demandé (question 4) d'établir les moyens que le répondant se donne pour atteindre son ou ses objectifs. On peut enfin relever que les questions sont autoadressées, formulées à la première personne du singulier, c'est-à-dire que dès la première séance, l'étudiant est placé dans une démarche individualisante et amené à inscrire les enseignements dans son parcours et à traduire ces enseignements en bénéfice individuel.

Dans cette optique, le « journal de bord » est un outil qui est utilisé tout au long du semestre. Il s'agit souvent de faire des synthèses de ses apprentissages et d'indiquer ce qu'ils ont apporté, mais il s'agit également d'envisager la suite du « parcours ». Voici deux exemples : l'exemple (2) est extrait d'un document distribué après un exposé oral, dans lequel il est d'abord demandé d'évaluer l'exposé que

10. «Projet » est un terme important, selon Boltanski et Chapiello (1999 : 729) : il est apparu dans le néolibéralisme il y a quelques décennies et devenu, dès les années 1990, un des lexèmes principaux de la littérature en management (avec « réseau » et « équipe »). 
l'étudiant vient d'écouter, puis de s'autoévaluer ; l'extrait présenté porte sur les critères linguistiques. L'exemple (3) est tiré, lui, d’une fiche synthèse.

(2, extraits du document)

Qualité de la langue orale

Au fil de la discussion,

-Ai-je été conscient(e) de ses erreurs de langage? Quelles sont-elles?

Qualité de la langue orale

Au fil de la discussion,

-Ai-je utilisé un registre de langue correct?

-Ai-je été conscient(e) de mes erreurs de langage? Quelles sont-elles?

(3, extraits du document)

À la suite de cet atelier en oral, voici le ou les défis que je me lance afin de devenir un meilleur locuteur en classe et dans ma vie quotidienne.

À la suite de cet atelier en oral, voici les pistes de solutions que je mettrai en pratique afin de devenir un meilleur locuteur en classe et dans ma vie quotidienne.

On retrouve ici des formulations à la première personne du singulier ; les questions sont autoadressées, ces documents doivent donc d'abord servir l'étudiant même. Dans l'exemple (2), il s'agit d'identifier ses potentielles « erreurs de langage », et chaque question du document est suivie d'un espace pour détailler « Mes points forts » et « Mes points faibles» (je reviens dans la section suivante sur ces termes). Dans l'exemple (3), il s'agit de « devenir un meilleur locuteur », ce qui reste implicite dans le document (2). Dans les deux cas, on est placé ici dans une logique de performance, que ce soit en classe ou dans la vie quotidienne. Pour Aubert (2006), la performance contient deux idées : celle des possibilités maximales et celle du mérite par son effort. Les données présentent bien ces deux idées : l'étudiant doit identifier ses problèmes, proposer des pistes de solution et se lancer des « défis », c'est-à-dire que pour progresser, il est demandé à chacun de se fixer des objectifs intermédiaires à réaliser leur permettant de s'améliorer, et donc de pousser plus loin ses possibilités. D’ailleurs, la formulation superlative « devenir meilleur », ne permettant pas de fixer un point d'arrivée concret, laisse l'individu face à une démarche d'amélioration potentiellement infinie : il s'agit d'aller toujours plus loin, dans une forme de « dépassement de soi ».

Un exercice semble en particulier concentrer ces tendances (la question du parcours individuel, des réalisations, de l'amélioration de soi et de la mise en avant de soi) : il s'agit de la simulation d'un entretien d'embauche. Plusieurs séances du cours sont destinées à préparer cet exercice qui vient en fin de semestre. En équipe, et en alternance, un candidat fait face à un comité de sélection constitué des camarades de classe. La simulation est accompagnée d'une grille d'observation des candidats, qui contient les six critères positifs suivants accompagnés d'un espace pour des commentaires : 
(4, grille complète ; je mets en gras)

Respecte le temps alloué ; A un regard soutenu, franc ; Poignée de main ferme, regard ;

Semble confiant ; Vouvoie les interrogateurs; Hésitations minimales

Au milieu de critères d'ordre pratique (le temps) ou linguistique (le vouvoiement), d'autres sont accompagnés de qualificatifs qui concernent directement l'attitude des individus, sinon leur caractère: franchise, fermeté, confiance. La grille est accompagnée d'une dizaine d'exemples de questions à poser aux candidats; en voici quelques-unes:

(5, extraits du document)

Quelles réalisations vous [ont] procuré le plus de satisfaction?

Où vous voyez-vous dans cinq ans?

Quels sont vos buts dans la vie?

Objectif de vie, parcours pour l'atteindre, réalisations personnelles : cette liste de questions possibles est en cohérence avec les journaux de bord et les synthèses présentés jusqu'ici. Il est certes demandé à la personne, comme dans tout entretien d'embauche, de savoir se vendre, mais plus que ça, c'est tout un esprit d'entreprendre qui se diffuse dans les activités du cours.

\subsubsection{Le sujet-entrepreneur et l'argumentaire de la réussite}

Chambard (2013) souligne que c'est dans les années 1990, en Europe, que les universités ont pris le tournant « entrepreneurial » dans une volonté parfaitement explicite d'amener les étudiants à s'insérer plus facilement dans l'économie de marché. Dit autrement, il s'agit alors de faire coïncider l'éducation avec l'économie de marché. Ce tournant a été pris bien plus tôt en Amérique du Nord (Vérin, 2011 [1982]).

Comment passe-t-on alors d'une logique d'éducation à une logique entrepreneuriale ? Il s'agit, comme on le voit dans les documents pédagogiques présentés, d'appliquer tout un vocable relevant d'attributs individuels (par exemple, le dynamisme, la créativité, l'initiative, l'ambition, v. exemple 4) à la réalisation concrète d'entreprises (au sens large de "choses que l'on entreprend ») : « projets », "découvertes », « décisions », etc. (v. exemples 1 et 5). C'est-à-dire détacher l'entrepreneuriat de la sphère économique pour le transformer en aptitude individuelle, détacher l'entreprise de ses conditions matérielles de possibilité pour la rattacher essentiellement à des capacités individuelles ${ }^{11}$.

Je crois que c'est dans ce sens qu'il faut comprendre l'insistance sur l'amélioration de soi que l'on observe dans les exercices. Telle qu'on la lit dans ces données, la performance est à la fois un moyen et un but en soi, car il ne s'agit pas seulement d'encourager le public étudiant à accomplir des choses

11. Dans la recherche anglo-saxonne, cette tendance est implantée depuis fort longtemps déjà, où l'on cherche à identifier quelles sont les caractéristiques psychologiques qui mènent au succès, v. par ex. Hornaday et Aboud (1971). 
(quelles qu'elles soient), mais à développer un esprit d'entreprendre (entrepreneurship). Et de fait, chaque personne est encouragée à entrer en compétition, non avec les autres, mais avec elle-même, à se poser des objectifs à remplir, et une fois remplis à s'en poser d'autres, à se « dépasser » en somme, dans une amélioration sans fin de soi.

Ce que j'appelle ici « l'interpellation des individus en sujets-entrepreneurs » repose sur un argumentaire de la réussite, où chaque étudiant est placé devant une incitation à performer et à accomplir.

\subsection{Le sujet-manager}

La deuxième figure type sur laquelle je voudrais m'arrêter et à laquelle le corps étudiant doit se conformer du mieux possible est celle du manager. Elle est caractérisée par deux axes complémentaires à ceux évoqués au point précédent : l'importance de l'autoévaluation et celle du leadership.

Une des fonctions principales du manager est le contrôle (Chamayou, 2018: 39-55). Ceci se traduit en classe par l'omniprésence de l'autoévaluation et de l'évaluation par les pairs : ce fut demandé formellement à huit reprises durant le semestre, c'est-à-dire avec une grille d'évaluation ou d'observation à remplir. L'exemple (6) est un journal de bord dans lequel il est demandé:

(6, document complet)

En vous référant à L'autoévaluation de mes compétences langagières à l'oral (l'autre document remis avec celui-ci), quels sont les points positifs et les points à améliorer que vous pouvez déjà identifier dans votre expression orale française? Voyez-vous d'autres forces ou faiblesses qui vous ont été révélées lors d'exercices en classe? Enfin, par quels moyens concrets comptez-vous vous améliorer? (Soyez spécifiques.)

N.B. - Relevez au moins une force et une faiblesse dans deux (des quatre) volets de compétences présentées dans la grille d'évaluation de l'oral à la fin du plan de cours.

Ici, une importance maximale est mise sur l'évaluation de ses forces et faiblesses (idée présente à trois reprises en quelques lignes) : cette formulation apparait très fréquemment dans les échanges oraux durant le semestre, parfois dans une euphémisation rhétorique, on parlera de « défis » ou de " points à améliorer » plutôt que de « faiblesses ». Un accent très important est mis sur les compétences linguistiques qu'il s'agit d'abord de sérier puis d'évaluer. L'exemple (6) fait ainsi référence à un document qui présente quatre compétences: (a) compétence linguistique - voix, (b) compétence linguistique - langue, (c) compétence discursive, (d) compétence communicative. En outre, une «Grille d'évaluation de l'oral » très pointue, distribuée lors de la première séance, établit quatre pages de tableau divisant ces quatre compétences en dix-sept critères $^{12}$, chacun étant divisé à son tour en

12. Dans le détail : (a) Articulation, timbre et portée de voix, prononciation, accentuation, rythme, intonation ; (b) Morphologie, syntaxe, vocabulaire ; (c) Organisation du discours, délimitation du sujet, pertinence et crédibilité ;

(d) Choix langagiers, relation avec l'auditoire, attitude générale, posture et tenue vestimentaire, gestes et regard. 
plusieurs points « positifs » ou «à améliorer ». À ces critères correspondent des leçons du manuel évoqué précédemment, lesquelles fournissent des informations, des exercices et des « conseils du coach ». Il s'agit, pour chaque étudiant, de jauger sa progression en français standard, presque à la manière d'un jeu vidéo où chaque critère est mesurable. Ceci rejoint l'analyse d'Urcioli (2015; 2018), qui décrit comment les étudiants dans le système universitaire sont progressivement pensés comme un capital humain (Hyslop-Margison et Sears, 2006) : « [they] are routinely urged to visit their career centers for skills audits to list on their résumés and to think of themselves as skills bundles » (2018:5).

Tout ceci est fait dans une ambiance bienveillante, car il faut noter que cette logique de contrôle est plus souvent exercée sur soi-même qu'envers ses pairs; dans mes données, par ailleurs, lorsque l'évaluation des pairs est requise, l'indulgence est en général une règle tacite.

Venons-en à l'autre face de l'individu-manager : la question du leadership, car l'autre fonction du manager est de diriger. Voici un autre exercice du « journal de bord »; celui-ci devait être fait à la maison et donner lieu ensuite à une restitution à l'oral face à la classe.

\section{(7, document complet)}

1. Nommez un membre de votre entourage immédiat qui, selon vous, communique efficacement. Expliquez, en donnant des exemples précis, ce qui justifie votre choix. En quoi aimeriez-vous ressembler à cette personne? Comment pouvez-vous vous en inspirer?

2. Nommez une personne célèbre qui se démarque pour ses talents de communicateur ou de communicatrice et justifiez votre choix.

3. Connaissez-vous des gens qui ont du succès au point de vue professionnel grâce à leurs habiletés de communication ? Comment expliquez-vous ce succès ? Comment pouvez-vous vous inspirer de ces personnes?

On y retrouve le champ sémantique de la performance : notamment l'idée de «communiquer efficacement », mais aussi de développer des « habiletés », d’isoler des « talents » de communicateur, d'identifier des « gens qui ont du succès » et d'expliquer « ce succès ». Autant de termes mélioratifs et superlatifs au milieu desquels émerge la figure du « modèle » à prendre en exemple. Que ce soit une « personne célèbre » ou un proche, il s'agit d'une figure placée sur un piédestal, une figure inspiratrice, qui suscite une forme d'admiration au point qu'il est demandé « en quoi [aimerait-on lui] ressembler » et par deux fois « comment [s'en] inspirer ». Les étudiants sont ainsi placés devant une idéalisation de réussite individuelle, qui se mesure aux représentations mélioratives qu'elles et ils ont d’untel ou d'unetelle (en classe, par exemple, le nom de Barack Obama a émergé).

On retrouve très régulièrement l'image du leader, comme encore dans l'exercice suivant, où il est demandé à chaque étudiant de rédiger un petit texte : 
(8, document complet)

$\underline{\text { Un communicateur exemplaire }}$

Imaginez que vous rencontrez un de vos communicateurs modèles et que vous lui demandez conseil. Il vous aidera à battre un sentier vers une communication orale et professionnelle. Que vous suggère-t-il ? Comment a-t-il développé ses talents de communicateur? Proposez des pas concrets qui vous engagent à suivre ses traces.

Cet exercice condense les caractéristiques relevées précédemment : l'image du communicateur " exemplaire » ainsi que le champ sémantique de la performance. Mais il développe surtout l'idée d'un parcours initiatique, avec la figure du leader à qui l'on « demande conseil » et qui « aidera à battre un sentier », « suggère » des choses et engage à « suivre ses traces ». La relation ainsi décrite est celle d'un parcours individuel d'initiation, jalonné d'épreuves, vers la position du leader pris en modèle. Les compétences linguistiques, finement sériées ailleurs, sont ici subsumées dans une image de communicateur modèle, c'est-à-dire décontextualisées et fondues dans une figure de leader charismatique (comme dans l'exemple 7 illustré en classe par Barack Obama).

Le terme même de « leader » n'apparait pas dans les documents pédagogiques, mais il est employé dans les rapports administratifs internes ayant présidé à la mise en place du cursus de français. Parmi les arguments qui soutiennent la création d'un cours de communication orale, on lit par exemple celui-ci, dans un rapport de 2007 :

(9, extrait de rapport)

Tous les universitaires ont besoin d'avoir une aisance en langue parlée de façon à pouvoir s'exprimer et à devenir des leaders. (Lefrançois et Vincent, $2007: 28)^{13}$

En classe, la question du leadership apparait aussi de temps en temps (une douzaine d'occurrences, v. section 4.1), par exemple dans cette intervention de la professeure à l'adresse de sa classe :

(10, extrait d'un cours, novembre 2013, transcription orthographique)

Professeure : Lorsque je suis devant un groupe et que je veux motiver les personnes, j'ai besoin d'employer des mots qui activent. Par exemple, au lieu de parler de travail dans une autre classe d'administration, quelqu'un m'a donné comme synonyme de travail, l'activité, j'ai beaucoup aimé ça. Puis je me suis dit, tiens, il ferait un bon leader, il peut choisir ses mots et motiver un groupe.

On comprend alors qu'il s'agit de replacer l'enseignement dans un objectif général : l'avenir professionnel des étudiants.

13. Le rapport est rédigé en 2005, puis réuni avec le mandat, des rapports d'autoévaluation et des synthèses de décisions en 2007 seulement par les services administratifs de l'Université ; la référence renvoie à la pagination de ce document colligé. 


\subsubsection{Le sujet-manager et l'argumentaire de la responsabilité}

Le cours veut donner aux étudiants les moyens de « réussir leur vie » (les guillemets soulignent ici que ce sont mes termes) en posant comme principe que ces moyens s'apprennent, se fabriquent ; on le voit en lisant les documents pédagogiques présentés jusqu'ici. II s'avère que cet objectif se traduit ici en exercices autocentrés : tenir un journal de bord, s'évaluer soi-même, faire le point sur ses avancées personnelles dans les objectifs que l'on s'est fixés, etc. Autant de techniques individuelles, individualisantes, qui ne s'appuient pas sur le collectif; pour le dire autrement, elles font peser la responsabilité sur l'individu et non sur les structures collectives (Charazac, 2010). Il en va de même pour les exercices centrés sur une « personne modèle à suivre », le modèle « exemplaire » est bel et bien ici un modèle responsable qu'il est responsable individuellement de chercher à imiter. Hache (2007) considère cette "responsabilité libératrice », selon ses propres termes, comme une arme de gouvernementalité néolibérale (terme emprunté à Foucault, 2004), notamment en ce sens qu'elle s'appuie sur cette idée fondatrice du libéralisme selon laquelle la poursuite de son intérêt particulier contribue à l'intérêt général. Intérêt général : comment mener une classe d'étudiants à « réussir sa vie » ? Intérêt particulier : en leur apprenant individuellement à maitriser les conditions individuelles de leur ascension sociale.

Il semble donc que ce que j'appelle ici «l'interpellation des individus en sujets-managers » soit intimement lié à un argumentaire de la responsabilité, outil majeur de l'individualisation, qui place chaque étudiant devant des logiques de contrôle et d'autocontrôle, et devant une quête de leadership.

\section{Conclusion}

Les discours analysés dans cet article peuvent être observés comme une des formes que prend l'argumentaire du profit, évoqué en introduction de ce texte, et qui consiste à présenter le français standard comme une variété de langue instrumentale, essentielle dans la réussite sociale - et, ce faisant, à légitimer une cohabitation consensuelle avec les pratiques linguistiques vernaculaires. Ce discours pédagogique autour de l'enseignement du français en Acadie s'adresse aux étudiants comme à de futurs entrepreneurs-managers. Cette figure archétypale du sujet-entrepreneur-manager, qui est au cœur de l'idéologie néolibérale, a quatre lignes de vie, si je puis dire : elle fait des projets, elle bâtit un parcours balisé vers la réalisation de ces projets (argumentaire du succès), elle (s’auto)contrôle et elle veut le leadership (argumentaire de la responsabilité).

Toute cette construction discursive est servie par des termes à connotations très positives (" talents », « habiletés », "succès », " solutions »), mêlés au champ sémantique de l'effort (" effort », «travail », " défis » et tous leurs dérivés lexicaux, les superlatifs comme « devenir meilleur » et l'accent porté sur l'amélioration de soi) ; c'est-à-dire, en fait, les champs sémantiques du succès et de la responsabilité. L'ensemble étalé sur quatre mois donne l'impression diffuse qu'il n'y a pas de dif- 
ficultés ou de problèmes en soi, uniquement des « défis » à relever, qu'il n'y a pas de tensions ou de déterminismes sociaux, seulement des efforts individuels à fournir. Les activités pédagogiques ainsi présentées conçoivent les pratiques linguistiques comme un obstacle parmi d'autres face auquel l'individu est seul décideur de son avenir. Ce qui rejoint ce que Ehrenberg écrivait dans Le culte de la performance:

Cette vision musclée de la vie en société déporte sur l'individu quelconque des responsabilités auparavant prises en charge par la seule sphère politique. Elle pousse le plus humble, l'exclu, à faire la preuve qu'il est capable de se gouverner par lui-même sans que soit rendue nécessaire la présence d'une autorité supérieure lui indiquant comment il doit être et comment il doit se comporter. (1991: 17)

Les idées de compétence, d'amélioration permanente de soi, de qualité de la langue, de planification stratégique d'un projet d'avenir, de construction d'un leadership : tout ceci me semble ressortir de ce qu'Urla appelait le « managérialisme », qui se voit, écrivait-elle, par « the distinctive terminology of managerial science: best practices, benchmarking, quality, strategic planning, to name a few » (2012: 75).

On peut se demander si le français standard lui-même dans sa forme ultra-normative ne correspond pas à un produit industriel normé. Car s'il est sociolinguistiquement impossible d'en tracer des contours précis dans une perspective variationniste, il répond pourtant parfaitement à une logique de tests et d'évaluation : tests de classement par exemple, mais aussi grilles d'évaluation extrêmement fines où l'on objective toutes les formes d'écart à la norme possibles. Dans sa forme linguistique comme dans sa pratique par les étudiants, il cadre ainsi parfaitement avec une culture de l'audit (Shore et Wright, 1999).

Il est donc intéressant d'analyser la salle de classe, dans cette situation, comme un espace discursif néolibéral institutionnalisé (Chun, 2009) où la structure administrative de l'université construit un cadre tel que le français standard est à la fois un produit marchand et une compétence valorisable sur le marché, et que les individus sont entrainés à s'adapter au marché du travail (Slaughter et Rhoades, 2000) par instillation d'un habitus entrepreneurial et managérial. Les discours que je viens de présenter me semblent alors une actualisation des grands thèmes néolibéraux que sont la libre entreprise et la libre concurrence, faisant de l'individu qui étudie un entrepreneur de lui-même. 


\section{Bibliographie}

Althusser, Louis (1976), Positions, Paris, Les Éditions Sociales.

Arrighi, Laurence (2013), « Un bagage linguistique diversifié comme capital humain : esquisse d'un (nouveau) rapport aux langues en Acadie », Revue de l'Université de Moncton, vol. 44, n², p. 7-34.

Arrighi, Laurence et Isabelle Violette (2013), « De la préservation linguistique et nationale : la qualité de la langue de la jeunesse acadienne, un débat linguistique idéologique », Revue de l'Université de Moncton, vol. 44, n², p. 67-101.

Arseneault, Samuel P. (1999), « Aires géographiques en Acadie », dans Joseph-Yvon Thériault (dir.), Francophonies minoritaires au Canada : l'état des lieux, Moncton, Éditions d’Acadie, p. 41-54.

Aubert, Nicole (2006), « Hyperformance et combustion de soi », Études, tome 405, p. 339-351.

Block, David, John Gray et Marnie Holborow (2012), Neoliberalism and Applied Linguistics, Londres, Routledge.

Blommaert, Jan (2010), The Sociolinguistics of Globalization, Cambridge, Cambridge University Press.

Boltanski, Luc et Ève Chapiello (1999), Le nouvel esprit du capitalisme, Paris, Gallimard.

Boudreau, Annette (2016), A l'ombre de la langue légitime: l'Acadie dans la francophonie, Paris, Classiques Garnier.

Chamayou, Grégoire (2018), La société ingouvernable : une généalogie du libéralisme autoritaire, Paris, La Fabrique.

Chambard, Olivia (2013), "La promotion de l'entrepreneuriat dans l'enseignement supérieur : les enjeux d'une création lexicale », Mots : les langages du politique, n 102, disponible sur https://doi. org/10.4000/mots.21374.

Charazac, Vincent (2010), «Le néolibéralisme au mépris du collectif : souffrance au travail, management par objectifs et délitement des groupes », Connexions, n 94, p. 121-133.

Chun, Christian W. (2009), "Contesting Neoliberal Discourses in EAP: Critical Praxis in IEP Classroom », Journal of English for Academic Purposes, vol. 8, n², p. 111-120, disponible sur https://doi.org/10.1016/j.jeap.2008.09.005.

Citton, Yves (2000), Portrait de l'économiste en physiocrate: critique littéraire de l'économie politique, Paris, L'Harmattan.

Commun, Patricia (2016), Les ordolibéraux, histoire d'un libéralisme à l'allemande, Paris, Les belleslettres.

Cormier, Clément (1975), L’Université de Moncton : historique, Moncton, Centre d'études acadiennes.

Coupland, Nik (dir.) (2010), The Handbook of Language and Globalization, Oxford, Wiley Blackwell. 
Cusset, François (2018), Le déchaînement du monde : logique nouvelle de la violence, Paris, La Découverte.

Daigle, Jean (dir.) (1993), L’Acadie des Maritimes, étude thématique des débuts à nos jours (2éd.), Moncton, Chaire d'études acadiennes.

D'Ornano, Barberine et Maria Besson (2011), A l'aise à l'oral: le cahier d'entrainement, Montrouge, ESF Editeur.

Duchêne, Alexandre et Monica Heller (dir.) (2012), Language in Late Capitalism : Pride and Profit, Londres, Routledge.

Ehrenberg, Alain (1991), Le culte de la performance, Paris, Le Seuil.

Fairclough, Norman (1992), Discourse and Social Change, Cambridge, Polity.

Fairclough, Norman (1993), «Critical Discourse Analysis and the Marketisation of Public Discourse: The Universities », Discourse and Society, vol. 4, n² 2, p. 133-168.

Fairclough, Norman (2001), Language and Power (2éd.), Londres, Longman.

Ferguson, Charles A. (1959), « Diglossia », Word, n 15, p. 325-340.

Foucault, Michel (2004), Naissance de la biopolitique : cours au collège de France (1978-1979), Paris, EHESS, Gallimard, Seuil.

Foucault, Michel (2017) [2000], Dits et écrits, II, 1976-1988, Paris, Gallimard.

Friedman, Milton (1982) [1962], Capitalism and Freedom, Chicago, The University of Chicago Press.

Hache, Émilie (2007), "La responsabilité, une technique de gouvernementalité néolibérale ? », Raisons politiques, $n^{\circ} 28$, p. 49-65.

Harvey, David (2005), A Brief History of Neoliberalism, Oxford, Oxford University Press.

Heller, Monica (2011), " Du français comme "droit" au français comme "valeur ajoutée" : de la politique à l'économique au Canada », Langage et société, n 136, p. 13-30.

Hornaday, John A. et John Aboud (1971), «Characteristics of Successful Entrepreneurs », Personnel Psychology, n² 24, p. 141-153.

Hyslop-Margison, Emery J. et Alan M. Sears (dir.) (2006), Neo-Liberalism, Globalization and Human Capital Learning: Reclaiming Education for Democratic Citizenship, Berlin, Springer.

Kelly-Holmes, Hellen (2016), "Theorizing the markets in sociolinguistics », dans Nikolas Coupland (dir.), Sociolinguistics: Theoretical Debates, Cambridge University Press, p. 157-172.

Kindleberger, Charles P. (1988), La grande crise mondiale, 1929-1939, Paris, Economica.

Landry, Nicolas et Nicole Lang (2014), Histoire de l'Acadie (2éd.), Montréal, Septentrion. 
LeBlanc, Ronnie-Gilles (dir.) (2005), Du Grand Dérangement à la déportation : nouvelles perspectives historiques, Moncton, Chaire d'études acadiennes.

Lefrançois, Pascale et Diane Vincent (2007), Rapport d'évaluation de la formation linguistique, Université de Moncton, document interne.

Lemaître, Denis (2018), «L'innovation pédagogique en question : analyse des discours de praticiens », Revue internationale de pédagogie de l'enseignement supérieur, vol. 34, n 1, disponible sur http://journals.openedition.org/ripes/1262.

Massignon, Geneviève (1962), Les parlers français d'Acadie : enquête linguistique, Paris, Klincksieck.

McElhinny, Bonnie (2012), "Silicon Valley Sociolinguistics ? Analyzing Language, Gender and Communities of Practice in the New Knowledge Economy ", dans Monica Heller et Alexandre Duchêne (dir.), Language in Late Capitalism : Pride and Profit, Londres, Routledge, p. 230-260.

Péronnet, Louise (1989), Le parler acadien du sud-est du Nouveau-Brunswick : éléments grammaticaux et lexicaux, Berne, Peter Lang.

Perrot, Marie-Ėve (1995), Aspects fondamentaux du métissage français/anglais dans le chiac de Moncton (Nouveau-Brunswick, Canada), thèse de doctorat, Université Paris 3.

Piller, Ingrid et Jinhyun Cho (2013), « Neoliberalism as Language Policy », Language in Society, vol. 42 , $n^{\circ} 1$, p. 23-44.

Shore, Cris et Susan Wright (2000), "Coercive Accountability: The Rise in Audit Culture in Higher Education », dans Marylin Strathern (dir.) Audit Cultures: Anthropological Studies in Accountability, Ethics and the Academy, Londres, Routledge, p. 5789.

Slaughter, Sheila et Gary Rhoades (2000), «The Neoliberal University », New Labor Forum, n 6, p. 73 79.

Smith, Adam (2000), Recherche sur la Nature et les Causes de la Richesse des Nations, Paris, Economica. [Titre original : An Inquiry into the Nature and Causes of the Wealth of Nations, Londres, W. Strahan et T. Cadell, 1776. Traduit de l'anglais par Philippe Jaudel et Jean-Michel Servet.]

Thériault, Joseph-Yvon (dir.) (1999), Francophonies minoritaires au Canada, l'état des lieux, Moncton, Éditions d'Acadie.

Turner, Rachel S. (2008), Neo-Liberal Ideology: History, Concepts and Policies, Édimbourg, Edinburg University Press.

Urcioli, Bonnie (2015), «La "diversité" comme capital : la re-conceptualisation néolibérale de la différence linguistique et sociale », Anthropologie et Sociétés, vol. 39, n³, p. 91-114, disponible sur https://doi.org/10.7202/1034761ar.

Urcioli, Bonnie (2018), "Introduction: Neoliberalizing Undergraduate Experience », dans Bonnie Urcioli (dir.), The Experience of Neoliberal Education, New York, Berghahn. 
Urla, Jacqueline (2012), «Total Quality Language Revival », dans Monica Heller et Alexandre Duchêne (dir.), Language in Late Capitalism : Pride and Profit, Londres, Routledge, p. 73-92.

Vérin, Hélène (2011) [1982], Entrepreneurs, entreprise : histoire d'une idée, Paris, Classiques Garnier.

Vernet, Samuel (2016), Discours, idéologies linguistiques et enseignement du français à l'Université de Moncton, thèse de doctorat, Moncton, Université de Moncton.

Vernet, Samuel (2019), «La "diversité linguistique” dans un modèle d'enseignement du français standardisé : les cours de français à l'Université de Moncton », dans Ali Reguigui, Julie Boissonneault, Leila Messaoudi, Hafida El Amrani et Hanane Bendahmane (dir.), Langues en contexte, Université laurentienne, Série monographique en sciences humaine, n²2, p. 363-380.

Vernet, Samuel (2021), «Entre français standard et vernaculaire acadien, l'invisibilisation du conflit linguistique », dans Geneviève Bernard Barbeau, Franz Meier et Sabine Schwarze (dir.), Conflit sur/dans la langue: perspectives linguistiques, argumentatives et discursives, Berne, Peter Lang, Collection « Sprache - Identität - Kultur», p. 99-117.

Vernet, Samuel et Simo Määttä (à paraitre), «L'Université de Moncton, la langue et les normes. Enjeux acadiens, échos finlandais », Revue de l'Université de Moncton, n’ 50. 


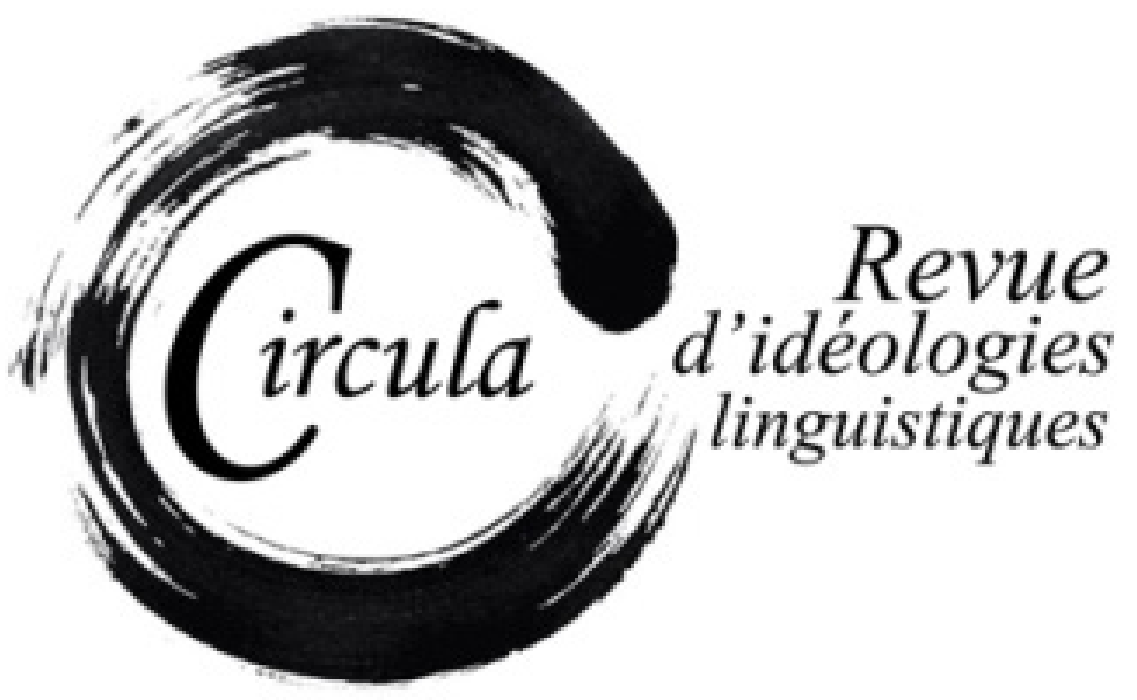

TITRE: LA NORMA LINGUISTICA NELL'EPOCA DEI SOCIAL NETWORK: DA PETALOSO A SCENDIIL CANE Auteur: GIANLUCA FRENGUELLI, UNIVERSITÀ DEGLI STUDI DI MACERATA

RevUe: CIRCULA, NUMÉRO 11

PAgES: $85-105$

ISSN: 2369-6761

URI: HTTP://HDL.HANDLE.NET/11143/17842

DOI: HTTPS://DOI.ORG/10.17118/11143/17842 


\section{La norma linguistica nell'epoca dei social network: da petaloso a scendi il cane}

Gianluca Frenguelli, Università degli studi di Macerata gianluca.frenguelli@unimc.it

Riassunto: Con l'avvento dei moderni mezzi di comunicazione di massa e, soprattutto, dei social network, le dispute linguistiche hanno assunto attori e prassi completamente diversi rispetto al passato: dalle accademie il dibattito si è ormai trasferito su internet e sui giornali, coinvolgendo un pubblico non specialista, ampio e diversificato per composizione e livello d'istruzione, il quale ha profondamente cambiato le modalità con cui vengono affrontate le questioni relative alla norma.

Attraverso l'analisi di alcune di dispute linguistiche salite agli onori della cronaca in questi ultimi anni, il contributo si propone di tracciare i nuovi percorsi e di comprendere i nuovi modi in cui si sviluppa ai giorni nostri il dibattito sulla norma linguistica, sia nei media tradizionali, sia nei Social media.

Parole chiave: norma linguistica; dibattito sulla lingua; italiano standard; Accademia della Crusca

Abstract: With the advent of modern mass media and, above all, of social networks, linguistic disputes, have acquired completely different actors and practices: from the academies the debate has now moved to the internet and the newspapers, involving a non-specialist public, broad and diversified in composition and level of education. This has deeply changed the ways in which norm-related issues are addressed.

Through the analysis of some of the linguistic disputes that have gained resonance in recent years, this paper aims to explore the new ways in which the debate on the linguistic norm is developing, both in the traditional and in social media.

Keywords: linguistic standard; debate on the language; standard Italian; Accademia della Crusca 


\section{Introduzione: la norma non è un monolite}

Il dibattito linguistico intorno alle questioni grammaticali è nato con lo studio della grammatica. Le dispute nascono infatti quando nasce la grammatica di senso specifico e di natura empirica, quale si è poi trasmessa a noi. Si pensi, ad esempio, alla controversia, scaturita dal problema del linguaggio ( prodotti della fantasia, e analogisti, che riducevano i fatti linguistici a fatti logici. Tra gli argomenti più frequentati del dibattito grammaticale, un posto di primo piano è occupato dalle discussioni sulla norma, le quali si articolano in una pluralità di aspetti e di problemi ${ }^{1}$.

Partiamo dalla definizione di norma linguistica e dalla sua espressione sociolinguistica principale: la lingua standard. In Italia lo standard tradizionale, l'italiano standard letterario, vale a dire l'italiano codificato dalla tradizione grammaticale e scolastica, ha un'impronta elitaria e letteraria, conseguente ai ben noti fattori storici di lunga durata, e si colloca nettamente più in alto a sinistra rispetto al centro geometrico dello schema linguistico di Berruto (1987), schema che costituisce ancora, con alcuni aggiustamenti, una valida rappresentazione della struttura dell'italiano contemporaneo. In effetti, fino a un recente passato la nostra lingua era principalmente scritta e fondata su modelli letterari: di conseguenza era molto conservativa. Tale è rimasta a lungo: fattori evolutivi sono stati nel Settecento l'influsso del francese, nell'Ottocento la "rivoluzione" democratica del Manzoni. Nel secolo scorso, dalla fine degli anni sessanta si è progressivamente affermata una varietà d'italiano innovativa nel lessico e nelle scelte morfosintattiche, alla quale si è dato il nome di neostandard, in una contrapposizione, per alcuni aspetti affrettata e poco fondata, con un italiano definito ancien règime. Comunque sia l'italiano neostandard è entrato nella cosiddetta "area della norma".

Vero è che oggi, a 30 anni dalla pubblicazione della Sociolinguistica dell'italiano contemporaneo, il concetto di neostandard è tutt'altro che scontato. I caratteri di questo registro medio della lingua, distinto dalla norma stabilita dalla tradizione e largamente condiviso da ampi strati di popolazione, sono interpretati diversamente dagli studiosi. Due anni prima del saggio di Berruto, tale varietà è stata descritta nei suoi tratti innovativi da Francesco Sabatini (1985), al quale si deve la denominazione di italiano dell'uso medio". Ancor prima, Mioni (1983), ha descritto l'italiano tendenziale. Non senza toni polemici Castellani (1991) ha parlato di italiano senza aggettivi. A ben vedere questa varietà della nostra lingua, presenta confini tuttora non chiaramente stabiliti e classificazioni incerte dei fenomeni

1. Non ci si soffermerà qui sulle tappe di questo dibattito, peraltro esaustivamente definite da Vitale (1978) al quale si rinvia; un'ampia sintesi si trova anche in Marazzini (2009). 
che la riguardano. Anche se vari studiosi si sono occupati di precisarne le caratteristiche², la maggior parte di questi contributi si proponeva di definire e delimitare «quello che può essere considerato il risultato finale della forte accelerazione che ha interessato il riassestamento della norma linguistica in Italia a partire dal secondo dopoguerra. I cambiamenti sociali dovuti all'industrializzazione e alle migrazioni interne, unitamente all'alfabetizzazione (con tutti i limiti che persistono tutt'oggi) e all'italianizzazione della popolazione, così ben descritti da Tullio De Mauro (2014), hanno determinato la grande pressione del parlato sulla scrittura, fino a quel momento unica» (Ondelli e Romanini, 2018: 186).

Riprendendo una definizione di Claudio Giovanardi, la norma linguistica può essere considerata "come un insieme di regole, che riguardano tutti i livelli della lingua (fonologia, morfologia, sintassi, lessico, testualità), accettato da una comunità di parlanti e scriventi (o per lo meno dalla stragrande maggioranza) in un determinato periodo e contesto storico-culturale» (Giovanardi, 2010: 17). Tale principio risale a Eugenio Coseriu, secondo il quale la norma è costituita dalla media delle realizzazioni individuali che i parlanti adottano all'interno delle possibilità offerte, in astratto, dal sistema; secondo lo studioso, insomma, la norma non è quella «stabilita od imposta secondo criteri di correttezza e di valutazione soggettiva di quel che viene espresso», ma quella «che seguiamo necessariamente se vogliamo essere membri di una comunità linguistica» (Coseriu, 1971: 76). Tale natura sociale della norma fa sì che essa costituisca, in un certo senso, la somma delle sensibilità linguistiche di tutta la popolazione.

Luca Serianni paragona la norma al comune senso del pudore, il quale, benché definito da una legge, muta con il mutare dei costumi e della sensibilità: «il concetto di pudore è andato e va soggetto a interpretazioni varie presso i tecnici del diritto: una situazione che poteva consigliarne l'applicazione in un ambiente rurale della Sicilia negli anni Cinquanta non potrebbe evidentemente valere nella

\footnotetext{
2. Per una definizione di carattere linguistico della norma, appare utile la consultazione di Siouffi / Steuckardt (2007). A proposito del dibattito sulla norma dell'italiano, v. almeno D’Achille (2010). Nel ricordare i punti principali di tale dibattito, possiamo citare : Dardano (1994); Galli de' Paratesi (1998), Antonelli (2011), Cortelazzo (2012), Arcangeli (2014) e il cap. V di Tomasin (2019) per aspetti generali riguardanti il rapporto tra norma e uso; Simone (1993) e Tavoni (2002) per quanto concerne la ristrutturazione del sistema verbale (cfr. anche D'Achille, 2011); Cortelazzo (2000: 16-21) sui pronomi; Renzi (2012: 37-76) si concentra soprattutto sulle dislocazioni; D’Achille/Proietti/Viviani (2005) e D’Achille (2014) sulla frase scissa. La situazione riguardante lo standard dell'italiano e delle principali lingue romanze è affrontata in Lebsanft/ Take 2020. Si vedano anche Settekorn (1988) e Winkelmann (1992) a proposito del francese, Lebsanft et al. (2012) per lo spagnolo. La norma dell'inglese è analizzata in Locher / Strässler (2008).

3. In Coseriu (1969: 250) si parla di norma «dipendente dall'estensione e dall'indole della comunità considerata». Gioverà illustrare brevemente la triade coseriana: con parole, lo studioso intende l'insieme degli atti linguistici considerati al momento della loro produzione; la norma rappresenta un primo grado di astrazione e comprende solo ciò che, nel parlare concreto, è ripetizione di modelli anteriori, vale a dire gli aspetti comuni costanti negli atti linguistici e nei loro modelli, al netto di tutto ciò che è inedito, variante individuale o occasionale e momentanea; il sistema, che rappresenta il secondo grado di astrazione, contiene solo ciò che nella norma è indispensabile e funzionalmente pertinente, senza considerare ciò che è abitudine, tradizione, elemento comune nel parlare della comunità. Sul concetto di norma nello studioso moldavo si veda la dettagliata analisi di Kabatek (2020).
} 
Milano del 2006. Allo stesso modo un repertorio grammaticale di cinquant'anni fa poteva deplorare innocui francesismi oggi stabilmente radicati nel lessico» (Serianni, 2006: 41-42).

In quanto «convenzione sociale e prodotto della storia», la norma presenta i caratteri di variabilità e relatività. La stessa nozione di errore, inteso come violazione della norma che provoca una sanzione sociale, è piuttosto uno scarto, una deviazione dal sentiero tracciato dal modello linguistico vigente: spesso «l'idea di correttezza o di scorrettezza nasce dalla continuità e dalla ripetizione automatica di un certo atto, per cui una maniera contraria è ritenuta insolita, disdicevole, sbagliata» (Beccaria, 2010: IX e 34)4. Apparirà superfluo ricordare che il rapporto tra ciò che è considerato giusto e ciò che è considerato sbagliato muta nel tempo e forme linguistiche ritenute errate possono entrare a far parte dello standard o, viceversa, ciò che era un tempo accettato può cadere in disuso, a volte fino a divenire errore. Va però detto che tale evoluzione in italiano è sì continua, ma lenta; tali processi richiedono più decenni, talvolta secoli. Inoltre, nel passato, numerose innovazioni sono state rifiutate dai grammatici in nome di una norma rigida, codificata una volta per tutte sulla base dei grandi modelli trecenteschi e mantenuta viva da una fiorente tradizione grammaticale.

Bisogna dire che tale situazione dipende in parte anche dalla nostra grammaticografia, soprattutto di quella di destinazione scolastica, la quale, come ricorda Bachis (2019: 135), nel corso del Novecento appare caratterizzata, «più che da un'evoluzione, da un'immobilità di fondo». Tale situazione è «la diretta conseguenza di una comunicazione non completa tra il mondo della ricerca linguistica e quello della pratica scolastica», ed è perdurata almeno fino alla fine degli anni Ottanta, anche se ancora oggi, «nonostante una grammatica dell'uso non sia completamente assente dai testi presi in considerazione, va segnalato che questa, tuttavia, non costituisce la normalità; anzi, spesso rappresenta un'eccezione. La lingua proposta che emerge è una lingua in molti casi non realistica, da studiare, non da parlare né da scrivere, insomma non da "usare"» 5 .

4. Tale idea è presente anche in Sgroi (2010: 26), per il quale «il problema dei (neo)puristi è quello di etichettare come "errori" usi linguistici che al massimo sono etichettabili come "sbagli", sia perché semanticamente del tutto comprensibili, sia perché a un tempo prodotti da parlanti per definizione non-subalterni, colti o mediamente colti, e quindi non attribuibili all'italiano cosiddetto "popolare".»

5. Bachis (2010-2011: 345), la quale prende in considerazione il trattamento di alcuni fenomeni morfosintattici che, pur rientrando pienamente tra le strutture dell'italiano, sono stati per secoli esclusi dalla cosiddetta area della norma. L'analisi, condotta su quattordici grammatiche scolastiche scelte tra le più adottate nell'anno scolastico 2011/2012 nella scuola secondaria di I e di II grado, conferma sostanzialmente le impressioni di Serianni (2010): «con gli anni Ottanta il livello è migliorato, ma il libro di grammatica mantiene ancora oggi alcuni difetti strutturali, legati non solo alla forza dell'inerzia, ma anche all'intento - espressamente raccomandato dai committenti editoriali - di non discostarsi dalla tradizione per non turbare l'orizzonte d'attesa di molti insegnanti, rischiando di compromettere le adozioni». Ancor più negativa è la situazione secondo De Roberto (2020: 326): «surveys conducted on grammars for schools in the last two decades have shown that grammarians often propose entirely outdated prescriptions, inspired by a rigid logicism [...]. The features of neostandard Italian are not always welcomed». 
Ma torniamo ai giorni nostri. Serianni (2014: 236) individua tre livelli della norma:

a) norma comunemente condivisa, la cui violazione non è ammessa in nessun livello della lingua;

b) norma scolastica, la cui caratteristica è quella di mantenere in vita (soprattutto nella scrittura) forme chiaramente obsolete e, in generale, di sanzionare il livello diafasico colloquiale, persino nelle situazioni in cui sarebbe l'unico appropriato;

c) norma microcomunitaria, esclusivamente orale e di carattere sociale anziché culturale: si tratta della norma cui si aderisce grazie al prestigio linguistico del «gruppo dei pari», e che diventa modello normativo preminente rispetto a quello scolastico e familiare.

La maggior parte dei parlanti comuni di livello culturale basso o medio-basso, a volte usciti dalla scuola con un'imperfetta alfabetizzazione, avrà una competenza "a macchia di leopardo" del livello b) e avrà come norma-modello quella del livello c); i parlanti di livello culturale medio-alto, i quali tuttavia non hanno compiuto, se non in rari casi, approfondite riflessioni sulla lingua, avranno come modello il livello b), vale a dire rimarranno ancorati a principi (o precetti), acquisiti durante gli anni della scuola.

Per una valutazione complessiva della norma, altri elementi importanti sono la crescita dell'alfabetizzazione, giunta al suo culmine nella seconda metà del secolo scorso, e la crescita delle occasioni di uso informale della lingua scritta, provocata dall'informatizzazione di massa, la quale ha avuto come conseguenze: a) una deproblematizzazione dell'atto scrittorio; b) la modificazione del rapporto tra lo scrivente e la norma; c) la diffusione contaminante di usi grafici e consuetudini linguistiche (Prada, 2015: 13). Tale processo rientra nel cosiddetto whateverismo linguistico, teorizzato da Baron (2002 e 2008), ovvero un disinteresse generalizzato scarso per la forma a favore del contenuto (per la spiegazione del fenomeno v. Gheno, 2019).

Questa situazione, fluida e in fase di grande accelerazione, ha portato, tra l'altro, grazie all'avvento dei social network (Facebook, in primo luogo, ma anche Twitter), a un ampliamento del dibattito linguistico sulla norma. Inoltre, dato che numerose istituzioni di carattere linguistico (prima fra tutte l'accademia della Crusca ${ }^{6}$ ) hanno da tempo iniziato a sfruttare questo nuovo mezzo, le dispute linguistiche hanno assunto attori e prassi completamente diversi rispetto al passato: dai trattati sulla lingua e dalle accademie, il dibattito si è ormai trasferito sui media tradizionali prima, successivamente su internet, coinvolgendo un pubblico ampio e diversificato e, soprattutto, non specialistico. II che ha profondamente cambiato le modalità di discussione e, in primo luogo, la percezione dei fatti di lingua. Tali fenomeni sono dovuti anche ai già menzionati tratti intrinseci al concetto di norma, che non risultano affatto chiari a un pubblico non specialistico, e che portano a fraintendimenti. Ai

6. Il sito dell'Accademia della Crusca è stato inaugurato nel 2012. Allo stesso anno risale il debutto sui social (il primo tweet è datato 7 novembre). 
nostri giorni tale situazione si avverte nell'incremento del dibattito sulla lingua nei media tradizionali (De Santis et. Fiorentino, 2018), e, soprattutto, nella rete.

Esaminiamo da vicino i caratteri e le modalità del fenomeno. Il percorso che ho tentato di delineare si snoda in tre tappe. Una questione, partita dalle pagine di consulenza linguistica del sito dell'Accademia della Crusca o dalle sue popolari pagine social, apre le discussioni, suscitate principalmente da tre ordini di motivi: i) una lettura o un'interpretazione disattente dei post dell'Accademia da parte degli utenti; ii) una risposta non netta dell'Accademia a una domanda del tipo "si può dire/ non si può dire?"; iii) una generale ignoranza, da parte degli utenti dei social, delle strutture e degli usi della nostra lingua e, in particolare, della norma linguistica. La questione si trasferisce successivamente ai media tradizionali (cartacei e non) e da questi rimbalza sulle stesse pagine social da cui è partita, ma con una zavorra di malintesi che alimenta le discussioni in atto. Dall'altro versante, il dibattito tra gli specialisti rimane per lo più confinato alle sedi abituali, mediante gli scambi con la posta elettronica, ma a un livello prevalentemente privato e personale.

Pertanto, come nel gioco del telefono senza fili, durante questo percorso nascono malintesi, ulteriori dubbi e incomprensioni, dovuti in primo luogo all'azione della stampa, la quale, anche sui temi di carattere linguistico, mira più al sensazionalismo che non alla correttezza delle notizie riportate e si avvale di giornalisti che, in quanto a competenza linguistica, sono generalmente piuttosto carenti ${ }^{7}$. È il più delle volte la stampa a innescare le reazioni di un pubblico eterogeneo socialmente e culturalmente, incapace di percepire la portata dei fenomeni: in particolare le dinamiche riguardanti la norma, la differenza tra norma e uso, l'esistenza di registri linguistici diversi, la necessità di denominare muovi referenti ecc. D’altro canto, ci sono utenti strenuamente attaccati alla norma tradizionale, nella quale identificano la tenuta stessa della lingua. Si tratta, in questo caso, di un atteggiamento millenaristico che, fondandosi su nozioni acquisite negli anni della scuola, porta tali soggetti a indignarsi di fronte a ogni minimo scarto da quelle che si considerano regole sacre e inviolabili, interiorizzate nell'infanzia, e a lasciarsi andare a reazioni eccessive, non commisurate all'importanza della questione. L'evoluzione dell'italiano e della sua norma viene descritta da costoro come una forma di corruzione che avrebbe portato all'imbarbarimento e all'impoverimento della lingua ${ }^{8}$. Entrambe queste posizioni rivelano una percezione della norma che rimane, nella coscienza dei parlanti, un monolite. Da distruggere a picconate da un lato, da conservare intatto dall'altro.

7. Soltanto per citare i giornalisti i cui brani riporteremo in questo contributo, Massimo Gramellini dopo il diploma di liceo ha intrapreso studi di giurisprudenza, presto interrotti, ed è stato a lungo giornalista sportivo; Deborah Dirani è laureata in lettere, ma con indirizzo antropologico; Ida Artiaco nel suo profilo pubblicato su internet si definisce «napoletana nel cuore, romana nella vita» e dice di occuparsi di startup, tecnologia, istituzioni e attualità; infatti dopo alcune esperienze in Tv e in quotidiani cartacei, è approdata sul web e ha co-fondato un magazine dedicato alla tecnologia indossabile.

8. A proposito dei quesiti posti al foglio "La crusca risponde", Serianni (2006), parlando dell'iperreattività del parlante, mostra come «il 'sentimento linguistico' da cui muovono i quesiti è spesso fondato su basi precarie, ispirate a un astratto logicismo e nutrito della convinzione di un'inarrestabile decadenza dell'italiano. Il giudizio iper-puristico di certi parlanti su ciò che è 'scorretto', pur essendo segno di una "lealtà" nei confronti della propria lingua, si rivela tuttavia assai discutibile». 
La maggior parte dei parlanti è all'oscuro della natura dinamica della norma e pretende da coloro che ritiene i depositari della norma «risposte chiare e univoche, che distinguano sistematicamente ciò che è giusto da ciò che è sbagliato» e «regole semplificate e incontrovertibili, valide in ogni occasione», rifacendosi a quel modello di italiano - standard e letterario - insegnato nella scuola fino ad alcuni decenni or sono. Raramente il linguista potrà rispondere in maniera univoca a quesiti sulla norma, perché in una lingua viva e parlata da quasi tutti gli italiani in quasi tutti gli usi comunicativi, «la norma si rifrange in una pluralità di norme» (Antonelli, 2016: 46).

Come si forma oggi la coscienza della norma linguistica nella maggioranza dei parlanti? quali sono i punti di riferimento a cui il parlante guarda per sapere cosa è giusto e cosa è sbagliato?

Quello che, a mio avviso, costituisce lo spartiacque tra il "vecchio" modo di concepire i dibattiti linguistici e il modo "nuovo" che sto cercando di descrivere in questa occasione, è il caso riguardante l'emblematico petaloso. Prima di esporre i particolari del noto affaire ricordo un dato significativo: le richieste di consulenza all'Accademia della Crusca sono state 394 nell'anno 2015, ben 5818 nel 2016 anno di petaloso: per chi ama i numeri dirò che l'incremento è stato del $1377 \%$.

\section{Petaloso}

Matteo, un alunno di terza elementare, ha come compito scrivere delle frasi ognuna delle quali deve contenere due aggettivi. Una di queste frasi suona cosi: fiore profumato petaloso. Ohibò, il bimbo intendeva dire 'che ha molti petali', 'ricco di petali': errore, errore certamente, ma un errore che deriva dall'applicazione di una regola della formazione delle parole piuttosto produttiva: boria > borioso, coraggio > coraggioso ecc. ecc. L'intraprendente educatrice decide di fare di quell'errore un'occasione didattica, esortando il bambino a chiedere un parere all'Accademia della Crusca, e compiendo in tal modo un'operazione doppiamente meritoria: insegnare alla sua classe che esiste un'istituzione in grado di dare indicazioni in materia di problemi linguistici e mostrare loro che tale istituzione non è un'entità soprannaturale, ma un interlocutore a cui è possibile rivolgersi per avere delle risposte. La maestra è troppo giovane per ricordare che nel 1983 la Fiat dedicò alla Uno lo slogan che conteneva gli aggettivi comodosa, sciccosa, risparmiosa, scattosa. La Crusca, per mano di Maria Cristina Torchia, risponde in maniera inappuntabile, dal punto di vista sia linguistico, sia didattico. Spiega che petaloso è una parola possibile in italiano, ma non è tuttavia sufficiente che una parola sia «bella e chiara» perché entri nei vocabolari e diventi patrimonio comune: «non sono gli studiosi, quelli che fanno i vocabolari, a decidere quali parole nuove sono belle o brutte, utili o inutili. Quando una parola nuova è sulla bocca di tutti (o di tanti), allora lo studioso capisce che quella parola è diventata una parola come le altre e la mette nel vocabolario».

La questione finisce sui media e, grazie alle scarse competenze dei nostri giornalisti in materia di norma linguistica, si genera un primo equivoco, vale a dire che la scelta di inserire la parola nel vocabolario della nostra lingua dipenda dall'Accademia. L'idea che ha percorso i mezzi di comunicazione 
di massa in quel periodo era che se ci fossero state tante richieste la Crusca avrebbe inserito la parola nel suo vocabolario. Ciò ha portato alla nascita dell'hashtag \#petaloso, che in breve tempo si propaga divenendo, come si dice, con encomiabile neologismo semantico, "virale".

Non appena si è diffusa la notizia, sono emerse tre "fake news", evidentemente già circolanti in maniera sotterranea tra gli utenti. Esse sono: 1) che la Crusca pubblica ancora il suo vocabolario; 2) che sia la stessa Crusca a decidere, sulla base della loro diffusione nei social network e dei like che ricevono, quali parole inserirvi: si pensa insomma che una parola abbia successo e sia inclusa nel vocabolario se riceve tanti «mi piace», con un trasferimento ai meccanismi linguistici dell'ottica dei Like propria dei social networks; 3) che grazie alla lettera del bambino, la Crusca abbia deciso di candidare petaloso tra le voci da aggiungere al vocabolario.

A questo punto, la notizia rimbalza sui media tradizionali, specchio deformante abituato a deformare sia per amore di sensazionalismo, sia per ignoranza sull'argomento. Una giornalista dell'"Huffington Post", Deborah Dirani, apre così il suo articolo, intitolato I Bambini non sono Petalosi geni, neanche se a dirlo è l'Accademia della Crusca:

"Il re è morto. Viva il re". Peccato che il re morto fosse un alessandrino genio della parola e il suo designato erede sia un bambino di Copparo che da stamattina viene additato come piccolo e formidabile eroe della lingua italiana poiché ha ottenuto (con la complicità della sua baldanzosa maestra) nientepopòdimenoche un riconoscimento dall'Accademia della Crusca.

Tuttavia, come abbiamo visto, il riconoscimento ottenuto dalla Crusca, che desta tanto scandalo nella giornalista, non è un diploma né una targa, ma una semplice lettera di risposta nella quale si dice che la parola è "bella". Un altro intervento supponente e disinformato è quello pubblicato sul blog de "Il fatto quotidiano" da Elisa D'Ospina, sedicente scrittrice (che già in questo breve lacerto dà prova delle sue qualità), ospite fissa della trasmissione televisiva "Detto fatto", la quale ci ricorda che:

\footnotetext{
"Petalous - having petals". Esisteva già nel dizionario inglese la parola "petaloso", bastava fare una piccola ricerca e si scopriva con estrema facilità che sono secoli che all'estero già esisteva come aggettivo. Indubbiamente la storia del piccolo Matteo è più ricamata, più romantica e porta alla luce la voglia di condividere il bello.
}

Quasi che il fatto che una parola esista in un'altra lingua, implichi che tale parola vada accolta nella nostra. Da qui a trovare su un blog dedicato alla scuola (tecnicadellascuola.it) un intervento che definisce petaloso "un altro prestito dall'inglese", il passo è breve. Intanto, la notizia dell'accoglimento da parte della crusca di petaloso finisce su «Le monde», su «El País», persino sul sito della BBC. È inevitabile che, con un tale lancio mediatico (sui social e in particolare sul profilo Facebook dell'Accademia), la questione esploda, dando luogo ai commenti più disparati: da «non si può sentire», quasi rituale nel caso di parole ed espressioni nuove, ai vari «dov'era la Crusca quando Banderas inventava 
inzupposo», «basta con i bambini ignoranti», «ai miei tempi anche il bidello mi avrebbe impedito di dire petaloso»; si passa poi a consigli rivolti a Claudio Marazzini («caro presidente mi pare esagerato ammetere queso [sic] aggettivo sul vocabolario!»), a dubbi sulla serietà dell'Accademia («Ho deciso che da oggi inizierò a dire che i treni sono ruotosi, che i libri sono paginosi e chi più ne ha più ne metta. Chissà, magari uno di questi termini prima o poi diventerà una parola...va bene il gioco, tutto molto simpatico ma siamo seri per favore»; tra l'altro, questo post riceve ben 24 like), a dubbi di carattere complottista («Voglio sapere di chi è parente il bambino Matteo!»), a vere e proprie contestazioni («...adesso abbiamo ben focalizzato in che mani sta la nostra povera lingua. \#anticrusca», «A parte l'inzupposo pubblicitario che sicuramente avrà influenzato un bambino di 9 anni, io fin da ragazzino uso il termine Palloso, sarò mica un genio? Chissà quanto ci costa tutta questa autorevole saccenza autoreferenziale!»); qualcuno giunge persino al turpiloquio e agli insulti («Ma che merda di aggettivo. Ma non è che dobbiamo creare parole solo perché un bambino ha detto una boiata...» e « Ma andate a zappare»). Dall'altro versante abbiamo commenti favorevoli («Ė così che dovrebbero essere tutti gli insegnanti! Petaloso esiste, usiamolo!») o improntati a un benaltrismo solidamente radicato nella mentalità italiana («Ma quanti siete tristi!!! Ma fatevela una risata e ricordate che, i problemi dell'Italia sono altri e che per quelli dovreste indignarvi e, non per la fantasia e l'ingenuità di un bimbo!!!»).

Per dare un'idea della popolarità del tema su Facebook, segnalo che un post satirico su petaloso, pubblicato nella pagina "se i quadri potessero parlare", cioè su una pagina non specializzata, ottiene circa 29.000 reazioni, 1200 commenti, 17000 condivisioni

La Crusca, per mano di Vera Gheno, all'epoca social media manager dell'Accademia, ha dovuto pubblicare un post sulla vicenda, nel quale sono confutate punto per punto tutte le false notizie che diffuse dalla stampa e dai social media ${ }^{10}$.

Al di là delle diverse opinioni (per lo più disinformate) di vari giornalisti, l'intervento più inappropriato è stato quello dell'allora Presidente del Consiglio, Matteo Renzi, che ha cavalcato l'onda del momento e, servendosi a fini di propaganda della parola messa in circolo dal suo piccolo omonimo, ha infilato nel corso di un suo intervento al Piccolo Teatro di Milano una serie di asserzioni ridicole e prive di senso, che dimostrano come l'ex Sindaco di Firenze non avesse la più pallida idea di quali siano i compiti di una delle principali istituzioni culturali italiane. Ecco la trascrizione (miei i corsivi):

9. Si tratta di un'immagine del dipinto "Donna che tiene un fiore" di Augustus Jules Bouvier, il quale reca, nella didascalia l'esclamazione «Com'è petaloso questo fiore!». Il post è consultabile all'indirizzo https://www.facebook.com/seiquadripotesseroparlare/photos/a.1425498444346582/1765217803707976

10. La stessa Gheno, in Social-linguistica, sintetizza compiutamente la questione: «Purtroppo, per vari motivi, la notizia subisce una fondamentale distorsione: invece di considerarlo un semplice e innocente gioco linguistico e mediatico, il messaggio compreso da molte persone è che la Crusca abbia approvato petaloso e l'abbia inserito nel suo Vocabolario. Per questo, occorre chiarire che in Italia non esiste un ente addetto alla cernita dei neologismi; [...] In secondo luogo, la Crusca ha terminato la sua attività lessicografica nel 1923 [...]; sarebbe quindi proprio impossibile per l'Accademia inserire una parola nel dizionario, dato che non ne compila» (Gheno, 2017: 68). 
leri è uscita una notizia abbastanza strana, che a me è piaciuta moltissimo. Ce l'ha raccontata l'Accademia della Crusca. Un bambino di 8 anni, di Ferrara, ha scritto insieme alla sua maestra, la sua insegnante - e dobbiamo dire brava alla sua insegnante, oltre a quel bambino -, una lettera all'Accademia della Crusca. Ovviamente l'idea di scrivere all'Accademia della Crusca immagino sia venuta all'insegnante. Ma quel bambino aveva scritto una parola, aveva coniato una parola, la parola petaloso, che l'Accademia della Crusca, dopo una lunga discussione tra i propri grandi esperti, ha ritenuto essere una parola che deve entrare nel vocabolario italiano. E allora quella parola, ieri i social della Crusca, e anche questa la dice lunga, i social network della Crusca hanno rilanciato la notizia e la parola petaloso è entrata dentro il grande vocabolario della lingua italiana, coniata da un bambino di 8 anni. Beh, questo progetto è un progetto petaloso, questo progetto è un progetto che ha più di un ambito di azione, è un progetto che davvero possiamo definire con questa espressione.

\title{
Siedi il bambino, ma con prudenza
}

Il secondo episodio che citerò in questa occasione riguarda l'espressione siedi il bambino, di origine tipicamente meridionale, ma diffusa un po' in tutta Italia, come mostra l'immagine, che riporta le risposte del quesito 16 di un'inchiesta dialettologica dell'Aliquot ${ }^{11}$.
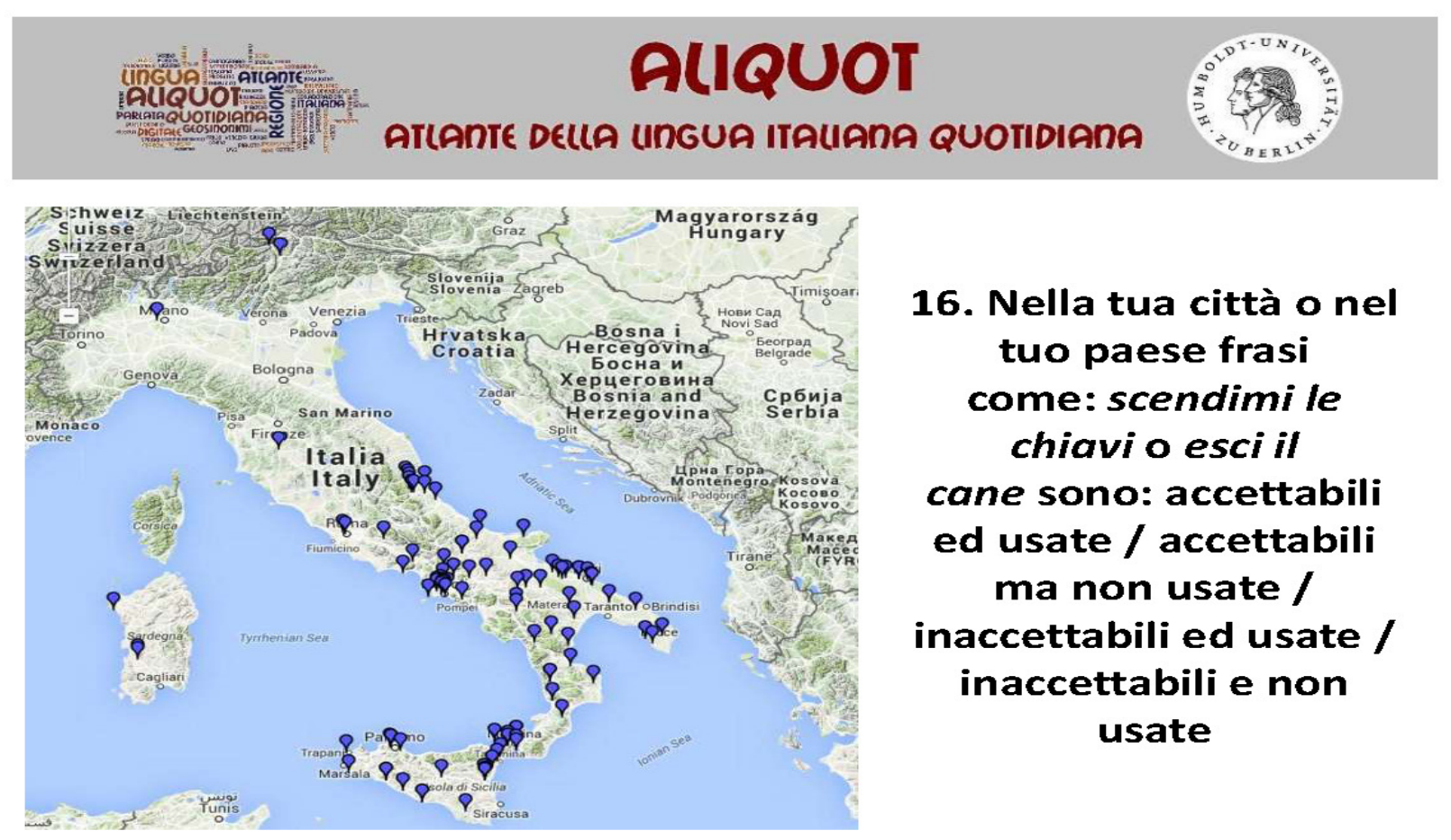

\author{
16. Nella tua città o nel \\ tuo paese frasi \\ come: scendimi le \\ chiavio esci il \\ cane sono: accettabili \\ ed usate / accettabili \\ ma non usate / \\ inaccettabili ed usate / \\ inaccettabili e non \\ usate
}

FIG. 1: DIFFUSIONE DELL'USO TRANSITIVO DI SCENDERE E USCIRE SECONDO L'ALLQUOT

11. Ripresa da Coluccia (2017). 
L'11 gennaio del 2019, Vittorio Coletti risponde su un dubbio espresso alla pagina di consulenza dell'Accademia, a proposito della correttezza dell'uso transitivo di alcuni verbi intransitivi (e riguardante, in particolare, espressioni come siedi il bambino). Ma non si tratta di una questione semplice, che, peraltro, si presenta in altre lingue europee.

Come riporta Maurizio Dardano in un suo recente intervento sul Corriere del Ticino (3/2019), Assoisle!, 'siedilo' (il bambino) è un uso normale nel francese; frequenti sono le espressioni: descendre les valises, 'scendere le valigie', e sortir la voiture, 'uscire l'auto', cioè farla uscire (dalla rimessa). Quanto al "cane" le cose sembrano andare diversamente: sors le chien, vuol dire 'prendilo e portalo fuori' invece fais sortir le chien vuol dire 'fallo uscire' (ma il padrone può anche rimanere a casa). Si noti tuttavia che in francese il costrutto non si applica a nomi con tratto [+ umano]; vale a dire, è possibile sors le chien ma non sors ma tante. Vediamo altri esempi: tomber, è un verbo intransitivo, eppure già nel secolo scorso il francese parlato conosceva: tomber l'adversaire (espressione proveniente dal pugilato), 'far cadere l'avversario', 'abbatterlo (a suon di pugni)'. Nel parlato si dice comunemente: j'ai tombé mon livre 'ho fatto cadere il libro', je tombe ma veste, 'mi tolgo la giacca'. In spagnolo sono possibili: bajar el perro, 'scendere il cane' (cioè farlo scendere dalle scale di casa e portarlo a spasso) e sentar al niño, 'sedere il bambino'; tuttavia in spagnolo "bajar" e "asentar" sono transitivi. Venendo all'inglese, il verbo intransitivo to sit (down) può anche essere usato con valore causativo: sit the baby down, 'siedi il bambino'. Ma, come accade in altre lingue germaniche, to sit ha in to seat il suo corrispondente transitivo: I'll seat John near her, 'farò sedere John vicino a lei'.

Per quanto riguarda la nostra lingua, si noti che è possibile (nel parlato, naturalmente), siedi il bambino, ma non siedi lo zio (si dirà piuttosto fai sedere lo zio), scendi la valigia, ma non scendi la suocera (si dirà piuttosto fai scendere la suocera). Vale a dire, l'uso transitivo di verbi di movimento intransitivi è possibile soltanto con soggetti che non presentano capacità di movimento autonomo.

Tornando alla risposta dell'Accademia della Crusca, questa si limita ad analizzare la questione e naturalmente è priva di qualsiasi indicazione di carattere prescrittivo. Anzi, se non si leggono con attenzione la premessa e la conclusione, sembra effettivamente che si sdogani l'uso del costrutto in tutte le varietà della lingua. Si inizia avvertendo il lettore che quesiti come quello posto

evocano situazioni, per cosi dire, tutte di ambito domestico, spesso caratterizzato da rapidità di linguaggio per affrontare determinate circostanze, ad esempio quando c'è urgenza di far sedere, mettere seduto, posare su una sedia o un divano un bambino, magari piangente

e si conclude con un'affermazione tutto sommato all'insegna della prudenza:

Diciamo insomma che sedere, come altri verbi di moto, ammette in usi regionali e popolari sempre più estesi anche con l'oggetto diretto e che in questa costruzione ha una sua efficacia e sinteticità espressiva che può indurre a sorvolare sui suoi limiti grammaticali. 
Tuttavia, nella parte centrale dell'articolo la risposta al quesito mostra tutt'altro atteggiamento:

Ė lecita allora la costruzione transitiva di sedere? Si può rispondere di sì, ormai è stata accolta nell'uso, anche se non ha paralleli in costrutti consolidati con l'oggetto interno come li hanno salire o scendere (le scale, un pendio). Non vedo il motivo per proibirla e neppure, a dire il vero, per sconsigliarla. Ma certo è problematico definirla transitiva

Questa affermazione, associata a una conclusione "non schierata", ha tratto in inganno tutti. Forse il linguista, sapendo di non parlare a un pubblico di specialisti, avrebbe potuto specificare con maggior chiarezza che tale espressione, possibile nel parlato informale, non lo è certamente nello scritto e nel parlato formale. "Siedi il bambino": ma con prudenza, verrebbe insomma voglia di aggiungere.

L'imprecisione dell'Accademia suscita nuovamente polemiche. Nella stampa italiana è stato un tema di primo piano per diversi giorni. Innanzi tutto perché il parlante comune si aspettava dalla Crusca qualcosa di diverso da una descrizione dello status quo sociolinguistico. Inoltre, a causa della sintesi rozza che fin dall'inizio è stata fatta da molti giornalisti, una sintesi che è divenuta verità, si è sentita ripetere in televisione e negli altri media la stessa conclusione: ormai gli alunni possono scrivere scendi il cane, esci l'auto, siedi il bambino perché la Crusca li ha sdoganati; vediamo a mo' di esempio alcuni passi di un articolo a firma di Ida Artiaco, pubblicato nella testata online Fanpage:

Dire "esci il cane" e "siedi il bambino" non è più sbagliato: la decisione della Crusca// L’Accademia della Crusca e la rivincita del Sud Italia: espressioni come "esci il cane", "entra i panni" e "siedi il bambino" sono corrette perché, nonostante si tratti di verbi di movimento generalmente intransitivi, "in questa costruzione hanno una loro efficacia e sinteticità espressiva che può indurre a sorvolare sui limiti grammaticali” [...].

L’Accademia della Crusca fa un regalo a tutti coloro che parlano i dialetti del Sud Italia. Da oggi espressioni di uso comune come "siedi il bambino", "esci il cane" o "entra i panni", molto diffuse proprio nelle regioni meridionali, non saranno più considerate sbagliate.

Analoga affermazione troviamo nuovamente nel titolo di un blog per insegnanti della scuola.

In alcuni casi la notizia è accompagnata da un atteggiamento derisorio nei confronti dell'Accademia. Un esempio per tutti è quello di Massimo Gramellini, che ha scritto un "Caffè" decisamente poco divertente, perché guidato anch'esso dall'ignoranza dei fatti:

A me un po mi dispiace tanto che il presidente dell'H-demmia della Crusca habbia fatto marcia nel didietro e coretto a uno dei suoi ex-ponenti più lustri, il professor Coletti. Il cuale, come anno letto anche cuelli che non s'hanno leggere, aveva spiegato che in itagliano ammodernato si può dire «scendi il cane» e «siedi il bambino». Sempre se cè un bambino da sedere o un cane da scendere, perche quì nessuno vuole obrigare a cualcuno a saliscendere a cualcun'altro. S'iamo una democrazzia intransitiva, ma se uno vuole sedere un bambino, o un cane, deve poterglielo fare. La lingua non va tenuta chiusa come un porto. La lingua va 
spalancata ai desiderati del po'polo. Se al presidente di tutte le Crusche non gli stà abbene, mi dispiace per egli. Chiedessimo al ministro della Drammatica, della Sintassica e della Nalisi Logica che si facesse un Re Ferendum repubblicano. Se la maggioranza dei propietari di cani voterebbe che il cane si scende, all'ora si scende ebbasta, così non bagna dapertutto. Si scende con il sacchetto e il guinz'aglio, pero senza l'amuseruola, perche l'Itaglia non è una dettatura, ma un paese Maduro..Cè solo un verbo che non mi trova accordato con al professor Coletti. Secondo il cui, andrebbe giusto d'ire anche «Esci i soldi». Non scherzassimo. I soldi e sempre meglio che non eschino, specie al giorno doggi, altrimenti glieli prendono i banch'ieri amichi di Macronne, l'economia siede, il Pil si scende e, se tutto andrebbe bene, fossimo rovinati. (Corriere della Sera, 19/1/2019)

Il post sulla pagina Facebook dell'Accademia raggiunge i 40 commenti, 30 condivisioni e circa 80 reazioni, che per le cruscanti pagine social sono numeri che rivelano un notevole interesse. II tenore dei commenti è interessante, perché rivela nuovamente quell'atteggiamento intollerante che abbiamo identificato all'inizio:

Infatti, oltre ai soliti commenti ironici o offensivi:

Quindi "scendi il cane che lo piscio” non è più una battuta?!

Mi pare che abbiate commesso un errore nell'hashtag credo debba essere \#LaCruscaescelarisposta

Ma avete bevuto? Roba da matti

Accademici? Mi fate venire il voltastomaco! Cambiate lavoro!

E voi sareste un punto di riferimento culturale?

sono interessanti soprattutto quei commenti che ci mostrano un atteggiamento intransigente nei confronti dell'errore grammaticale. Un utente attribuisce alla Crusca addirittura la responsabilità della tenuta del paese. Peraltro, la scrittura del post in questione lascia intravvedere un livello culturale non proprio basso.

Semplicemente aberrante: dopo la "scienza democratica", ci mancava solo la grammatica democratica, che eleva l'uso - ogni uso - a criterio assiologico assoluto. A questo punto, non vedo perché mai censurare espressioni ancor più invalse, come il diffusissimo "piuttosto che" con valore disgiuntivo, o magari svarioni marchiani come "squola*". Se persino l'ultima (presunta, ormai da decenni) roccaforte della lingua italiana cede all'ideologia, questo Paese è definitivamente fottuto.

Interessanti sono soprattutto i seguenti due commenti, perché ci dicono che cosa si attende il pubblico dei parlanti comuni e degli utenti del social network dall'Accademia, vale a dire la difesa della lingua italiana: 
L'Accademia della Crusca sta rischiando di sdoganare qualsiasi testimonianza di ignoranza, con la scusa che, se è diffusa, va accettata. A questo punto, se prende piede questa regola irragionevole, possiamo anche concludere che l'Accademia ha esaurito, dopo 436 anni di vita, il suo compito. Da oggi in poi, va bene tutto!!

Ma si, giustifichiamo qualsiasi boiata lessicale! Perché non giustificare anche "chiudi la luce"??? Forse l'avete fatto in qualche post e me lo sono persa!... spero vivamente di no! Comunque che che ne dica l'autore della risposta "siedi il bimbo" o "scendi il cane" è usato solo al sud! Se lo ha sentito al nord è stato detto sicuramente da persona di origine meridionale o x scherzare qualcuno!

NON SI POSSONO SENTIRE! NE TANTO MENO VEDERE SCRITTI!!!! VI PREGO! L'ITALIANO VA PROTETTO!!

Anche su Twitter monta la polemica: anche qui il Leitmotiv è che scopo primario dell'Accademia dovrebbe essere quello di conferire sicurezza a utenti sempre più insicuri. Probabilmente perché consapevoli di avere una competenza dell'italiano decisamente inferiore rispetto a coetanei delle generazioni precedenti

Possedevo ancora una sicurezza, barcollò tenuemente con \#petaloso, oggi con gli occhi umidi devo prendere atto che è in fase terminale anche l’\#AccademiadellaCrusca Uscite gli scatoli e andate in pensione

Nello stesso giorno, è il Presidente della Crusca, Claudio Marazzini, a fornire all'AGI quelle precisazioni che sono mancate alla risposta di Coletti. Leggiamo dal "Corriere" del 27/1/2019:

«No, su "scendere il cane" l'Accademia della Crusca non ha cambiato idea», ha dichiarato il presidente della Crusca Claudio Marazzini all'Agi. Si dice anche divertito dal «moto di entusiasmo e dalla grande soddisfazione» con cui i «parlanti» che usano i verbi di moto in modo transitivo «hanno visto promuovere un errore tipico a tendenza di interesse, ma non bisogna dimenticare che resta estraneo a un italiano formale sorvegliato e di livello alto». Poi conclude: «Certo non si sono riuniti tutti gli accademici per deliberare ma su una cosa gli insegnanti devono stare tranquilli: potranno continuare a correggere gli studenti che scrivono «esci la sedia». Anche se, almeno nel linguaggio colloquiale, le espressioni si possono usare senza essere troppo bacchettati.

In quest'opera di ristabilimento della verità, Marazzini è stato coadiuvato ancora una volta da Vera Gheno, alla quale tocca il compito di spiegare la funzione di Crusca e Treccani:

Né Crusca né Treccani hanno il potere di "sdoganare" alcunché o di "approvare ufficialmente" i neologismi: il loro compito è un altro, cioè quello di analizzare e studiare i fenomeni linguistici sia in una prospettiva diacronica (cioè nel tempo) sia sincronica (concentrandosi sulla contemporaneità, sul presente), spiegarli, ed eventualmente consigliare o sconsigliare l'impiego di una forma, una parola, un costrutto. [...] In altri termini, nelle loro multiformi attività, questi 
due enti (assieme a molti altri che lavorano nello stesso campo) hanno un atteggiamento che viene definito descrittivo più che prescrittivo: descrivono la realtà linguistica ma, di fatto, non hanno il potere di prescrivere il comportamento linguistico, ovvero imporlo ai parlanti.

[...] Ma se prevale l'atteggiamento descrittivo, e il linguista sta quasi nelle retrovie a osservare i mutamenti linguistici, chi si prende cura della lingua? Chi ha il compito di preservarla, mantenerla, forse difenderla? La risposta è, allo stesso tempo, prevedibile e sorprendente: il compito è di ognuno di noi, in qualità di membro di quella certa comunità linguistica, cioè parlante di quella lingua. La lingua si modifica a causa di come la usiamo noi tutti i giorni; le parole si estinguono oppure entrano, da neologismi, nel vocabolario, sempre grazie a noi. (“Toscana Oggi", 3 marzo 2019)12

Dall'analisi degli esempi analizzati emergono due aspetti, che vorrei porre brevemente in evidenza. Innanzi tutto, bisogna notare che le particolari modalità di fruizione dei social network (prime fra tutte rapidità di lettura) influiscono sugli esiti del dibattito. Non capita di rado, infatti, che un post o un intervento vengano letti solamente in parte dagli utenti oppure totalmente tralasciati ${ }^{13}$. Ogniqualvolta non si proceda approfonditamente nella lettura, si origina il ricorrente commento, a sua volta generato dalla scarsa comprensione del caso, «dopo petaloso l'Accademia della Crusca non è più attendibile». Citiamo, a tal proposito, un tipico scambio di battute sul tema, nel quale notiamo che gli utenti (nella fattispecie U2) spesso sembrano non leggere le risposte dell'Accademia della Crusca $[=\mathrm{AdC}]$ :

U1: Dopo l'articolo sulla parola "petaloso" si era capito che qualcosa stava cambiando.

AdC: Ancora? Forse dovrebbe rileggere qui: http://www.accademiadellacrusca.it/.../parola-petaloso.

U2: Petaloso! Ahahahah

AdC: U2, è passato un bel po' di tempo, non è possibile che non sappia ancora com'è andata! Forse dovrebbe leggere qui: http://www.accademiadellacrusca.it/.../parola-petaloso.

12. Non sarà ozioso ricordare gli obiettivi delle attività che oggi si pone l'Accademia della Crusca, così come sono indicati nel suo sito Internet: 1) «sostenere, attraverso i suoi Centri specializzati e in rapporto di collaborazione e integrazione con le Università, l'attività scientifica e la formazione di nuovi ricercatori nel campo della linguistica e della filologia italiana»; 2) «acquisire e diffondere, nella società italiana e in particolare nella scuola, la conoscenza storica della nostra lingua e la coscienza critica della sua evoluzione attuale, nel quadro degli scambi interlinguistici del mondo contemporaneo»; 3) «collaborare con le principali istituzioni affini di Paesi esteri e con le istituzioni governative italiane e dell'Unione Europea per la politica a favore del plurilinguismo del nostro continente».

13. Ciò accade anche riguardo al link che, nei post Facebook dell'Accademia, rimanda al relativo articolo contenuto nelle pagine di consulenza dell'Accademia della Crusca: la maggior parte degli utenti (e, a mio avviso, dei giornalisti) si concentra unicamente sul titolo del post, senza leggere l'articolo; per tale motivo, frequentemente le reazioni negative sono poco inerenti alla sostanza dell'argomento. 
U2: Si lo so com'è andata! Ma se permettete fa ridere ugualmente l'idea che un errore diventi una regola perché le maestre non correggono più gli errori.

U2: Mio figlio propone Cerbiattoso!

U3: U2 o non ha letto com'è andata la vicenda di petaloso oppure ha letto e non ha compreso com'è andata la vicenda di petaloso. Vuole continuare?

Ciò fa pensare, oltre a giudizi preconcetti nei confronti dell'Accademia, a un generale atteggiamento rissoso di numerosi utenti social, i quali, spesso, sono propensi all'insulto e all'aggressione verbale più che alla discussione, come si vede chiaramente nei commenti di un altro post, nel quale gli utenti si aggrediscono reciprocamente, rimarcando gli errori contenuti nei rispettivi commenti:

U1: Domanda: qual'è [sic] la motivazione che ha permesso ai docenti dei vari gradi d'istruzio-

ne di far arrivare questi ragazzi fino all'università senza intervenire?

U2: Di sicuro lei non può saperlo, a giudicare da come scrive.

$[\ldots]$

U3: La stessa motivazione che ha consentito a lei di proseguire con gli studi.

Insomma, la storia si ripete, come si ripetono gli errori. Come fare per evitare tali discussioni, che alla fine risultano sterili e fuorvianti, nonché scarsamente educative per il parlante comune?

Dal tono degli interventi sopra menzionati emerge come la già citata visione monolitica della lingua da parte degli utenti abbia, come prima conseguenza, la noncuranza delle riflessioni offerte dai linguisti che in fatto di lingua non propongono l'unitarietà ma la molteplicità, proiettando il lettore verso il confine fluido tra norma e uso.

Per tale motivo, a mio avviso i linguisti dovrebbero con decisione sempre maggiore riappropriarsi della loro funzione sociale, e stimolare una conoscenza più profonda del funzionamento della lingua, in primo luogo nelle scuole di ogni ordine e grado, mediante la formazione degli insegnanti, e mediante veri e propri interventi sul campo, ma, soprattutto, anche sui mezzi di comunicazione di massa, dove le questioni linguistiche vanno sottratte al dilettantismo e al sensazionalismo della stampa generalista, il cui livello, sia per la precarizzazione del mestiere del giornalista, sia per la moltiplicazione delle testate dovuta all'avvento di internet, è andato progressivamente abbassandosi.

La stessa Crusca dovrebbe continuare, pur con i metodi della moderna ricerca linguistica e fondandosi (come peraltro già fa) su una moderna concezione della norma, a fornire il suo contributo, facendo sì che alla descrizione e alla giustificazione dei fenomeni si aggiunga anche qualche indicazione in più riguardante l'uso. Insomma, l'Accademia non dovrebbe occuparsi soltanto dei basiletti, ma anche (e forse in prima istanza) degli acroletti. In tale ottica, non dovrebbe limitarsi a dire che 
l'una o l'altra forma sono ammissibili "nel linguaggio familiare", ma spiegare anche quali sono le forme corrette negli usi formali e scritti della lingua, evidenziandone le motivazioni. Questo è, infatti, quanto chiedono i parlanti (spesso insegnanti di scuola) che si rivolgono alle pagine di consulenza dell'Accademia. In un secolo di profondi rivolgimenti che investono la nostra lingua, in presenza di una continua opera di impoverimento del sistema scolastico e universitario da parte dello Stato (senza distinzione di schieramento né di bandiera), spetta alle istituzioni culturali (in primo luogo alle accademie) il compito di preservare la lingua e la cultura di un paese. 


\section{Bibliografia}

Antonelli, Giuseppe (2016), L'italiano nella società della comunicazione. 2.0, Bologna, Il Mulino.

Arcangeli, Massimo (2014), "Allegro con brio. La grammatica dalla parte del parlante nell'era di Internet», in Sergio Lubello (ed.), Lezioni d'italiano. Riflessioni sulla lingua del nuovo millennio, Bologna, il Mulino, p. 135-160.

Bachis, Dalila (2010-2011) [ma 2013], «Norma e uso nella grammaticografia scolastica attuale», Studi di grammatica italiana, n. 29-30, p. 329-348.

Bachis, Dalila (2019), Le grammatiche scolastiche dell'italiano edite dal 1919 al 2018, Firenze, Accademia della Crusca.

Baron, Naomi S. (2002), “"Whatever.": A New Language Model?», Paper Presented at the 2002 Convention of the Modern Language Association (December 27-30), New York.

Baron, Naomi S. (2008), Always On: Language in an Online and Mobile World, New York, Oxford University Press.

Beccaria, Gian Luigi (2010), Il mare in un imbuto. Dove va la lingua italiana, Torino, Einaudi.

Berruto, Gaetano (1987). Sociolinguistica dell'italiano contemporaneo, Roma, La Nuova Italia Scientifica.

Castellani, Arrigo (1991), «Italiano dell'uso medio o italiano senza aggettivi?», Studi linguistici italiani, n. 17, p. 233-256.

Coluccia, Rosario (2017), «Esci il cane? Mettiti la museruola», /l Quotidiano di Puglia, 21/5/2017, p. 13.

Cortelazzo, Michele (2000), «La lingua italiana di fine millennio», in Id., Italiano d’oggi, Padova, Esedra, p. 9-24.

Cortelazzo, Michele (2012), «Evoluzione della lingua, percezione del cambiamento, staticità della norma», in Chiara Di Benedetto et al. (ed.), I sentieri della lingua. Saggi sugli usi dell'italiano tra passato e presente, Padova, Esedra, p. 15-20.

Coseriu, Eugenio (1969), «Sistema, norma e "parole"», in Studi linguistici in onore di Vittore Pisani, Brescia, Paideia, vol. 1, p. 235-254.

Coseriu, Eugenio (1971), Sistema, norma e «parole», in Id., Teoria del linguaggio e linguistica generale: sette studi, Bari, Laterza, p. 19-103.

D’Achille, Paolo (2010), «Lingua d'oggi», in Enciclopedia dell'italiano, Roma, Istituto della Enciclopedia Italiana, vol. 1, p. 793-799. 
D’Achille, Paolo (2011), «Norma linguistica», in Enciclopedia dell'italiano, 2 vol., Roma, Istituto della Enciclopedia italiana, vol. 2, p. 961-965.

D’Achille, Paolo (2014), «Dove va l'italiano? Linee di tendenza della lingua di oggi», in Lubello (2014), p. 235-246.

D’Achille, Paolo, Proietti, Domenico e Viviani, Andrea (2005), «La frase scissa in italiano: aspetti e problemi», in Paolo D’Achille e Iørn Korzen (ed.), Tipologia linguistica e società. Considerazioni inter- e intralinguistiche. Due Giornate italo-danesi di studi linguistici (Roma, 27-28 novembre 2003), Firenze, Cesati, p. 249-279.

De Santis, Cristiana e Fiorentino, Giuliana (2018), «La carica dei 600: la campagna mediatica sul declino della lingua italiana», Circula - Rivista di ideologie linguistiche, n. 7, p. 1-28.

Dardano, Maurizio (1994), «Profilo dell'italiano contemporaneo», in Luca Serianni e Pietro Trifone (ed.), Storia della lingua italiana, vol. 2, Scritto e parlato, Torino, Einaudi, p. 343-432.

De Mauro, Tullio (2014). Storia linguistica dell'talia repubblicana dal 1946 ai nostri giorni, Roma-Bari Laterza.

De Roberto, Elisa (2020), «Normative Grammars», in Lebsanft e Tacke (2020), p. 317-341.

Galli de' Paratesi, Nora (1988), «Norma in linguistica e sociolinguistica e incongruenze tra norma e uso nell'italiano di oggi», Linguistica, n. 28, p. 3-13.

Gheno, Vera (2017), Social-linguistica. Italiano e italiani dei social network, Firenze, Cesati.

Gheno, Vera (2019), Paese Reale 2.0: whateverismo linguistico e maestrine dalla penna rossa nell'Italia dei social network, in Sabina Gola (a cura di), L'italiano che Parliamo e Scriviamo, Firenze, Cesati, p. 103-120.

Giovanardi, Claudio (2010), L'italiano da scrivere. Strutture, risposte, proposte, Napoli, Liguori.

Kabatek, Johannes (2020), «Linguistic Norm in the Linguistic Theory of Eugenio Coseriu», in Lebsanft e Tacke (2020), p. 127-144.

Lebsanft Franz et al. (ed.) (2012), El español, ¿desde las variedades a la lengua pluricéntrica?, Frankfurt a. M. / Madrid, Vervuert / Iberoamericana.

Lebsanft, Franz e Tacke Felix (ed.) (2020), Manual of Standardization in the Romance Languages, ("Manuals of Romance Linguistics", ed. by Gunther Holtus e Fernando Sánchez-Miret, 24), Berlin/ Boston, de Gruyter.

Locher Miriam A. e Strässler Jürg (ed.) (2008), Standards and Norms in the English Language, Berlin / New York, Mouton de Gruyter.

Mioni, Alberto A. (1983), «Italiano tendenziale: osservazioni su alcuni aspetti della standardizzazione», in Paola Benincà (ed.), Scritti linguistici in onore di Giovan Battista Pellegrini, Pisa, Pacini, vol. 1 p. 495-517 
Marazzini, Claudio (2009), Da Dante alla lingua selvaggia. Sette secoli di dibattiti sull'italiano, Roma, Carocci (1a ed. 1999).

Ondelli, Stefano e Romanini Fabio (2018), «Norma interiorizzata e uso: un'indagine preliminare su parlanti italiani», in Daniel Słapek (ed.), Grammatica italiana, fra teoria e didattica, Italica Wratislawentia, n. 9, p. 185-208.

Prada, Massimo (2015), L'italiano in rete. Usi e generi della comunicazione mediata tecnicamente, Milano, Angeli.

Renzi, Lorenzo (2012). Come cambia la lingua. L'italiano in movimento, Bologna, il Mulino.

Sabatini, Francesco (1985), «L"“italiano dell'uso medio": una realtà tra le varietà linguistiche italiane», in Günter Holtus ed Edgar Radtke (ed.), Gesprochenes Italienisch in Geschichte und Gegenwart, Tübingen, Narr, p. 154-184.

Serianni, Luca (2006), Prima lezione di grammatica. Roma-Bari: Laterza.

Serianni, Luca (2007), «La norma sommersa», Lingua e stile, n. 42, p. 283-298.

Serianni Luca (2010), L’ora di italiano, Roma-Bari, Laterza.

Serianni Luca (2014), «Giusto e sbagliato: dove comincia il territorio dell'errore?», in Lubello (2014), p. 235-246.

Settekorn, Wolfgang (1988), Sprachnorm und Sprachnormierung in Frankreich. Einführung in die begrifflichen, historischen und materiellen Grundlagen, Tübingen, Niemeyer.

Sgroi, Salvatore Claudio (2010), Per una grammatica laica. Esercizi di analisi linguistica dalla parte del parlante, Torino, UTET Università.

Simone, Raffaele (1993), Stabilità e instabilità nei caratteri originali dell'italiano. Struttura e variazioni, Roma-Bari, Laterza, p. 41-100.

Siouffi, Gilles e Steuckardt, Agnès (2007), Les linguistes et la norme. Aspects normatifs du discours linguistique, Bern etc., Peter Lang.

Tavoni, Mirko (2002), «Caratteristiche dell'italiano contemporaneo e insegnamento della scrittura», in Francesco Bruni e Tommaso Raso (ed.), Manuale dell'italiano professionale. Teoria e didattica, Bologna, Zanichelli, p. 139-152.

Tomasin, Lorenzo (2019), Il caos e l'ordine. Le lingue romanze nella storia della cultura europea, Torino, Piccola Biblioteca Einaudi.

Vitale, Maurizio (1978), La questione della lingua, Nuova ed., Palermo, Palumbo.

Winkelmann, Otto (1990): «Französisch: Sprachnormierung und Standardsprache. Norme et Standard», in: Günter Holtus, Michael Metzeltin, e Christian Schmitt, (eds.), Lexikon der Romanischen Sprachen (LRL), Tübingen, Niemeyer, Vol. V, 1, Französisch, p. 334-353. 


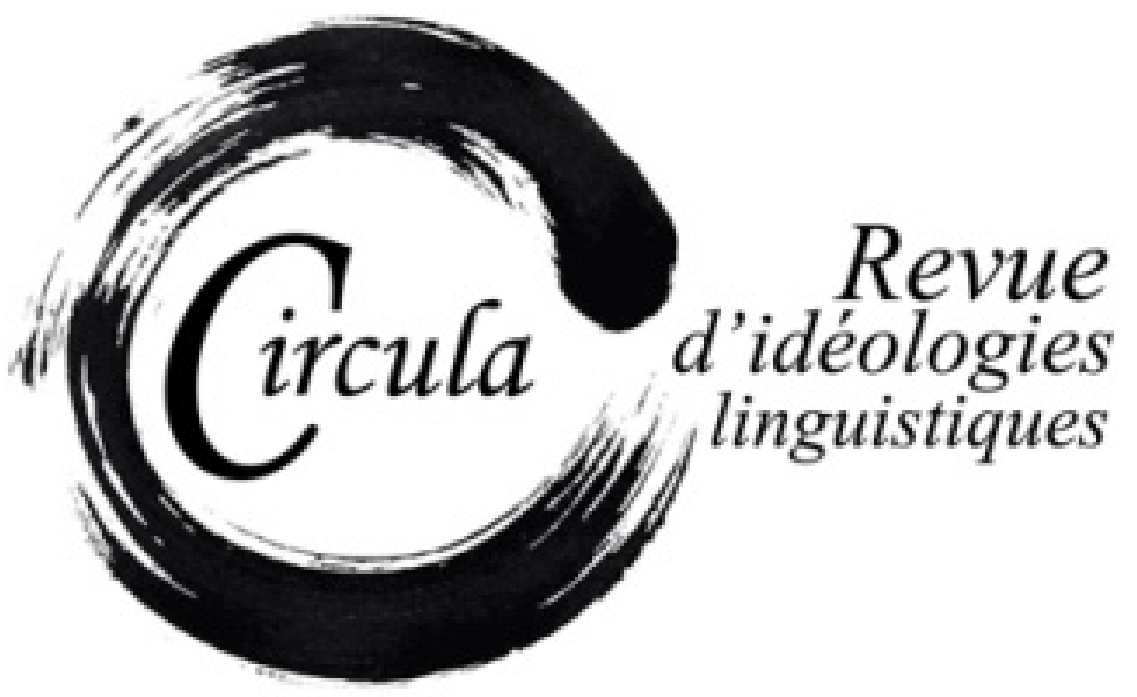

TITRE: QU'EST-CE QUE LA LEXICOGRAPHIE PARASITE ? TYPOLOGIE D'UNE PRATIQUE QUI INFLUENCE LA REPRÉSENTATION DU FRANÇAIS QUÉBÉCOIS

Auteur: NADINE VINCENT, UnIVERSITÉ DE SHERBROOKE

Revue: CIRCULA, NUMÉRO 11

PAGES: $106-124$

ISSN: 2369-6761

URI: HTTP://HDL.HANDLE.NET/11143/17843

DOI: HTTPS://DOI.ORG/10.17118/11143/17843 


\title{
Qu'est-ce que la lexicographie parasite? Typologie d'une pratique qui influence la représentation du français québécois ${ }^{1}$
}

\author{
Nadine Vincent, Université de Sherbrooke \\ Nadine.Vincent @ USherbrooke.ca
}

Pour paraître, un dictionnaire doit en premier lieu paraître sérieux :on ne s'impose pas sans en imposer.

(Georges Elgozy, L'Esprit des mots, ou l'antidictionnaire, 1981)²

Résumé : Au cours des dernières années, certaines productions hexagonales (guide de conjugaison, roman, film) ont voulu tenir compte du français québécois ou ont tenté de reproduire cette variété de français. Ces aventures n'ont pas toujours été heureuses, et pourtant elles s'étaient basées sur des dictionnaires produits au Québec. En analysant en parallèle les critiques reçues au Québec par ces productions françaises et par les dictionnaires qui leur ont servi de source, nous établissons dans cet article une typologie de cette branche de la lexicographie profane que nous nommons la lexicographie parasite.

Mots clés : dictionnaires ; lexicographie profane ; lexicographie parasite ; français québécois

Abstract: In recent years, some French productions (conjugation guide, novel, film) have wanted to take into account French of Quebec or have tried to reproduce this variety of French. These adventures were not always happy, and yet they were based on dictionaries produced in Quebec. By analyzing in parallel the criticisms received in Quebec by these French productions and by the dictionaries that served as their source, we establish in this article a typology of this branch of profane lexicography that we call parasitic lexicography.

Keywords: dictionaries; folk lexicography; parasitic lexicography; Québécois French

1. L'auteure remercie Paméla Vachon pour la relecture attentive de cet article, autant pour la forme que pour le fond. 2. http://dicocitations.lemonde.fr/citations/citation-85735.php [page consultée le 9 mars 2018] 


\section{Introduction}

Depuis quelques années, l'intérêt de la France pour le français en usage au Québec semble croissant. Des personnalités québécoises sont fréquemment invitées dans des émissions françaises grand public où on ne manque pas de leur parler de leur accent ou d'autres de leurs spécificités linguistiques, des personnages québécois font leur apparition dans des publicités ou dans des numéros d'humoristes; bref le locuteur québécois prend place dans l'imaginaire hexagonal.

Or, il arrive fréquemment que les Québécois réagissent mal à la représentation faite de leur langue de l'autre côté de l'Atlantique. On pourrait croire à une simple question de susceptibilité, mais des études scientifiques ou de simples faits révélés par les journaux parviennent parfois à identifier la source du malaise : pour reproduire le français du Québec, les Français pointés du doigt se sont parfois basés sur des sources québécoises inadéquates.

C'est à ces prétendus "dictionnaires de québécois », produits par des non-lexicographes et qui connaissent un grand succès de librairie, que nous nous intéressons ici. Cette branche de la pratique lexicographique profane semble allier deux éléments apparemment contradictoires : une capacité à séduire l'usager et une piètre qualité de production. Les dictionnaires dont il sera question ici parviennent donc à donner l'illusion de leur pertinence, tout en mettant dans l'embarras ceux qui décident de s'en servir. Mais avant d'identifier notre corpus, commençons par cerner l'objet de notre étude.

\section{Qu'est-ce que la lexicographie?}

La lexicographie est l'étude scientifique des faits de langue en vue de la production de dictionnaires. Comme la naissance d'un nouveau dictionnaire n'est pas si courante, la majorité des linguistes qui s'intéressent à cette discipline deviennent des métalexicographes, qui étudient les dictionnaires plutôt que d'en rédiger. À l'inverse, comme un dictionnaire nait souvent d'un besoin précis à un moment déterminé, il n'est pas toujours l'œuvre de lexicographes formés en la matière. Ainsi, Émile Littré était médecin, Pierre Larousse, instituteur, et Paul Robert, diplômé en droit. Ils sont pourtant aujourd'hui trois monstres sacrés de la lexicographie. 


\subsection{La lexicographie professionnelle}

La frontière entre amateur et professionnel n'est pas toujours facile à tracer, et nombreux sont les domaines où l'apport des non-spécialistes a permis d'enrichir les savoirs. La production de dictionnaires présente un cas de figure particulier, dans la mesure où le métier s'apprend généralement par la pratique. C'est donc en évaluant l'œuvre achevée que l'on peut mesurer la qualification de ses artisans, et les critères de cette évaluation sont variables et tous potentiellement subjectifs à des degrés divers : qualité et pertinence de la description, innovation, succès d'estime, utilité pour le public, etc. Pourtant, nous savons intuitivement qu'il existe une distinction entre la lexicographie professionnelle et la lexicographie profane, entre les dictionnaires « sérieux » et les pseudo-dictionnaires, et ces deux pratiques ont toujours coexisté.

La lexicographie dite professionnelle peut être commerciale ou institutionnelle. Littré, Larousse et Robert ont œuvré pour l'entreprise privée et ont produit des dictionnaires commerciaux, qui portent aujourd'hui leurs noms et qui sont devenus des repères pour le public.

Pour tout le monde, initiés et non-initiés, évoquer les dictionnaires Robert et Larousse par exemple, c'est en termes de représentation faire appel à des références telles qu'elles ont valeur d'institution, au point même de pouvoir faire autorité dans les jeux radiophoniques et télévisés portant sur la langue française. (Pruvost, 2002 : 17)

Nous qualifions d'institutionnels les dictionnaires produits par des organismes publics, par exemple le Dictionnaire de l'Académie française. Ses auteurs n'ont pas de formation en lexicographie, ils ne sont généralement pas même linguistes, mais le Dictionnaire lui-même, malgré toutes les critiques que l'on peut lui adresser, est le produit d'une tradition et le fruit d'un savoir-faire. On peut aussi mentionner dans cette catégorie le Grand dictionnaire terminologique de l'Office québécois de la langue française. Enfin, certains ouvrages émanent de groupes de recherche universitaires : pensons à des ressources comme le Trésor de la langue française (aujourd'hui informatisé), à des ouvrages plus ciblés comme le Dictionnaire historique du français québécois ou la Banque de données lexicographiques panfrancophone, ou encore à des dictionnaires plus usuels comme le dictionnaire québécois Usito. Certains de ces ouvrages n'existent qu'en format papier, d'autres qu'en format numérique ou en ligne, et d'autres enfin sont disponibles sur plusieurs supports. Cet élément n'est donc pas un critère pertinent pour distinguer la lexicographie professionnelle de la lexicographie profane. 


\subsection{Pourquoi profane?}

Nous avons choisi d'utiliser la dénomination lexicographie profane par opposition à ce que serait une lexicographie sacrée, cette dernière étant construite en respect d'une certaine tradition, de certaines normes, voire de certains dogmes. Une lexicographie profane réussie permettrait donc de remettre en question les règles établies et d'innover en matière de description et de représentations de la langue.

Bien qu'il présente l'avantage d'être rattaché à une certaine tradition de description, l'adjectif populaire nous semble trop polysémique pour être satisfaisant. S’appliquerait-il à une lexicographie qui émane du peuple, qui est destinée au peuple ou qui obtient un certain succès auprès du peuple? Et à quelle acception de peuple fait-on ici référence? Plusieurs interprétations sont possibles et donc aptes à créer de la confusion. Les anglophones parlent aussi de folk linguistics (Preston, 1993; Niedzielski et Preston, 2000), étiquette en train de pénétrer en français, mais elle nous semble un emprunt inutile qui vient aussi avec son lot d'ambiguïtés.

Quant à l'adjectif amateur qui s'oppose bien sûr à professionnel, il peut parfois être péjoratif alors que la majorité des lexicographes apprennent leur métier avec l'expérience et sont donc, pendant la rédaction de leurs premiers articles, des amateurs. Enfin, nous n'avons pas retenu les adjectifs naïf et spontané, qui paraissent éliminer toute possibilité d'une démarche ou d'une réflexion sous-jacente au travail lexicographique.

Nous aurions pu enfin créer un néologisme, à partir du préfixe para-, sur le modèle de paralittérature, et parler de paralexicographie, parce qu'elle transmet cette idée d'une description de la langue en parallèle de la lexicographie traditionnelle. Toutefois, après vérification, nous avons constaté que cette étiquette a déjà été utilisée pour décrire les dictionnaires de spécialité (voir notamment Margarito, 2007); nous ne l'avons donc pas retenue.

Pour toutes ces raisons, nous parlerons ici de lexicographie profane, avec en tête le joli mot d'Amélie Cure (repris par Achard-Bayle et Paveau, 2008), qui parlait de la linguistique profane comme d'une linguistique « hors du temple ». En absolu, la lexicographie profane englobe toute description de la langue faite par des non-spécialistes, dans un cadre non professionnel. Cela inclut la lexicographie collaborative (Wiktionnaire, La Parlure, Dico des mots, etc.; voir notamment Murano, 2014; Molinari et Vincent, 2017; Dolar, 2017 et 2018), qui permet à des internautes de proposer des articles ou des éléments de description qui seront bonifiés, approuvés ou rejetés par d'autres internautes selon une hiérarchie qui varie d'un projet à l'autre. Caractérisée par les notions de communauté et d'interactivité, la lexicographie collaborative appuie sa crédibilité sur la validation de chacune de ses descriptions par les utilisateurs. 
La lexicographie profane désigne aussi des pratiques plus anciennes et plus individuelles que la lexicographie collaborative, qui n'ont pas fait l'objet d'études approfondies par des spécialistes. Nous nous intéressons ici à une pratique qui a précédé le web interactif et qui continue à prospérer en format papier. Il s'agit d'une branche de la lexicographie profane que nous tenterons de définir et de baliser. Pour dégager une typologie, nous nous concentrerons sur l'édition québécoise où des publications de ce type abondent et connaissent des succès commerciaux importants. Si cette pratique peut sembler à première vue inoffensive, il lui arrive d'avoir une influence réelle sur la représentation du français québécois et elle contribue parfois à en diffuser une image dénoncée par certains comme étant erronée.

\section{Le français québécois dans certaines productions françaises}

Pour définir notre corpus, ou plus justement pour identifier certains ouvrages qui semblent propager une description inadéquate du français québécois, nous procéderons à rebours, en partant de projets français critiqués pour leur intégration du français québécois, et en cherchant si un dictionnaire fait au Québec pourrait être la source du malentendu. Nous présentons ici trois de ces productions, datées de 1997, de 2006 et de 2017, dont les maladresses peuvent vraisemblablement être attribuées à l'utilisation de dictionnaires profanes québécois spécifiques.

\subsection{La conjugaison pour tous, guide Bescherelle publié chez Hatier (1997)}

En 1997, l'édition française du guide de conjugaison Bescherelle décide d'ajouter à son index général des verbes de la francophonie hors de France : d'Afrique (sans précision du ou des pays), de Belgique et du Québec. Pour le Québec, des verbes bien attestés à l'écrit comme abrier, achaler et magasiner cohabitent avec des formes orales plus approximatives comme affarmir, xaminer ou yérir. Des centaines de verbes étiquetés comme étant québécois font ainsi leur entrée dans La conjugaison pour tous, au plus grand dam de l'éditeur québécois Hurtubise $\mathrm{HMH}$, qui détient les droits canadiens de distribution sur l'ouvrage, et qui refuse l'accès au territoire à la version parisienne du célèbre guide de conjugaison. Une nouvelle édition locale sera préparée et diffusée à partir de mars 1998. Elle ne retient que 17 verbes caractéristiques du français québécois, reconnus par l'Office québécois de la langue française. Depuis 1998, c'est cette version qui est diffusée dans toute la francophonie. On pourrait croire à une simple erreur de parcours, mais les réactions au Québec ont été significatives.

Notre langue française américaine est ici représentée par celle d’un individu, le Québécois Léandre Bergeron, qui a commis en 1980 [...] un malheureux et prétentieux Dictionnaire de la langue québécoise [...]. Ce dictionnaire a été vivement critiqué lors de sa parution et semblait avoir été relégué aux oubliettes. Or c'est précisément cet ouvrage que le réputé linguiste Michel Arrivé a approuvé pour faire place, dans les listes bescherelliennes, à la langue québécoise [...]. (Séguin, 1997 : A9) 
[...] les québécismes cités par centaines dans le guide de la conjugaison étaient tirés du Dictionnaire de la langue québécoise de Léandre Bergeron. Parmi les 608 verbes sélectionnés, la plupart n'étaient même pas formellement reconnus par les Québécois. On pouvait alors y trouver les verbes apprivouéser, anvaler, acmoder, néteyer et haguir. [...] Partout, on s'étonnait qu'un livre réputé donne une aussi piètre image de la langue française parlée au Québec. (Villeneuve, 2016) 3

On reproche principalement à l'éditeur français Hatier et au linguiste français Michel Arrivé de s'être appuyés sur une source québécoise non scientifique, et critiquée au Québec, pour attester des usages québécois. Le dictionnaire de Léandre Bergeron était facilement accessible et visiblement assez crédible pour donner l'illusion à des spécialistes de la langue, mais non-natifs du français québécois, qu’il donnait une description juste de cette variété de français.

\subsection{Sous les vents de Neptune, roman de Fred Vargas (2004)}

En 2004, la « reine française du polar, Fred Vargas ${ }^{4}$ », publie Sous les vents de Neptune, dont l'histoire se déroule en partie au Québec. L'auteure tente de reproduire du français québécois oral dans les dialogues de son roman. Si la critique française est élogieuse quant à la vraisemblance de la langue, au Québec, elle est unanimement négative.

On se souviendra que dans le neuvième rompol, Sous les vents de Neptune, le commissaire Adamsberg avait failli mourir dans les boisés de Gatineau au Québec. Et que les lecteurs et lectrices québécois avaient de leur côté failli mourir de rire en découvrant une nouvelle version de leur langue, inventée par Mme Vargas. Certains ont moins ri que d'autres, ils en ont même voulu à l'auteure. (Lepage, 2006 : 11)

Et ils parlent, mes amis, ils parlent. «Tu crois-tu que c'est lequel, le commissaire ?» « Pas trop ébarroui par le voyage ?» [...] «Il est boqué comme un ours. » «Tais ton bec, le Français. » «Faut qu'on se mouve. Si le boss nous pogne à brasser de l'air, il va manger ses bas. » «Criss, on va pas javasser des heures. » [...] je vous en conjure, si vous connaissez quelqu'un qui parle comme ça, dites-lui de m'écrire, je publierai son portrait. (Dion, 2004 : 2002)

À la suite de ces critiques, Fred Vargas a prétendu avoir inventé « du "faux québécois", compressant et tordant la langue » (Vargas, 2006 : 13); des études ont plutôt démontré qu'elle s'était appuyée sur un dictionnaire profane québécois très présent dans les librairies.

3. Notons que l'extrait cité provient de la section « archives » du site canadien de Bescherelle. Ce blogue a été rédigé le 27 juillet 2016, dix-neuf ans après les faits, preuve que cet événement a été marquant pour les éditions Hurtubise HMH, distributeur canadien de Bescherelle.

4. http://www.rfi.fr/contenu/20091101-reine-francaise-polar-fred-vargas-adaptee-television [page consultée le 12 mars 2018] 
Une partie des erreurs de Vargas sont apparemment dues aux indications inexactes données par le Dictionnaire des expressions québécoises de Pierre DesRuisseaux [...], en particulier pour les expressions, qui sont les éléments lexicaux les moins transparents. (Larrivée, 2006 : $118)^{5}$

Ici aussi, le contraste est frappant entre la réaction des non-natifs du Québec (l'auteure et les lecteurs français), qui ont « reconnu » le français québécois dans la langue décrite par DesRuisseaux, et les lecteurs québécois qui n’ont vu dans les mots de Vargas que des aberrations ou de tristes caricatures.

\subsection{Rock'n'Roll, film de Guillaume Canet (2017)}

Dans Rock and Roll (2017), le dernier film de Guillaume Canet, Marion Cotillard, sa compagne à la ville et à l'écran, se prépare pour un rôle que lui a proposé le réalisateur québécois Xavier Dolan. Pour ce faire, elle s'imagine qu'elle doit apprendre à parler québécois. Aiguillée par sa coach québécoise, elle a choisi de se procurer mon Dictionnaire québécois-français. Le livre apparaît dans plusieurs scènes du film. ${ }^{6}$

C'est Lionel Meney, auteur d'un dictionnaire paru en 1999, qui s'exprime ainsi sur son blogue. II affirme donc lui-même que le français québécois de Cotillard dans le film de Canet serait inspiré de son ouvrage. Cependant, aucune autre source ne permet de faire ce recoupement, outre le fait bien sûr que le Dictionnaire québécois-français de Meney soit facilement reconnaissable à l'écran. N'a-til été qu'un accessoire ou a-t-il vraiment servi d'inspiration au français québécois émis par Marion Cotillard? Rien ne nous permet de le savoir, bien qu'une mise en parallèle des critiques reçues par le film et par le dictionnaire laisse apparaître une certaine analogie.

Les critiques ont été élogieuses en France pour l'interprétation de Cotillard, mais le Huffington Post a eu envie de savoir ce qu'en pensaient les Québécois.

Si le résultat peut sembler plutôt réussi, il n’a pas tout à fait convaincu les habitants de la Belle Province. Pour avoir des explications, l'édition française de l'Huffington Post est allée demander à ses confrères du Québec ce qu'il en était. « Un bel effort de la part de Marion Cotillard mais l'accent est fortement exagéré voire raté malgré les bonnes intentions », commente l'un, tandis qu'un autre déclare: "On sent que c'est forcé et ça ne rend pas justice à notre langue française. Les Québécois passent un peu pour des sans-génies dans cet extrait ».?

5. Voir aussi Vincent, 2014. Des recherches plus récentes démontrent que Vargas se serait aussi servie du Dictionnaire de la langue québécoise de Léandre Bergeron pour écrire ses dialogues (voir Martin, 2020).

6. https://carnetdunlinguiste.blogspot.ca/2017/12/entre-marion-cotillard-et-guillaume.html [page consultée le 12 mars 2018]

7. http://www.vanityfair.fr/actualites/articles/que-pensent-les-quebecois-de-laccent-de-marion-cotillard-dansrocknroll-/59823 [page consultée le 12 mars 2018] 
Marion Cotillard est-elle en train de faire un arrêt cardiovasculaire ? Non. Il semblerait plutôt qu'elle tente d'imiter l'accent québécois... et ce n'est pas très réussi. ${ }^{8}$

Les critiques sont plus modérées que pour le Bescherelle de conjugaison et le roman de Vargas, mais elles recoupent étrangement certains des commentaires faits sur le dictionnaire de Meney, ce qui permettrait d'établir un lien entre le Dictionnaire québécois-français et le film Rock'n'roll de Guillaume Canet. En effet, on reproche aux deux productions de donner une image dépréciative du français en usage au Québec, et, par association, des Québécois eux-mêmes (voir détails sur l'ouvrage de Meney en 5.3.).

\section{4. Établissement d'une typologie}

Les remous causés par la parution du guide de conjugaison de Bescherelle, du roman de Fred Vargas et, plus hypothétiquement, du film de Guillaume Canet, ont ceci en commun qu'ils sont le fruit du travail de Français qui, pour reproduire le français québécois, se sont notamment fiés aux ouvrages suivants, publiés au Québec:

- Le dictionnaire de la langue québécois de Léandre Bergeron, 1980 (réédité en format poche en 1981, en 1997, et sans cesse réimprimé depuis. Il existe aussi une version anglaise de ce dictionnaire, publiée en 1982 sous le titre The Québécois Dictionary).

- Le dictionnaire des expressions québécoises de Pierre DesRuisseaux, 1990 (réédité en 2003 et en 2009)

- Le dictionnaire québécois-français, pour mieux se comprendre entre francophones de Lionel Meney, 1999 (réédité en 2003).

Les auteurs de ces dictionnaires ont été respectivement professeur de français, puis boulanger (Bergeron), poète et écrivain (DesRuisseaux), linguiste et professeur de français, de russe et de traduction à l'université (Meney).

C'est à partir de ces trois dictionnaires, ou plutôt à partir d'analyses et de comptes rendus de ces trois dictionnaires faits par des linguistes québécois au fil du temps, que nous allons proposer une typologie d'une certaine branche de la lexicographie profane. Celle-ci a comme caractéristique d'avoir une influence sur la représentation du français québécois en en transmettant une image jugée inexacte, voire caricaturale par des spécialistes du français québécois. Les trois livres à l'étude ont trois autres points communs qui se détectent au premier regard.

Ils sont tous signés par un seul auteur. Contrairement à la lexicographie collaborative ou à la lexicographie professionnelle, par exemple, la pratique profane à laquelle nous nous intéressons ici n'est

8. http://quebec.huffingtonpost.ca/2017/02/17/marion-cotillard-accent-quebecois_n_14816502.html [page consultée le 12 mars 2018] 
donc apparemment soumise à aucun procédé de validation (outre l'approbation d'un éditeur), par des pairs ou des experts, à l'interne ou à l'externe. C'est un premier critère.

Ces auteurs attribuent à tort le titre de dictionnaire à leur travail (voir commentaires des spécialistes pour chacun des ouvrages), empruntant ainsi l'autorité et la crédibilité attribuées à cet ouvrage de référence emblématique. C'est un deuxième critère. Notons que Pierre DesRuisseaux commence par publier en 1979 Le livre des expressions québécoises. C'est au moment de son édition en format poche en 1990 que le livre deviendra dictionnaire?.

Enfin, les auteurs de ces ouvrages annoncent une description du québécois, plutôt que du français en usage au Québec ou du français québécois. Or, ce dernier n’est pas une langue autonome, mais une variété de français. C'est un troisième critère. Ils démontrent ainsi qu'ils semblent davantage répondre aux impératifs du marketing qu'à ceux d'une description scientifique, et n’hésitent pas à mettre de l'avant des clichés ou des inexactitudes pour attirer la clientèle.

Voyons maintenant comment ces livres ont été reçus par le public et par les spécialistes du domaine, ce qui nous permettra d'identifier d'autres critères pouvant permettre de baliser cette branche de la lexicographie profane.

\section{La réception des dictionnaires à l'étude}

Pour compléter notre typologie, nous avons relevé les commentaires faits sur ces ouvrages lors de leur parution par des spécialistes québécois. Ce procédé, qui peut paraître inhabituel, a comme objectif de multiplier les regards, par des contemporains, de façon à minimiser les à priori. Rappelons que ces dictionnaires ont la caractéristique de plaire à certains publics, qui s'y réfèrent avec confiance, et d'attirer les critiques d'autres personnes. Plutôt que d'ajouter notre analyse personnelle aux propos déjà émis, il nous semble plus constructif de brosser le portrait global de leur réception au Québec pour mieux comprendre là où le bât blesse. Nous n'avons pas tenu compte de leur réception en France, où elle est bien sûr nettement plus discrète, mais semble tout de même unanimement positive autant de la part du public que des spécialistes de la langue. Au Québec, les opinions sont plus partagées : si ces ouvrages sont généralement appréciés par le grand public (ainsi que le démontre leurs ventes et leurs nombreuses rééditions), et par la plupart des journalistes, ils sont plus fréquemment critiqués par les linguistes, lexicographes et quelques journalistes spécialisés.

9. DesRuisseaux a aussi préalablement publié Le livre des proverbes québécois (1974, réédition 1978) qui deviendra le Dictionnaire des proverbes québécois en passant en édition de poche (1991, 1997 et 2005). En 2018, cet ouvrage devient le Dictionnaire des proverbes, dictons et adages québécois. 


\subsection{Le dictionnaire de la langue québécoise de Léandre Bergeron}

Ce dictionnaire paru en 1980 a battu très rapidement des records de vente. Cinq mois après sa sortie, l'éditeur annonçait déjà 12000 exemplaires vendus, et l'ouvrage paraissait en format de poche dix mois après sa première édition, qui atteignait alors 23000 exemplaires vendus. Le dictionnaire de Léandre Bergeron est depuis constamment réimprimé et trône encore sur les rayons des librairies près de 40 ans après sa publication.

Compte tenu de son succès immédiat, il a rapidement attiré l'attention des linguistes dont les commentaires se recoupent : on salue l'intention, mais on pourfend le résultat. Nous citons également les remarques d'un journaliste culturel et spécialiste des questions linguistiques, Paul Morisset, qui n'a pas été tendre avec l'ouvrage de Bergeron.

Léandre Bergeron nous propose un dictionnaire de la langue québécoise dans lequel il veut rassembler tous les mots proprement et spécifiquement québécois et qui vise à la plus grande exhaustivité possible. Le projet est d'envergure et les intentions qui le sous-tendent sont louables. Cependant, le produit fini qui en est issu est carrément décevant. [...] En bref, le Dictionnaire de la langue québécoise ne remplit convenablement à peu près aucune des exigences raisonnables que n'importe quel lecteur, qu'il soit spécialiste ou profane, est en droit d'attendre d'un dictionnaire. (Patry, 1982: 209)

L'idée d'un lexique « actuel » du français au Québec est séduisante, et, si l'on se fie aux propos de l'auteur et de l'éditeur, le public a favorablement répondu au battage publicitaire qui a accompagné le lancement du dictionnaire : plusieurs milliers d'exemplaires vendus, ce n'est plus un succès d'estime, mais un best-seller. Une première consultation de l'ouvrage m'avait laissé une impression désagréable de « déjà lu », impression qu'une fréquentation plus assidue n'a fait que confirmer, au point que, malgré ma placidité habituelle, j’ai failli en être révolté. Il suffit en effet d'avoir un peu utilisé le Glossaire du parler français au Canada (1930) pour que sautent aux yeux les très nombreux « emprunts » que l'auteur y fait et qui laissent au lecteur un peu « averti » ''impression d'une supercherie. (Seutin, 1982: 191)

L'ouvrage le plus important jamais consacré au français d'ici a paru il y a deux mois dans l'indifférence générale. [...] Tous les projecteurs de l'actualité linguistique étaient alors braqués, il est vrai, sur le Dictionnaire de la langue québécoise, de Léandre Bergeron, ouvrage qui a peu de chose d'un dictionnaire à part l'ordre alphabétique [...]. La situation a quelque chose d'aberrant et d'un peu pathétique vu que le Dictionnaire de la langue québécoise est au Parler populaire du Québec et de ses régions voisines ce qu'une digue de castor très moyenne est au barrage de Manic V. (Morisset, 1981 : 24) 
Patry et Morisset remettent tous deuxen question le titre de dictionnaire attribué au livre de Bergeron, ce qui justifie le deuxième critère de notre typologie. De plus, Seutin et Morisset soulignent le succès commercial du dictionnaire, qui semble inversement proportionnel à sa rigueur scientifique. Les commentaires de Seutin nous incitent à ajouter un quatrième critère qui permettrait d'identifier la lexicographie profane à l'étude : elle présente des données non usuelles sans les mettre en contexte, qu'elles soient anciennes, familières, rares ou autre. Ici, des informations publiées 50 ans plus tôt sont reproduites comme si elles étaient de la dernière actualité.

Nous ajoutons enfin un cinquième critère : cette lexicographie profane n'obtient pas la reconnaissance des spécialistes du domaine qui la considèrent peu rigoureuse et non représentative de la variété de français qu'elle prétend décrire.

\subsection{Le dictionnaire des expressions québécoises de Pierre DesRuisseaux}

Le dictionnaire de DesRuisseaux a généralement été épargné par la critique. En fait, nous n'en avons trouvé aucun compte rendu, ni positif ni négatif, fait par un spécialiste (linguiste, lexicographe ou autre).

Dans la presse généraliste, ce genre d’ouvrages est souvent apprécié, présenté sous un jour favorable, parfois pour illustrer une anecdote. Ce regard bienveillant explique sûrement en partie ses succès de vente.

Dès que son invité posera le pied sur le sol québécois, le lecteur lui offrira le Dictionnaire des expressions québécoises (BQ) de Pierre DesRuisseaux. Ce livre de référence sera bien utile lorsque le lecteur, apprenant qu'une valise pleine de livres s'est perdue, s'exclamera : «Quelle baddeloque! » Grâce à ce bel ouvrage, l'invité découvrira plusieurs des expressions imagées de la langue qu'on parle en ce pays. (Jarry, 2003 : F1)

Il faut fouiller un peu pour trouver des commentaires plus critiques. Par exemple, dès 1990, le journaliste littéraire du quotidien La Presse, Réginald Martel, note qu' « une édition plus savante et plus complète situerait dans le temps et l'espace bien des expressions qui peuvent être inconnues pour plusieurs. » (1990 : K3) Il ajoute cependant que « Le plaisir de feuilleter ce dictionnaire n'en est pas trop affecté. »

Le journaliste du quotidien Le Soleil, Didier Fessou, relève pour sa part quelques inexactitudes apparemment anodines, mais dont l'accumulation suffit pour remettre en doute la crédibilité de l'ouvrage de DesRuisseaux. 
Je n'ai pas trouvé « ramasse-jeunesse » dans le Dictionnaire des expressions québécoises de Pierre DesRuisseaux, dico dont une nouvelle édition vient d'être publiée dans la collection de poche BQ. [...] Il y [a] autre chose qui me chicote chez DesRuisseaux : il attribue à la langue québécoise des expressions qui sont en usage non seulement au Québec, mais partout ailleurs dans la francophonie. Un exemple? L'expression « chaud lapin ». Par contre, dans le voisinage de chaud lapin, DesRuisseaux a ignoré le verbe chicoter. Des singularités du genre, j'en ai relevé plusieurs. Assez, en tout cas, pour ne pas m'y fier les yeux fermés. (Fessou, 2003 : B2)

Ce reproche de considérer comme des québécismes des emplois panfrancophones avait aussi été fait par Seutin à Bergeron ${ }^{10}$ et signale un manque de rigueur dans le classement des emplois.

Le seul indice qui laisse supposer que les spécialistes n'endossaient pas le travail de DesRuisseaux se trouve dans la dépêche de la Presse canadienne publiée au moment du décès de l'auteur.

Pierre DesRuisseaux a également écrit des essais sur la culture populaire du Québec, dont le Dictionnaire des proverbes québécois et le Dictionnaire des expressions québécoises, deux livres qui obtinrent un important succès de librairie, même si les linguistes lui reprochaient souvent des recherches approximatives. » (La Presse canadienne, 2016 : B8)

Cette piste serait à explorer, mais on y devine déjà le même contraste entre « succès de librairie » et « reconnaissance des spécialistes » qui caractérise le dictionnaire de Bergeron et qui correspond à notre cinquième critère. Nous verrons que la situation n'est pas différente pour l'ouvrage de Lionel Meney.

\subsection{Le dictionnaire québécois-français de Lionel Meney}

Le dictionnaire de Lionel Meney a fait l'objet de nombreux commentaires. Si l'ouvrage semble généralement apprécié dans la presse, et même par certains spécialistes de la langue, notamment hors Québec, il est plus largement critiqué par les linguistes québécois. Meney étant lui-même linguiste, il n’a pas été épargné par ses confrères et consœurs dont les blâmes se répètent d'un compte rendu à l'autre.

On lui reproche d'abord de considérer le québécois comme une langue autonome, alors que c'est une variété de français. Cette distinction, qui correspond à notre troisième critère, a été passée sous silence par les critiques pour les non-linguistes Bergeron et DesRuisseaux, mais elle semble inconcevable de la part d'un spécialiste de la langue.

10. «Une troisième remarque: le Dictionnaire de la langue québécoise est rempli de mots et d'expressions bien françaises, donnés par l'auteur comme typiques du Québec. Cela tient à la copie non-critique du Glossaire. » (Seutin, 1982 : 191) 
Cet ouvrage qui se présente sous la forme d'un dictionnaire de traduction n'est ni à proprement parler un dictionnaire de langue, ni véritablement un dictionnaire bilingue. En premier lieu, les deux « langues » mises en équivalence sont deux variétés de français, celle du Québec et le français en usage en France, tous niveaux de langue confondus et que l'auteur qualifie de «français standard ». (Bouchard, $2000: 202)$

[...] l'essentiel de cet ouvrage porte sur le « québécois » considéré comme un idiome qui ne peut être compris des autres francophones. [...] Le Québécois qui a eu l'occasion de parler avec des Français ou qui a déjà visité la France éprouvera un pincement au cœur : «Est-il possible qu'on ait fait semblant de me comprendre...? » (Poirier, 2000 : 101)

Voilà tout le problème [...] : le québécois est une langue... qui n'en est pas une! C'est une langue: on lui donne donc un nom de langue autonome («le québécois») et non pas le nom d'une variété régionale du français, auquel cas on l'appellerait « le français québécois » ou « le francoquébécois ». Et on amplifie encore l'illusion en fournissant un instrument permettant la traduction de cette prétendue langue étrangère vers le français. (Faribault, 2002 : 619)

Ensuite, on note dans l'ouvrage de Meney, comme dans ceux de Bergeron et de DesRuisseaux, une absence de classement des emplois pour guider le lecteur et distinguer, par exemple, les usages courants des emplois rares ou des archaïsmes (quatrième critère). Cette façon de faire est associée à une absence de rigueur, voire à de la négligence.

[... ] rien ne permet de faire le partage de ce qui est usuel et de ce qui ne l'est pas. Ainsi, cossineuse est un emploi régional peu attesté, ce qui n'est pas mentionné. L'expression passer une épinette à qqn, qui est très rare, est traité sur le même pied que passer un sapin à qqn, qui se dit partout au Québec. Épeurement, qui ne paraît attesté qu'une seule fois, a droit lui aussi à un article complet. (Poirier, $2000: 103)$

[...] un bon nombre de mots ou d'acceptions faisant l'objet d'un article sont tirés d'ouvrages lexicographiques anciens ou d'œuvres littéraires du XIX` siècle ou du début du XX siècle et ne sont plus en usage de nos jours (acertainer « affirmer », ou acheter dans le sens de " accoucher », par exemple), or aucune marque ne le précise. (Bouchard, 2000 : 203)

Les marques d'usage sont presque inexistantes pour ce qui est des emplois de la variété source (le " québécois ») alors qu'elles sont extrêmement développées pour ce qui est de variété cible (le « français standard »). Ainsi, bien des emplois rares et même des hapax sont présentés sans aucune marque, donc comme s'ils étaient courants au Québec. [...] L'ouvrage abonde également en emplois vieillis ou désuets, sinon carrément sortis de l'usage, mais qui ne sont pas présentés comme tels. (Mercier et Verreault, 2002 : 95)

De plus, on reproche à Meney un manque d'objectivité frôlant l'idéologie, et qui tiendrait au mieux de l'incompréhension du contexte québécois, au pire de l'incompétence en matière de description de la langue. Les trois prochains commentaires trouvent un écho dans le film de Guillaume Canet, où le français québécois reproduit fait passer les Québécois eux-mêmes pour des «sans-génies ». 
[Lionel Meney] semble n'avoir pas compris la problématique de la qualité de la langue dans le contexte québécois et nord-américain et parait peu sensible aux valeurs et au sentiment linguistique de la société dans laquelle il vit depuis plus de trente ans. (Poirier, 2000 : 103)

Les dictionnaires donnent une information objective d'intérêt général qui a valeur de vérité dans le système sémio-culturel des lecteurs. Le dictionnaire n'exprime pas l'opinion personnelle d'un auteur. [...] On ne peut malheureusement reconnaitre de telles qualités au DQF, notamment en raison de la sélection des exemples et de la formulation des commentaires qui trahissent souvent un point de vue très personnel et très subjectif sur la culture québécoise. En effet, de trop nombreux exemples [...] ne manqueront certainement pas de heurter les lecteurs attentifs et, par là, de s'aliéner leur adhésion, ou encore de susciter la controverse. (Mercier et Verreault, 2002: 99)

[...] le Dictionnaire québécois français fait figure d'anachronisme (chose périmée), de rossignol (objet démodé, marchandise invendable), d'avatar (mésaventure, malheur) et d'imposteur (qui cherche à en imposer par de fausses apparences). (Faribault, 2002 : 621)

Enfin, comme pour Bergeron dont on a dit que l'ouvrage avait « peu de chose d'un dictionnaire à part l'ordre alphabétique », on sous-entend que l'ouvrage de Meney ne mérite pas de s'appeler un dictionnaire.

En définitive, le titre de « Dictionnaire » donné à cet ouvrage se justifie par le format du volume, semblable à celui des Petit Robert et Petit Larousse, et par le fait qu'il s'agit d'une compilation de matériaux linguistiques présentés en ordre alphabétique. Mais à qui peut bien servir un ouvrage de ce type? (Faribault, $2002: 621$ )

Tel qu'il se présente, le DQF fait figure d'inventaire plutôt que de dictionnaire. À ce titre, il peut être utile aux spécialistes de la langue, lesquels sont en mesure d'interpréter avec un esprit critique les relevés et les explications de l'auteur. On peut toutefois se demander pourquoi Guérin a jugé bon de présenter ce travail au grand public dans cet état. (Poirier, 2000 : 103)

Tout bien considéré, la parution du DQF ne nous parait pas devoir être prise à la légère. Si l'ouvrage présente des qualités certaines, il est toutefois loin de répondre à toutes les exigences modernes de la lexicographie, notamment en ce qui a trait à la rigueur et à l'objectivité de la description. (Mercier et Verreault, 2002 : 103)

Ces critiques ne sont pas exhaustives, mais permettent de donner un aperçu des principales lacunes reprochées au Dictionnaire québécois-français de Lionel Meney par ses pairs. 


\section{Conclusion}

Notre objectif était d'identifier certaines sources en partie responsables de l'image déformée qui circule sur le français au Québec, et qui a notamment eu un impact sur certaines productions françaises. Une fois ces sources repérées, nous avons voulu analyser si elles avaient des traits communs qui permettraient de baliser un certain type de lexicographie profane.

Nous avons établi cinq critères, auxquels répondent les trois dictionnaires à l'étude.

1. L'ouvrage est signé par un seul auteur (plutôt que par une équipe);

2. L'ouvrage porte à tort le titre de dictionnaire;

3. L'ouvrage prétend décrire le québécois plutôt que le français québécois;

4. L'ouvrage amalgame différents registres du français québécois et omet de marquer les emplois non usuels (vieillis, rares, hapax, archaïsmes, etc.);

5. L'ouvrage n'est pas reconnu par les spécialistes du domaine (linguistes ou lexicographes québécois) en raison de son manque de rigueur ou de représentativité du français québécois.

Nous avons l'intention d'élargir nos recherches pour appliquer certains de ces critères à d'autres types d'ouvrages. Nous pensons notamment aux guides de conversation pour touristes et nouveaux arrivants (voir Vincent, 2019) qui pourraient répondre à quatre des cinq critères précédents (excluant le $2^{\mathrm{e}}$, bien sûr).

Nous sommes bien consciente que la description que nous avons faite d'une branche de la lexicographie profane au Québec rapproche davantage cette dernière de la profanation que de la désacralisation. Faudrait-il donc renommer ce sous-ensemble pour le distinguer d'une lexicographie profane plus diversifiée? Ce serait sans doute souhaitable. Après avoir pensé avec un sourire en coin, pour rester dans le champ sémantique du sacré, à des appellations comme lexicographie profanatrice ou lexicographie sacrilège, nous proposons sur un ton plus sérieux et moins mélodramatique la dénomination lexicographie parasite. Cette dernière rappelle que cette pratique peut perturber la communication en émettant des signaux incompréhensibles et usurpe l'identité du dictionnaire, s’appropriant son autorité et sa crédibilité.

Dans leur critique du dictionnaire de Lionel Meney, Mercier et Verreault résument bien les principaux enjeux liés à la lexicographie parasite. 
Il nous semble que le moment est venu d'exiger de telles qualités [rigueur et objectivité de la description] de la part des auteurs qui revendiquent le titre de lexicographes. Le marché est déjà plus qu'encombré de " dictionnaires » folkloriques ou humoristiques du « québécois » (cf. Le québécois de poche, 1998; Le Québécois... [sic] pour mieux voyager, 1999, Béliveau et Granger, 2000). D’une part, de tels ouvrages ne parviennent à présenter aux Québécois qu'une image dévalorisante de leur variété de français, ce qui entretient forcément chez eux l'insécurité linguistique dont ils souffrent tant. D’autre part, en raison de la difformité même de cette image, ces ouvrages continuent à induire en erreur bien des étrangers qui en arrivent à fantasmer une variété qui n'existe en fait nulle part [...]. (2002 : 103)

II resterait à analyser de façon plus fine ce qui fait illusion dans ces ouvrages à large tirage qui arrivent à séduire le public francophone en général (y compris québécois), et même plusieurs linguistes hors-Québec. La puissance de la mise en marché y est assurément pour quelque chose, mais il faudrait aussi chercher du côté de la répétition de stéréotypes et d’idées préconçues qui semble servir de puissant élément de renforcement. Difficile ici de ne pas faire de rapprochement avec le concept de fausse nouvelle... 


\section{Références}

Achard-Bayle, Guy et Anne-Marie Paveau (2008), « Linguistique populaire ? », Pratiques : linguistique, littérature, didactique, nos 139-140, p. 3-16.

Bouchard, Chantal (2000), « Lionel Meney, Dictionnaire québécois-français, Guérin, Montréal, 1999 », TTR: traduction, terminologie, rédaction, vol. 13, nº 1, p. 202-203.

Dion, Jean (2004), « Vous êtes formidables », Le Devoir, 10 juillet, p. B2.

Dolar, Kaja (2017), Les dictionnaires collaboratifs en tant qu'objets discursifs, linguistiques et sociaux, thèse de doctorat, Université Paris Ouest Nanterre La Défense.

Dolar, Kaja (2018), « Les dictionnaires collaboratifs en ligne, des objets métalinguistiques profanes », Les Carnets du Cediscor, n 14, p. 33-50, disponible sur http://journals.openedition.org/cediscor/1161. [Page consultée le 17 octobre 2020.]

Faribault, Marthe (2002), «Lionel Meney, Dictionnaire québécois français : mieux se comprendre entre francophones, Montréal, Guérin, 1999, 1884 p. », Recherches sociographiques, vol. 32, n³, p. 619621.

Fessou, Didier (2003), « Ramasse-jeunesse », Le Soleil, 20 juin, p. B2.

Jarry, Johanne (2003), «L'été dans la poche », Le Devoir, 14 juin, p. F1.

Larrivée, Pierre (2006), «Les normes linguistiques et leur changement : la légitimation en cours du français québécois dans la littérature gallicane », Langage et société, nº 115, p. 103-127.

Lepage, Jocelyne (2006), « Le cadeau de Fred Vargas », La Presse, 4 juin, p. 11.

Margarito, Marie Grazia (2007), «Entre rigueur et agrément : de quelques microstructures de dictionnaires contemporains », Enrica Galazzi et Chiara Molinari (dir.), Les français en émergence, Bern, Peter Lang, p. 171-182.

Martel, Réginald (1990), « La langue d’ici », La Presse, 7 avril, p. K3.

Martin, Gabriel (2020), Ces mots-zombies qui occupent la lexicographie québécoise : contribution aux études métalexicographiques, mémoire de maîtrise, Université de Sherbrooke.

Mercier, Louis et Claude Verreault (2002), «Opposer français "standard” et français québécois pour mieux se comprendre entre francophones? Le cas du Dictionnaire québécois français », Le Français moderne, tome $70, n^{\circ} 1$, p. 87-108.

Molinari, Chiara et Nadine Vincent (dir.) (2017), « Dictionnaires, culture numérique et décentralisation de la norme dans l'espace francophone », numéro thématique de Repères-DORIF, $\mathrm{n}^{\circ}$ 14, disponible sur http://dorif.it/ezine/show_issue.php?iss_id=25.

Morisset, Paul (1981), « Monument à la gloire du parler profane », Le Devoir, 4 avril, p. 24. 
Murano, Michela (2014), « La lexicographie 2.0 : nous sommes tous lexicographes? », Ruggero Druetta et Caterina Falbo (dir.), Docteurs et recherche...une aventure qui continue, Trieste, Edizioni Università di Trieste, p. 147-162.

Niedzielski, Nancy A. et Dennis R. Preston (2000), Folk Linguistics, De Gruyter Mouton.

Patry, Richard (1982), « Dictionnaire de la langue québécoise, L. Bergeron, VLB éditeur, 1980 », Revue québécoise de linguistique, vol. 12, nº 1, p. 209-216.

Poirier, Claude (2000), « Faut-il "traduire” le "québécois” ? », Québec français, n 118, p. 102-103.

La Presse canadienne (2016), « Décès du poète Pierre DesRuisseaux », Le Devoir, 20 janvier, p. B8.

Preston, Dennis R. (1993), «The uses of folk linguistics », International Journal of Applied Linguistics, vol. 3, n² 2, p. 181-259.

Pruvost, Jean (2002), Les dictionnaires de langue française, Paris, PUF, coll. « Que sais-je?, 3622 ».

Séguin, Hubert (1997), «Le Bescherelle nouveau s'en vient: ouatchez-vous! », Le Devoir, 17 décembre, p. A9.

Seutin, Émile (1982), «Bergeron, Léandre, Dictionnaire de la langue québécoise [...] », Revue canadienne de linguistique, vol. 27, n² 2, p. 191-193.

Vargas, Fred (2006), «Fred Vargas nous écrit », La Presse, 11 juin, p. 13.

Villeneuve, Marianne (2016), «1998: Bescherelle au centre d'une polémique », billet de blogue du site canadien de Bescherelle, 27 juillet, disponible sur http://bescherelle.ca/1998-bescherelle-une-polemique/ [Page consultée le 12 mars 2018.]

Vincent, Nadine (2014), «Écrire dans la variante de l'autre : le cas de Sous les vents de Neptune de Fred Vargas », Continents Manuscrits, n² 2, disponible sur http://coma.revues.org/317.

Vincent, Nadine (2019), « Analyse du traitement des anglicismes dans des guides de français québécois pour touristes ", Circula : revue d'idéologies linguistiques, n 9 (A-t-on encore peur des anglicismes? Perception actuelle des anglicismes au Québec et dans l'espace francophone, dirigé par Mireille Elchacar et Nadine Vincent), p. 128-150. 


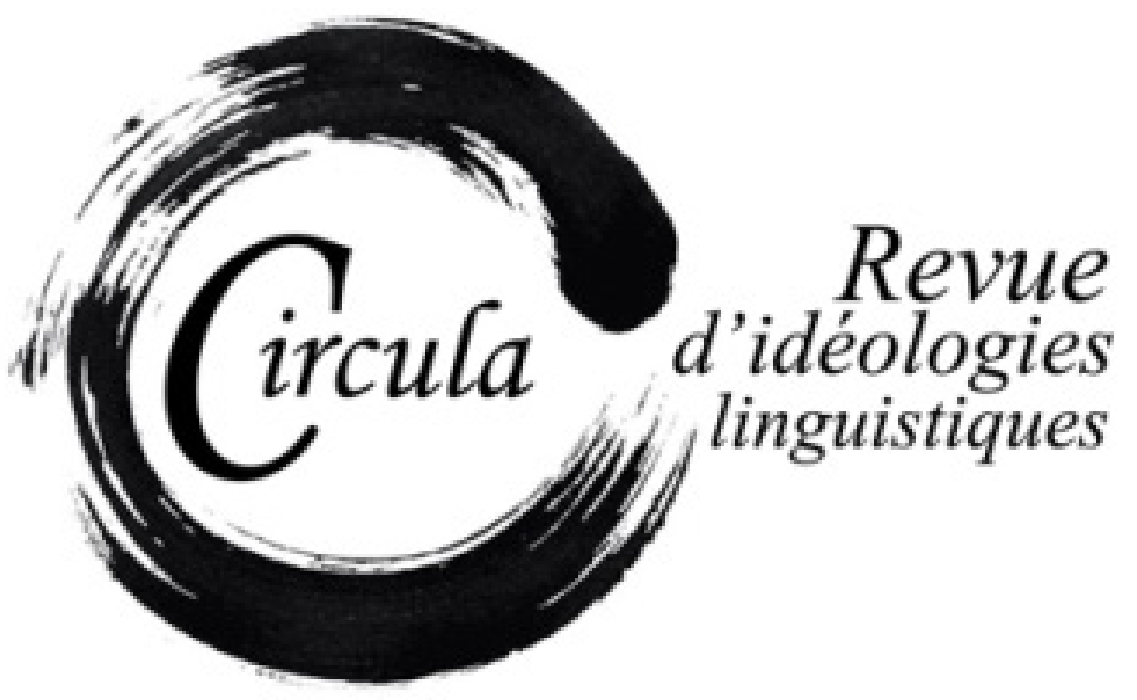

TITRE: ChISS, JeAN-LOUIS (2018), LA CULTURE DU LANGAGE ET LES IDÉOLOGIES LINGUISTIQUES, LIMOGES, LAMBERTLUCAS, 234 P. [ISBN : 978-2-35935-238-2]

Auteur: LAUREnCE ARrighi, Université de Moncton

Revue: CIRCULA, NUMÉRO 11

PAGES: $125-130$

ISSN: 2369-6761

URI: HTTP://HDL.HANDLE.NET/11143/17844 


\section{Chiss, Jean-Louis (2018), La culture du langage et les idéologies linguistiques, Limoges, Lambert-Lucas, 234 p. [ISBN : 978-2-35935-238-2]}

Laurence Arrighi, Université de Moncton

laurence.arrighi@umoncton.ca

" J'ai décidé de rassembler sous le titre La Culture du langage et les idéologies linguistiques des travaux écrits au fil des années, partiellement réécrits, que j’ai organisés en trois lignes de force avec interférences, échos, rappels » (p. 11). C'est avec ces mots que Jean-Louis Chiss nous convie, en un volume, à suivre un parcours de recherche, à comprendre un itinéraire intellectuel et in fine à saisir une pensée, qui sur plus de 40 ans, s'est déployée dans des champs majeurs de notre discipline: de l'étude des idéologies linguistiques, à la réflexion sur la didactique du français en passant par l'histoire et l'épistémologie des sciences du langage.

Le thème de "la crise du français », cher à l'auteur (qui en reste l'un des plus habiles contempteurs) est l'élément qui permet de fédérer ces trois grands champs et de les éclairer mutuellement. Rappelons que comme linguiste tout comme didacticien du français, le chercheur s'est vu interpelé, voire vilipendé, à plusieurs reprises dans le débat rémanent sur une supposée crise de la langue. Dans ce débat, cette dernière est souvent posée à la fois comme une crise interne (une supposée déliquescence de la forme) et une crise de la transmission qui serait mal assurée selon les analyses d'aucuns en raison des errements des linguistes et des didacticiens ${ }^{1}$. On voit mieux dès lors comment les trois champs susmentionnés gagnent à être penser de concert. Pour cela il faut déployer une formidable érudition soutenue par une forme d'engagement scientifique qui permet de faire face à cette naturalité du discours sur la langue consistant à penser bien des sujets linguistiques sans le recours au linguiste.

Arrêtons-nous sur les trois parcours proposés par l'auteur. Le premier « La crise du français et des langues » regroupe huit chapitres au sein desquels la crise du français est pensée en tant qu'idéologie linguistique. Dans ces pages, l'auteur plaide avant tout pour une mise en perspective historique

1. En guise d'exemple, certains, certaines se souviennent peut-être d'une polémique (re)lancée par la publication en 2005 d’un numéro (le 135) de la revue Le Débat, où plusieurs intellectuels français bien connus du paysage médiatique de ce pays (Marc Fumaroli, Régis Debray, Jean d'Ormesson, Philippe Sollers et bien d'autres) ont étalé nombre de clichés antilinguistiques et antididactiques faisant des nomenclatures et du savoir des linguistes et didacticiens un jargon absurde. En ayant contribué à intégrer aux programmes scolaires des notions telles celles de pronoms déictiques ou d'ancrage énonciatif, linguistes et didacticiens auraient conduit l'écolier français moyen à ne plus maitriser sa langue. Chiss rappelle brièvement ce débat en introduction de sa première partie (voir p. 15). 
des discours de crise alors même que ce qui les caractérise, justement, c'est le règne du présentisme. Ce faisant, le régime d'historicité des enjeux didactiques et linguistiques que ces discours prétendent vouloir interroger reste hors d'atteinte. Or, dès le chapitre 1, l'auteur rappelle que l'« on voit mal comment la consolidation d'une didactique des langues [...] pourrait ignorer les dimensions historiques et épistémologiques des sciences du langage » (p. 17). Dans le chapitre 2, c'est la notion de « génie de la langue » que l'auteur nous propose d'historiciser. En examinant la place du travail de Charles Bally, un travail ayant œuvré au « retour cyclique » (p. 27) de la notion, Chiss revient sur les discussions sur l'ordre naturel dont la syntaxe du français serait porteuse. La brève histoire du thème conduit l'auteur à interroger la recherche de la spécificité d'une langue, une recherche qui permet alors d'éclairer les liens parfois ténus entre science et idéologie. C'est encore une notion chère à Bally qui revient au chapitre 3, celle de «culture de la langue » au centre d'un cycle de conférences donné par ce dernier à Genève en $1930^{2}$, précisément au sujet de la crise du français. Là encore, dans l'analyse de ces conférences que nous propose Chiss, on peut voir l'intrication entre science et idéologie ${ }^{3}$. Le chapitre 4 interroge l'articulation entre la « crise du français » et le débat plus large de la «crise » de l'école. A contrario de trop de discours d'évidence qui se proposent de régler les questions de réussite scolaire pour tous par un retour à la vieille grammaire, l'auteur appelle à une véritable théorie du langage en lien avec une théorie du sujet et de la société. Au chapitre 5, la réflexion sur la crise du français est envisagée en relation avec la crise des Humanités. Ici, comme au chapitre suivant, Chiss affirme la nécessité de penser la relation langue, littérature, culture dans une théorie du langage qui travaillerait à déplacer et transformer les découpages disciplinaires. On reconnait là la tâche assignée à la théorie du langage par Meschonnic ${ }^{4}$ qui est justement le dédicataire du chapitre 6. Le chapitre 7 aborde quelques aspects de la dialectique système / norme(s) / variations et souligne la difficulté de l'école (dans l'espace francophone en entier et non pas seulement en France) à faire affaire avec la pluralité interne de notre langue. Enfin, le chapitre 8 conclut bien cette partie en insistant d'une part sur la nécessaire appréhension des idéologies dans leur historicité et d'autre part, en s'appuyant sur une proposition répétée de Humboldt à Meschonnic, en passant par Saussure et Benveniste, de séparer langue et discours afin « précisément de récuser le topos toujours renaissant des valeurs qui seraient attachées aux langues quand il n'y a que des discours qui portent des valeurs » (p. 83).

Le deuxième parcours propose, en six chapitres, un arrêt sur des conceptions de la littérature en lien avec la théorie du langage. Le chapitre 9 s'intéresse à « l'inflation contemporaine [en fait depuis les années 1980] d'une littérature de témoignage » (p. 89) où le vécu est roi, la vie objet de savoir et la parole tenue pour authentique. Avec le chapitre 10, Chiss poursuit sa réflexion sur la typologie

2. Publié en 1931 par Charles Bally et réédité en 2004 par Jean-Louis Chiss et Christian Puech en 2004.

3. En effet nous montre l'auteur si Bally « démonte le discours "catastrophiste", toute la thématique de la victimisation du français, la nostalgie de "I'universalité du français", son argumentaire n'évite pas l'héritage lexical du "génie" de la langue française... » (p. 37)

4. Chiss fait ici référence plus particulièrement à une publication de Meschonnic dont le titre («Plan d'urgence pour enseigner la théorie du langage », 2000) et le contenu est révélateur de leur préoccupation mutuelle de didacticiens et de linguistes pour la langue et la littérature. 
des discours. C'est aussi essentiellement au genre du récit qu'est consacré le chapitre suivant. Les deux chapitres subséquents sont plus directement consacrés à des questions scolaires au sein du système éducatif de la France. On ne s'étonne pas après la lecture de la première partie de l'ouvrage que notre auteur interroge " cette coupure langue / littérature dans la discipline dite "français" » (p. 135) (chapitre 12), de même qu'au chapitre suivant il lie méthode d'apprentissage de la lecture et théorisations de la littérature. Le dernier chapitre de cette partie est une réflexion liée à la publication de nouveaux écrits en Saussure en 2002, publication qui fut un « véritable événement » (p. 151) et l'occasion pour bien des linguistes d’interroger l'héritage du «maitre ».

Trouver un fil directeur au troisième parcours, « Politiques du langage » est plus délicat. Cela n'enlève rien à l'intérêt des cinq chapitres qui composent cette dernière partie. Le chapitre 15 en particulier retient l'attention. L'auteur, qui rédigea son texte en 1984 (l'année Orwell, comme il le précise), se livre à une critique de l'expression « c'est une façon de parler », vide de sens alors que « [ces façons de parler] interdisent la construction d'une relation entre le sujet et l'histoire en occultant, dissolvant les spécificités dans l'unitaire de l'universel » (p. 174) ou, dit autrement, on traite ici de la langue de bois. Toutefois, Chiss nous rappelle aussi que si les critiques de cette langue de bois sont légion, elles ont souvent le travers d'un certain binarisme opposant celle-ci à la langue de tous les jours supposée vraie et transparente ${ }^{5}$. Les écrits de Meschonnic, déjà présents dans d'autres chapitres de l'ouvrage, tiennent une bonne place dans les chapitres 16 et 17. Rappelant, chapitre 16, que les activités de ce linguiste, poète, traducteur et théoricien ont toutes été guidées par son attention au langage, Chiss place cette « attitude, [cette] disposition permanente » (p. 185) au cœur d'une théorie du langage-éthique-politique qui fait l'honneur de Meschonnic ${ }^{6}$. Les écrits de Meschonnic toujours servent à penser le lien entre théorie du langage et politique au chapitre suivant où l'auteur analyse des positions de Chomsky ainsi que de Heidegger (et certains de ses commentateurs français) sur les liens langage et politique, liens pour Meschonnic et Chiss indéniables mais que les auteurs commentés (et bien de leurs commentateurs) refusent d'assumer. Le chapitre 18 s'arrête sur les enjeux du comparatisme en linguistique et au-delà. On comprend aux citations mises en exergue « ... la bêtise de l'incomparabilité » (Détienne, 2000 : 182) que notre auteur plaide en faveur du comparatisme... oui mais en « [c]ompar[ant], [...] autrement qu'à la façon du café du Commerce » (Détienne, 2000 : 146) ${ }^{7}$. Enfin, dans son ultime chapitre, celui qui s'est souvent présenté tout au long de l'ouvrage

5. Pour une bonne illustration de ce travers, le lectorat de Circula pourra consulter un excellent article d'Alice KriegPlanque qui met précisément de l'avant cette tension (numéro 7, printemps 2018).

6. Commentant deux articles de Meschonnic publiés en 2005 dans Le Monde (repris dans un ouvrage de 2012) contre l'utilisation du mot Shoah, Chiss rappelle « l'exigence de faire toujours entendre la valeur des mots dans leur historicité, de les prendre comme des discours avec lesquels l'histoire a affaire par nécessité, sans confondre les mots et les choses, sans réduire l'histoire aux discours qui la disent » (p. 185).

7. Notre auteur est conscient des apories et des dérives de l'acte de comparer en sciences mais aussi de la portée heuristique que peut revêtir le fait de le faire. En la matière, citons-le, ce qui donnera aussi une idée de sa plume : « Il est clair qu'il apparait difficile d'installer autour de l'acte de comparer une espèce de cordon sanitaire qui éviterait toute la série de conséquences en cascade : différencier, classer, hiérarchiser, valoriser. Indispensable pour repérer les éléments "invisibles" à l'analyse interne, pour garantir la prise de distance, la recontextualisation dans le long terme ou l'éloignement apparent, le comparatisme est producteur de savoir » (p. 207-208). 
comme un linguiste préoccupé par l'histoire des théories sur le langage et un didacticien intéressé aux conceptions de l'enseignement des langues, indique que cette dualité est trompeuse. En effet, le cadre général de la réflexion de notre auteur entend justement dépasser cette séparation - ce que l'on voit poindre en filigrane tout au long du texte. Le terrain de réflexion que revendique Chiss est celui « de l'histoire culturelle des disciplines qui traitent du langage, des langues, des discours et des textes, incluant par nécessité la littérature » (p. 211). Bref, une anthropologie historique du langage telle qu'elle est évoquée tout au long de ce dense et passionnant ouvrage. 


\section{Références bibliographiques}

Bally, Charles (2004) [1931], La Crise du français : notre langue maternelle à l'école, Avant-propos et Postface de Jean-Louis Chiss et Christian Puech, Genève/Paris, Droz.

Le Débat, n¹35, disponible sur https://www.cairn.info/revue-le-debat-2005-3.htm.

Krieg-Planque, Alice (2018), " Les instruments de la critique politique et sociale comme objets pour l'étude des idéologies langagières : l'exemple d'un "Atelier de désintoxication de la langue de bois" », Circula, n 7, p. 29-50, disponible sur http://circula.recherche.usherbrooke.ca/numero-7/.

Meschonnic, Henri (2000), «Plan d'urgence pour enseigner la théorie du langage », Le français aujourd'hui, n¹30, p. 100-107.

Meschonnic, Henri (2012), Langage, histoire, une même théorie, Lagrasse, Verdier.

Saussure (de), Ferdinand (2002), Écrits de linguistique générale, édités par Simon Bouquet et Rudolf Engler avec la collaboration d'Antoinette Weil, Paris, Gallimard. 